Florida International University

FIU Digital Commons

6-6-2019

\title{
Examining the Feasibility and Acceptability of Behavioral Consultation with Latinx Teachers and Students
}

Anne S. Morrow

Florida International University, amorr036@fiu.edu

Follow this and additional works at: https://digitalcommons.fiu.edu/etd

Part of the Clinical Psychology Commons

\section{Recommended Citation}

Morrow, Anne S., "Examining the Feasibility and Acceptability of Behavioral Consultation with Latinx Teachers and Students" (2019). FIU Electronic Theses and Dissertations. 4274.

https://digitalcommons.fiu.edu/etd/4274

This work is brought to you for free and open access by the University Graduate School at FIU Digital Commons. It has been accepted for inclusion in FIU Electronic Theses and Dissertations by an authorized administrator of FIU Digital Commons. For more information, please contact dcc@fiu.edu. 


\title{
FLORIDA INTERNATIONAL UNIVERSITY
}

Miami, Florida

\section{EXAMINING THE FEASIBILITY AND ACCEPTABILITY OF BEHAVIORAL CONSULTATION WITH LATINX TEACHERS AND STUDENTS}

\author{
A dissertation submitted in partial fulfillment of \\ the requirements for the degree of \\ DOCTOR OF PHILOSOPHY \\ in \\ PSYCHOLOGY \\ by \\ Anne S. Morrow \\ 2019
}


To: Dean Michael R. Heithaus

College of Arts, Sciences and Education

This dissertation, written by Anne S. Morrow, and entitled Examining the Feasibility and Acceptability of Behavioral Consultation with Latinx Teachers and Students, having been approved in respect to style and intellectual content, is referred to you for judgment.

We have read this dissertation and recommend that it be approved.

Miguel Villodas

Dionne Stephens

Gladys Ibañez

Joseph Raiker

Stacy Frazier, Major Professor

Date of Defense: June 6, 2019

The dissertation of Anne S. Morrow is approved.

Dean Michael R. Heithaus College of Arts, Sciences and Education

Andrés G. Gil

Vice President for Research and Economic Development and Dean of the University Graduate School

Florida International University, 2019 
(C) Copyright 2019 by Anne S. Morrow

All rights reserved. 


\section{DEDICATION}

I dedicate this dissertation to my family, and to the children, families, teachers, and individuals that I have worked with throughout my training. Without my family behind me, I simply would not have been able to complete this work. I have had the honor of working with many people over the past few years, as a trainee who provided evidence-based mental health services. One inspiring mother described me to her husband as the woman who helps her-in only a few words, she summarized my aspirations for my entire career. I hope to help others. I am forever grateful to the individuals that I was supposed to be helping; in the end, I think you were the ones helping me. Your exuberance, wisdom, and generosity with your time have meant so much to me. 


\section{ACKNOWLEDGMENTS}

I wish to thank the members of my committee for their support, flexibility, and wisdom. Dr. Stacy Frazier and Dr. Joseph Raiker have done so much for me to make this project become a reality. Most importantly, it is truly difficult to describe all of the ways that my life has changed for the better since I have had the opportunity to join Dr. Miguel Villodas' team. You have taught me so much about how to develop new ideas and to test them. You lead by example, illustrating how to be an innovative, productive, and meaningful researcher. Of course, a highlight of working on your team includes the opportunity to know and to learn from Dr. Feion Villodasthank you so much for your lessons in how to conduct community-based clinical research, and also, how to become a better person.

I have been so lucky to work as a team with so many collaborators to implement this study. I cannot thank the teacher consultants enough for their time, as well as the qualitative coders. Finally, I will forever be indebted to the students, families, teachers, and the school counselor, without whom this project would not have been possible. 


\title{
ABSTRACT OF THE DISSERTATION \\ EXAMINING THE FEASIBILITY AND ACCEPTABILITY OF BEHAVIORAL CONSULTATION WITH LATINX TEACHERS AND STUDENTS
}

by

\author{
Anne S. Morrow \\ Florida International University, 2019 \\ Miami, Florida \\ Professor Stacy Frazier, Major Professor
}

Daily behavioral report cards are an efficacious intervention for children with ADHD, yet there is little information on Latinx teachers' perceptions about ADHD and preferences related to behavioral treatment, including the Daily Report Card (DRC). The purpose of our convergent, mixed-method study was to examine the feasibility and acceptability of behavioral consultation with Latinx teachers and students, as well as potentially associated factors. Teachers completed DRCs which included a chart with individualized, operationalized target behaviors, such as remaining in seat/area. Their students' behavioral targets were titrated via a changing criterion design, and students' daily performance was rewarded via a menu of reinforcers (e.g., screen time) if approximately $80 \%$ or more of a student's daily behavioral goals were successfully completed. We found that Latinx teachers' $(n=23)$ DRC completion rates $(80 \%)$ were comparable to previous studies with predominantly non-Latinx white teachers and students (Fabiano et al., 2010; Owens, Murphy, Richerson, Girio, \& Himawan, 2008). Quantitative indicators of acceptability were also similar to previous research conducted (Chafouleas et al., 2006), with teachers in our study reporting that the DRC was somewhat beneficial to students. Notably, meetings attended were brief, and teachers completed DRCs for more than two students in their class on average. Qualitative findings expanded upon these trends; thematic analyses revealed two overarching themes, that (1) teachers' attitudes toward behavioral interventions 
matter a great deal, and that (2) teachers' perceived behavioral control over DRC implementation depends a lot on the environment. Findings highlight the importance of stakeholders' perspectives in translating research to routine practice. 


\section{TABLE OF CONTENTS}

CHAPTER

PAGE

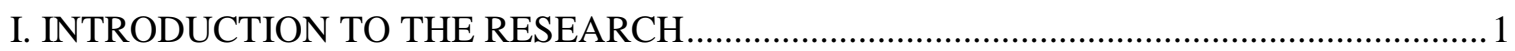

II. CHAPTER 1. DIRECT AND INDIRECT PATHWAYS FROM ADVERSE CHILDHOOD
EXPERIENCES TO HIGH SCHOOL DROPOUT AMONG HIGH-RISK ADOLESCENTS
Introduction
Method
Results

III. CHAPTER 2. IDENTIFYING PROSPECTIVE RISK FACTORS FOR JUVENILE JUSTICE INVOLVEMENT IN A SAMPLE OF YOUTH AT-RISK FOR

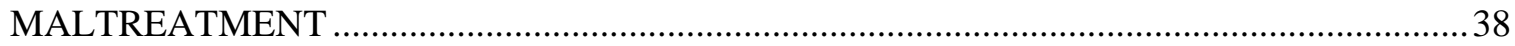

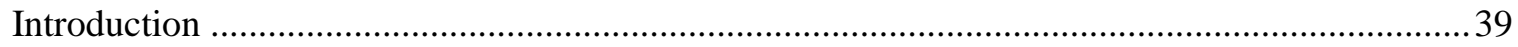

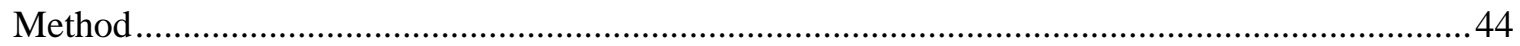

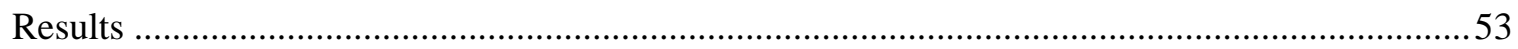

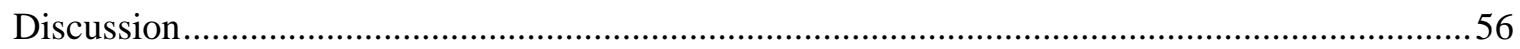

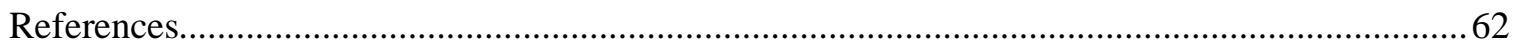

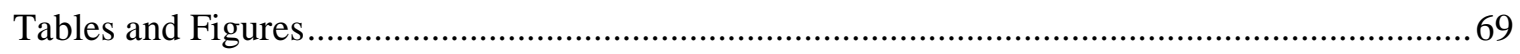

IV. CHAPTER 3. MIXED-METHOD EXAMINATION OF LATINX TEACHERS'

PERCEPTIONS OF DAILY BEHAVIORAL REPORT CARD INTERVENTIONS TO

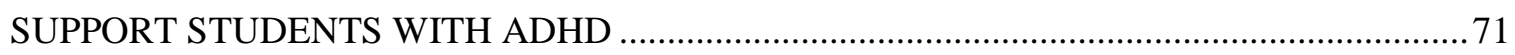

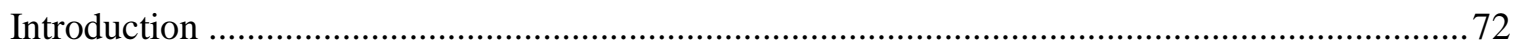

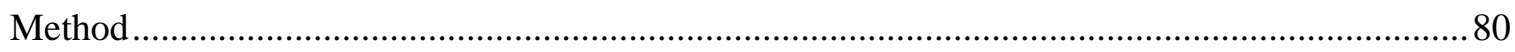

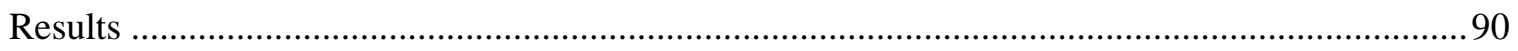

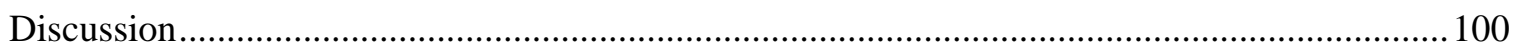

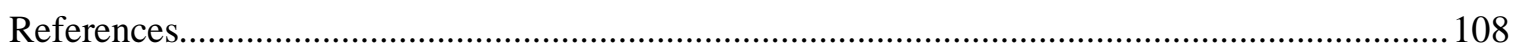

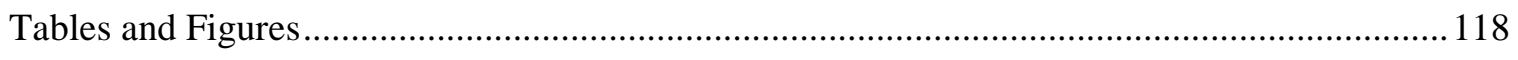

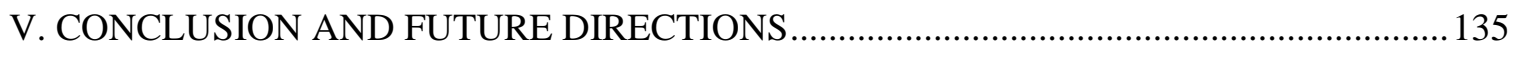

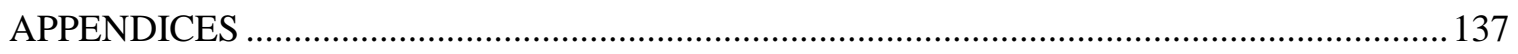

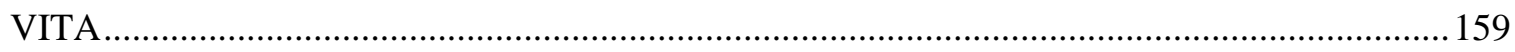




\section{LIST OF TABLES}

TABLE

PAGE

1. The Slow Pace of Translation from Science to Practice in the Field of ADHD Treatment .... 118

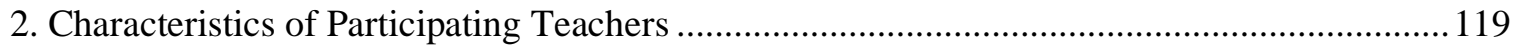

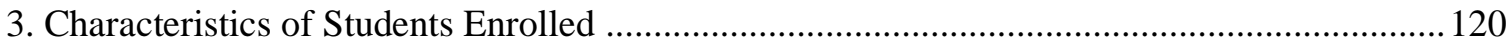

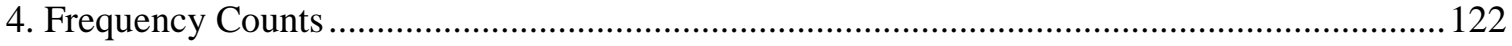

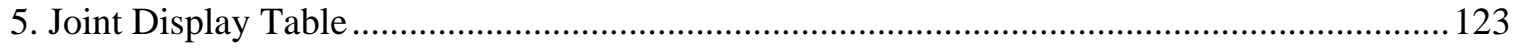

6. Descriptive Statistics of Behavioral Teacher Consultation Meetings .....................................124

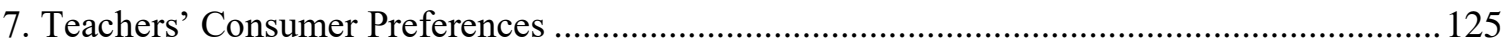

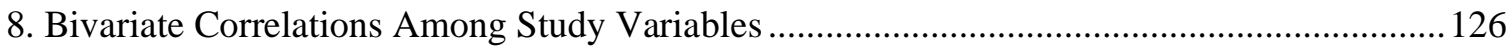




\section{INTRODUCTION TO THE RESEARCH}

My program of research focuses broadly on the phenomenology and treatment of children's mental health problems among traditionally underserved populations. In one line of research, I have studied childhood adversity, externalizing behavior problems, and functional outcomes (e.g., school performance). In the other line, I am particularly interested in implementation research on behavioral interventions aiming to address mental healthcare disparities.

\section{Rationale for the Research}

Externalizing disorders are common and costly (Danielson et al., 2018; Pelham, Foster, \& Robb, 2007). Accumulating evidence suggests that externalizing problems lie on a pathway between inherited risk factors and/or characteristics of a child's environment and poor functional outcomes, such as school performance (Loe \& Feldman, 2007; Moilanen, Shaw, \& Maxwell, 2010). Further, disparities in care plague mental health services aimed at ameliorating these concerns (Eiraldi \& Diaz, 2010; Merikangas et al., 2011). In order to address the unmet need for care, translational scientists have called for more studies conducted in everyday, community settings, often referred to as "T3" or "T4" research (Westfall \& Mensah, 2018). In the third manuscript of my dissertation (see Chapter 3), I have emphasized the priority of community settings, selecting to conduct my study in a Title I elementary school. In sum, the overarching theme uniting the body of my doctoral work centers on discovering practical solutions to intervene to address the effect of externalizing behavior on functional outcomes, particularly school performance.

My interest in school performance was originally born out of research on learning during my post-baccalaureate training fellowship at the National Institute of Mental Health (NIMH) under Dr. Carolyn Beebe Smith, Ph.D and Dr. Dante Picchioni, Ph.D. At that time, I worked on studies investigating the neural correlates of learning at a very fundamental unit of analysis; rates 
of regional cerebral protein synthesis. I coauthored two presentations presented at national conferences, as well as served as a second author on a manuscript on the effect of prior sleep deprivation on perceptual learning (McWhirter, Morrow, et al., 2015). Further, I co-authored a manuscript on regionally selective and sleep-dependent differences in cerebral protein synthesis involved in a perceptual learning task (Picchioni et al., 2018). This invaluable training opportunity sparked my interest in learning, yet I noticed the translation of our findings on learning from the bench to clinical practice lied on a long road, beyond the scope of our lab's work.

Following my post-baccalaureate fellowship, I had the opportunity to collaborate on clinic-based psychosocial treatment for externalizing disorders, Attention Deficit/Hyperactivity Disorder (ADHD) in particular (Altzuler, Morrow, et al., 2017; Merrill, Morrow et al., 2016; Morrow et al., under review). During my time as a graduate student at Florida International University, I also worked on multiple randomized trials involving stimulant medication, including NIH-R01 studies on the effect of stimulants on growth, and the development of tolerance to stimulants, as well as an industry-funded FDA trial of a transdermal delivery system for a stimulant medication. Across these projects, I noticed that stimulant medication, behavioral interventions such as the Daily Report Card (DRC), and the combination of the two often led to a salient reduction in externalizing symptoms.

\section{Presentation of Research Findings}

Yet clinic-based treatments only reach a limited number of youth, and my curiosity about helping children beyond the clinic setting was growing rapidly. Following my desire to address mental health disparities, I joined Dr. Villodas' team at the start of my fourth year in my graduate program. I had the opportunity to conduct secondary analyses with a nationally archived dataset, the Longitudinal Studies of Child Abuse and Neglect (LONGSCAN). Using LONGSCAN data, I have investigated the cascading effects of childhood adversity on high school dropout through 
several mediating pathways during adolescence (Morrow \& Villodas, 2017), such as externalizing symptoms. The manuscript was published in the Journal of Research on Adolescence, and our findings are presented in my dissertation as Chapter 1 (Morrow \& Villodas, 2017). Further, I investigated ecological risk and protective factors for juvenile arrest (Morrow, Villodas, \& Cunius, 2019), including externalizing symptoms and school engagement. The manuscript was published in the journal, Child Maltreatment, and our findings are presented in my dissertation as Chapter 2 (Morrow, Villodas, \& Cunius, 2019). That is, the first two manuscripts included in my dissertation examined the phenomenology of several constructs, including yet not limited to externalizing behavior and school performance. Lastly, as discussed above, the third manuscript in my dissertation focused on translational "T3" research (Westfall \& Mensah, 2018) on a behavioral intervention designed to ameliorate externalizing symptoms and school performance. More specifically, Chapter 3 of my dissertation is a manuscript (intended for submission in the journal Administration and Policy in Mental Health) investigated the feasibility and acceptability of behavioral consultation with Latinx teachers and students, as well as potentially associated factors via a convergent, mixed-method design. 


\section{CHAPTER 1.}

\section{DIRECT AND INDIRECT PATHWAYS FROM ADVERSE CHILDHOOD EXPERIENCES}

\section{TO HIGH SCHOOL DROPOUT AMONG HIGH-RISK ADOLESCENTS}

This manuscript has been published in Journal of Research on Adolescence, Volume 28, Issue 2, pages 327 to 341 .

Morrow, A. S., \& Villodas, M.T. (2017). Direct and Indirect Pathways from Adverse Childhood Experiences to High School Dropout Among High-Risk Adolescents. Journal of Research on Adolescence. 28(2), 327-341. doi: 10.1111/jora.12332 


\begin{abstract}
Adverse childhood experiences (ACEs) are associated with an increased risk for school dropout. The present study examined pathways from childhood adversity to school dropout through academic, behavioral, emotional, and social pathways. Data were collected prospectively from 728 adolescents and their caregivers who participated in the Longitudinal Studies of Child Abuse and Neglect and from child protective services records. Path analyses revealed a direct association between ACEs and dropout, as well as indirect effects through poor reading achievement and elevated externalizing problems. ACEs were associated with elevated internalizing problems, which were negatively associated with dropout. However, ACEs were not associated with peer influences. Implications of the identified mechanisms in the ACEs and school dropout association for future preventive interventions are discussed.
\end{abstract}

\title{
Literature Review
}

Adverse childhood experiences (ACEs), which include child abuse and neglect, as well as a host of other household risk factors (e.g., substance use, mental illness) that often occur during childhood and adolescence, are costly to society and represent a major public health concern in the U.S. (Cuijpers et al., 2011; Fang, Brown, Florence, \& Mercy, 2012). For example, Fang and colleagues estimated that the average lifetime cost associated with each new case of abuse and neglect in the U.S. exceeded $\$ 210,000$. Population-based epidemiological studies have revealed that nearly two-thirds of youth in the nation have had at least one ACE and more than one-third have had two or more ACEs (Centers for Disease Control and Prevention; CDC, 2010). ACEs have been linked to serious negative adult outcomes, including physical and mental health problems, reduced economic well-being (i.e., lower levels of employment, earnings, and fewer assets), and criminality (Currie \& Widom, 2010; Fang et al., 2012; Felitti, 2009). ACEs also have been linked to negative adolescent outcomes, such as increased risk for school dropout 
(Giovanelli, Reynolds, Mondi, \& Ou, 2016; Dube, Cook, \& Edwards, 2010); however, the specific mechanisms that explain this association remain unclear. The present study examined several pathways to school dropout in a prospective study of adolescents at high risk for ACEs.

\section{ACEs and School Dropout}

High school graduation has been identified as the leading social determinant of health (U.S. Department of Health and Human Services, 2015). The consequences of high school dropout are often severe and pervasive and may include reduced quality of life (e.g., lower reported happiness), and an increased risk for joblessness, criminality, and single parenthood (United States Department of Education, 2015; Lansford, Dodge, Pettit, \& Bates, 2016). Existing studies have revealed that ACEs are associated with an increased risk for high school dropout (Giovanelli, Reynolds, Mondi, \& Ou, 2016; Boden et al., 2007; Dube et al., 2010). The association between ACEs and educational attainment is best characterized as a gradient, such that as the number of ACEs increase, educational attainment decreases (Dube et al., 2010). Consistent with these findings, a population-based study found that students who reported experiencing potentially traumatic life events were more than one and one-half times more likely to drop out of high school (Porche, Fortuna, Lin, \& Alegria, 2011). Additionally, ACEs have been found to be associated with reduced employment outcomes, and educational attainment plays a significant meditational role in this relationship (Liu et al., 2013). While there is clearly an association between ACEs and subsequent academic and occupational achievement, the mechanisms that explain the association between ACEs and school dropout have not been previously explored.

Theoretical models have proposed a developmental progression from ACEs to pervasive health-risk behaviors and social problems via altered neurological and cognitive/socio-emotional functioning (Hildyard \& Wolfe, 2002). Consistent with a developmental psychopathology perspective, the cumulative nature of deficits in these diverse domains of functioning (e.g., 
emotional, cognitive, behavioral), especially within the context of academic development, can have cascading effects, precluding the mastery of subsequent competencies (Moilanen, Shaw, \& Maxwell, 2010). Based on this theory, it is logical that childhood disadvantage may contribute strongly to school disengagement, a complex, dynamic process that may begin early in a student's education, and eventually lead to school dropout (Finn, 1989). For example, the home environment provides a critical foundation for building the emotional, cognitive, and behavioral skills involved in forming a connection to school (Bethell, Newacheck, Hawes, \& Halfon, 2014; Cicchetti \& Toth, 2005). Researchers have found that when children who were maltreated begin school, the transition to a new environment is difficult for a number of reasons: 1) maltreating (e.g., neglectful) homes may provide insufficient stimulation to adequately prepare children for the academic and behavioral expectations of the school setting; 2) maladaptive interpersonal interaction patterns formed at home may be difficult to escape; and 3) exposure to novel settings and people could be perceived as threatening and lead to increased stress (Kendall-Tackett \& Eckenrode, 1996; Cicchetti \& Toth, 2005).

\section{Pathways to School Dropout}

Based on a life-course perspective, a leading theoretical framework for understanding high school dropout is school withdrawal or disengagement (Alexander, Entwisle, \& Horsey, 1997; Finn, 1989). Consistent with this theoretical perspective, recommended practices for promoting school completion and preventing dropout focus on increasing school engagement (Christenson et al., 2008; Christenson, Sinclair, Lehr, \& Godber, 2001). Measurements of school engagement in research and practice often include student performance variables such as attendance, behavior, and course failure, providing strong quantitative support for this theoretical concept (Bowers, Sprott, \& Taff, 2013), but it should be noted that the concept of school engagement represents the entirety of the student's bond to school. That is to say, connection to school life develops both implicitly as the student identifies with and develops an emotional bond 
to schooling over time through successful academic experiences, and explicitly, through active participation in schooling and school-related activities (Finn, 1989). Additionally, because school engagement encompasses the intrinsic motivation of the student, it can be considered an internal developmental asset (Benson, 2007). Thus, engagement may be especially critical for high school students with a childhood history of ACEs, often lacking in external developmental assets such as family support. Therefore, in this study, we consider the pathways to dropout through intervening variables that are not only indicators of school engagement such as attendance, but potentially key facilitators of or obstacles to school engagement for youth at high risk for ACEs, such as reading achievement, emotional and behavioral problems, and peer influences.

One particularly salient reason that students drop out of school is because of persistently low academic achievement or course failure (Balfanz, Herzog, \& Mac Iver, 2007; Bowers \& Sprott, 2012). Studies of adolescents from the general population have found that early reading ability is significantly associated with risk for high school dropout (Lansford et al., 2016). As mentioned above, academic development relies heavily on the sequential accumulation of knowledge, which may be precluded by early academic deficits (e.g., a student cannot read the history lesson; Musen, 2010). Previous studies have revealed that ACEs (e.g., child maltreatment) were significantly associated with the likelihood of grade repetition (Bethell et al., 2014), as well as poor grades in math and/or English, and poor performance on achievement tests (Eckenrode et al., 1995; Rowe \& Eckenrode, 1999). These findings indicate that academic deficits associated with early childhood adversity could play a particularly important role in the association between ACEs and school dropout.

Accumulating evidence also indicates that emotional (e.g., depression) and behavioral (e.g., conduct) problems contribute to the process of school disengagement, and ultimately dropout (Balfanz et al., 2007; Bowers \& Sprott, 2012; Porche et al., 2011). For instance, one longitudinal study of approximately 13,000 urban middle school students provides support that 
emotional and behavioral indicators of school disengagement were associated with an increased risk for high school dropout (Balfanz et al., 2007). Other studies have identified subgroups of adolescents who dropped out of school who were generally well-behaved, but were characterized by elevated depressive symptoms (Fortin, Marcotte, Potvin, Royer, \& Joly, 2006), and/or socially withdrawn behavior (Bowers \& Sprott, 2012). There is also some evidence that anxiety is associated with disengagement from school, and high school dropout, although findings regarding the form (e.g., linear vs. curvilinear) and direction (i.e., positive vs. negative) of this association have been mixed (Caraway, Tucker, Reinke, \& Hall, 2003; Duchesne, Vitaro, Larose, \& Tremblay, 2008; Van Ameringen, Mancini, \& Farvolden, 2003). Given previous findings that ACEs are associated with elevated levels of emotional and behavioral problems in adolescents (Schilling et al. , 2007), these pathways could play a particularly important role in the association between ACEs and school dropout.

During adolescence, the increasing importance of peer influences and tendency to be drawn toward similar others (i.e., homophily; Brechwald \& Prinstein, 2011) are important contributors to school dropout (Rosenthal, 1998; Mahoney, 2014; Pyrooz, 2014). Homophily can function as a "double-edged sword," at times associated with the acceleration of positive growth in character, community engagement, and skills, and in other instances, associated with affiliation with deviant peers, maladaptive interpersonal patterns, and higher rates of violence (Dishion, Eddy, Haas, Li, \& Spracklen, 1997). In perhaps the most extreme form of the phenomenon of deviant peer association, joining a gang has been found to be associated with dramatic reductions in the likelihood of graduating from high school (Pyrooz, 2014). Child maltreatment, as well as several other household adversities (e.g., parent criminal offending, parent substance and alcohol abuse, etc.) are known to increase the odds of deviant peer association during adolescence (Bender, 2010), while there is some evidence that association with prosocial peers is protective against dropout among at-risk students (Mahoney, 2014). More research is needed to delineate the 
roles of prosocial and deviant peer affiliation in the association between ACEs and dropout (Brechwald \& Prinstein, 2011).

Additionally, researchers have used person-centered analysis strategies (e.g., Latent Class Analysis) to identify groups of adolescents with similar profiles of risk factors for dropping out. One study identified a subset of adolescents who had dropped out of school and who had poor academic/reading ability, high levels of externalizing behavior problems, and many deviant peer associations (Bowers \& Sprott, 2012). Though each of these factors has been found to increase the risk of dropout on its own, their combination may elevate this risk (Bowers \& Sprott, 2012). Conceptually, this constellation of problems illustrates the complicated nature of the forces acting on high school students, which have been identified as "push" and "pull" factors in the school disengagement process (Doll, Eslami, \& Walters, 2013). Poor academic performance pushes a student out of school with the consequence of course failure, behavior problems can push a student out with suspensions, and deviant peers pull a student away from school life (Doll, Eslami, \& Walters, 2013). Because the risk and protective factors involved in school disengagement are complex, varying, and often intertwined, studying multiple factors within one model may be pivotal to understanding high school dropout. Given that childhood adversities are associated with greater impairments in each of the domains identified in Bowers \& Sprott's (2012) subtype, this profile may be particularly relevant for adolescents who are at a high risk for adversity.

Despite the considerable literature that has identified ACEs, academic achievement, emotional and behavioral problems, and peer influences as important risk factors for school dropout, the temporal sequencing of these relationships is not well understood (Dube et al., 2010; Boden et al., 2007) for several reasons: 1) many studies of ACEs have primarily relied on retrospective self-reports of childhood adversities (Boden et al., 2007; CDC, 2010); 2) many studies of ACEs have also been cross-sectional, which limits their ability to identify mediators of 
their associations with maladaptive outcomes (Widom, Raphael, \& DuMont, 2004); 3)

prospective, longitudinal studies of academic performance and school dropout typically have been conducted in general population samples in which the rates of ACEs are relatively low (United States Department of Education, 2015; Lansford et al., 2016).

\section{The Present Study}

The purpose of the present study was to prospectively evaluate reading achievement, internalizing and externalizing problems, and prosocial and deviant peer associations as potential pathways from ACEs to school dropout in a sample of adolescents identified as high-risk for a number of adversities (e.g., exposure to family violence). The first aim of the present study was to examine the associations between ACEs and putative mediating variables, including reading achievement, externalizing and internalizing behavior problems, and prosocial and deviant peer associations. Consistent with previous research, it was hypothesized that more ACEs would be associated with poorer reading achievement, more internalizing and externalizing behavior problems, association with fewer prosocial peers and association with more deviant peers. The second aim of the present study was to examine the associations between ACEs and putative mediating variables on school dropout. It was hypothesized that ACEs, poorer reading achievement, more externalizing and internalizing problems, association with fewer prosocial peers, and association with more deviant peers would be independently associated with higher risk for high school dropout. Finally, the third aim was to determine the roles of the putative mediating variables in the association between ACEs and school dropout. It was hypothesized that ACEs would have significant indirect effects on school dropout through reading achievement, externalizing and internalizing problems, and prosocial and deviant peer associations. 


\section{Method}

\section{Sample}

The present study used data collected from 728 adolescents who participated in a multisite consortium of prospective studies, the Longitudinal Studies of Child Abuse and Neglect (LONGSCAN). LONGSCAN included 1354 youth and their caregivers who were recruited across five sites and varied with respect to their levels of risk for family violence. More specifically, the Northwestern and Southwestern sites recruited children who had been reported for abuse and/or neglect, the Eastern site recruited children attending pediatric clinics considered high-risk for maltreatment based on demographic risk factors, and the Southern and Midwestern sites recruited both children that had been reported for maltreatment, as well as children who were considered high-risk for maltreatment (see Runyan et al., 1998, for further description of the overall study design, as well as more details about site-specific recruitment procedures).

Of the 1354 adolescents-caregiver dyads included in the full LONGSCAN sample, 897 could be located to participate in either a caregiver or adolescent interview at age 16 (89\% completed both). Of those 897,728 adolescents also could be located to participate in an interview at age 18 and were included in the present study. Sample descriptive statistics are presented in Table 1 . There were slightly more girls (56\%) in the sample, the adolescents were on average 18.40 years old (standard deviation $[\mathrm{SD}]=.50$ ) at the time of the age 18 interview, and they were racially/ethnically diverse (26\% White, $54 \%$ Black, $6 \%$ Hispanic/Latino, $14 \%$ of more than one or another race/ethnicity), consistent with the demographics of the overall LONGSCAN sample reported previously (e.g., Runyan et al., 1998). Notably, $81 \%$ of adolescents ever lived in

a family with a total income below the federal poverty limit between age 4 and 14 interviews, and $48 \%$ of adolescents had at least one caregiver who did not complete high school throughout that time period as well. 


\section{Procedures}

LONGSCAN sites used identical data collection, entry, and management protocols.

Following institutional review board approval, informed consent was obtained from caregivers, and assent was obtained from the youth prior to conducting each interview. Adolescents and their caregivers received a fixed, nominal amount for their participation at each interview. They were recruited to participate when the youth were either 4 or 6 years old and were assessed face-to-face biannually between ages 4 and 16 using developmentally appropriate measures of the youth, their caregivers, families, neighborhoods, and schools. Adolescents were also interviewed when they were approximately 18 years old. Administrative child protective services records for all youth participants were reviewed continuously and coded for indicators of maltreatment (see information about coding procedures below).

\section{Measures}

Demographic Information. Demographic information on the adolescent-caregiver dyads was collected at each assessment. Adolescent sex, race/ethnicity, and date of birth were assessed at the baseline interview, and family income, number of dependents, and caregiver education were collected at the age 4, 6, 8, 12, and 14 interviews. Dichotomous indicators of whether or not families' reported incomes were below the federal poverty level for the year during which they completed each interview, given their reported number of dependents, were calculated and summed to create an indicator of the number of interviews at which the adolescent's total family income was below the federal poverty level between the age 4 and 14 interviews. Dichotomous indicators of whether or not adolescents' primary caregivers at each interview had completed high school were calculated, summed, and the sum was dichotomized to create an indicator of whether or not adolescents had lived with a primary caregiver who did not graduate high school between the age 4 and 14 interviews. 
Adverse Childhood Experiences. An indicator of the number of childhood adversities adolescents experienced was created to represent ACEs from birth until the age 14 interview (8 indicators: caregiver mental health problem, family member substance use or incarceration, witnessed family violence, child neglect, and physical, sexual, and emotional abuse). Consistent with the ACEs studies (e.g., Dube et al., 2010), we created a composite of the summed dichotomous indicators of whether or not adolescents ever experienced each of the 8 ACEs based on all available data.

Child neglect, physical, sexual, or emotional abuse. Child Protective Services (CPS) records were systematically reviewed to identify reports of alleged maltreatment and coded using a modification of the Maltreatment Classification System (MMCS; Barnett, Manly, \& Cicchetti, 1993; English \& the LONGSCAN Investigators, 1997). Coders were trained to use the MMCS by experienced coders until they reached $90 \%$ agreement with the gold standard. To further ensure reliability, coders coded a subsample $(n=109)$ of the CPS narratives and Kappas were high (ranging from .73 for emotional maltreatment to .87 for physical abuse; English \& the LONGSCAN Investigators, 1997). The present study used dichotomous indicators (i.e., $0=$ not alleged, $1=$ alleged) of whether or not adolescents had allegations for each of the 4 maltreatment subtypes (i.e., physical abuse, sexual abuse, neglect, and emotional maltreatment) from birth until the age 14 interview. The decision to use allegations of maltreatment was based on previous findings that children with alleged and substantiated maltreatment are at a similarly increased risk for maltreatment recidivism and mental health and behavioral consequences (Drake, Jonson-Reid, Way, \& Chung, 2003; Hussey et al., 2005; Kohl, Jonson-Reid, \& Drake, 2009).

Caregivers also reported their own aggressive behavior toward their child in the past year on the Conflict Tactics Scales-Parent-Child version (CTSPC; Straus, Hamby, Finkelhor, Moore, \& Runyan, 1998). They completed the severe physical assault scale (3 items; e.g., hit child with fist or kicked hard, threw or knocked child down) at the age 8,12, and 14 interviews, and the 
extreme physical assault scale (4 items; e.g., grabbed and choked child around the neck, beat child up, burned or scalded child on purpose) at the age 12 and 14. Although these scales have demonstrated good validity, they tend to show weak evidence of internal consistency because of the relatively low frequency of each of the behaviors (Straus et al., 1998). The severe and extreme physical assault scales and the CPS indicator of allegations of physical abuse were summed and dichotomized to form a single, binary indicator of whether or not adolescents experienced any act of physical abuse between birth and the age 14 interview.

Witnessed family violence. The Life Events Scale is a caregiver-report measure that was adapted by LONGSCAN from Coddington's (1972) Life Event Records to include whether or not the child has experienced any of 30 stressful life events in the past year. At the ages $6,8,10,12$, and 14 interviews, caregivers reported adolescents' experiences of witnessed family violence on five dichotomous indicators of whether or not the child witnessed a family member 1) threatened with a weapon, 2) hit, kicked, or slapped, 3) shot or stabbed, 4) raped or sexually assaulted, or 5) killed or murdered. The History of Witnessed Violence measure is an adolescent-report measure completed at the age 12 and 14 interviews, including seven dichotomous indicators of whether or not the child witnessed during their lifetime any family member 1) hit, kicked, slapped, or beaten up, 2) threatened with a knife, 3) threatened with a gun, 4) stabbed or cut with a weapon, 5) shot, 6) killed, or 7) sexually assaulted. The items from these two scales were combined with an indicator of whether or not family violence between adults in the home was included as a risk factor in CPS records between birth and the age 16 interview based on the MMCS to form a single dichotomous indicator of the presence of witnessed family violence.

Household member substance use. The CAGE (Bradley et al., 1998) alcohol questionnaire is a widely used measure that contains four non-threatening questions about whether or not the caregiver felt they should reduce their drinking, were annoyed or criticized for their drinking, felt guilty about their drinking, or drank first thing in the morning. The scale was 
administered to caregivers at the age 4 interview and a dichotomous indicator of whether or not the caregiver endorsed more than one item was created. At the age 8 interview, caregivers completed the Caregiver Substance Use scale to assess their current use of illicit drugs, such as marijuana, cocaine, hallucinogens, heroin, stimulants, and tranquilizers. At the age 12 and 14 interviews, adolescents completed the Risk Behaviors of Family and Friends self-report measure of whether or not their household members (i.e., anyone who lives in the home, including but not limited to family members) used marijuana, cocaine, methamphetamine, LSD, heroin, or other intravenous drugs. A dichotomous indicator was created to represent the presence of any substance use across the three measures between the age 4 and 14 interviews.

Caregiver mental health. The Center for Epidemiologic Studies Depression (CES-D) scale is a 20-item self-report measure of depressive symptoms experienced by caregivers in the past week (Radloff, 1977). Each item is scored on a 4-point scale ranging from 0 (rarely or none of the time) to 3 (most or all of the time) with a cutoff score of 16 indicating "high depressive symptoms" as recommended by the author. The measure was administered at the age $4,6,12$, and 14 interviews. The Brief Symptom Inventory (Derogatis, 1993) is a 53-item (5-point scale ranging from $0=$ not at all to $4=$ extremely) measure that assesses caregivers' experiences during the previous seven days of nine symptom scales, which were identified through factor analyses: Somatization (seven items), Obsession-Compulsion (six items), Interpersonal Sensitivity (four items), Depression (six items), Anxiety (six items), Hostility (five items), Phobic Anxiety (five items), Paranoid Ideation (five items), and Psychoticism (five items). It was administered to caregivers at the age 8 interview, T-scores were calculated based on the adult non-patient normative data for the measure, and the standard case rule $(\mathrm{T}>63)$ was applied. A dichotomous indicator was created to represent whether or not caregivers were above the clinical cut-off score on any of the BSI scales or on the CES-D at any age. 
Household member jailed. One item was included from the Life Events Scale (see description above) at the age $6,8,10,12$, and 14 interviews that assessed whether or not any of the adolescent's household members had been incarcerated in the past year.

Potential Mediators. The following are measures of the mediators tested in the proposed analytic model:

Adolescent Emotional and Behavioral Problems. Caregivers completed the Child Behavior Checklist (CBCL; Achenbach, 1991) at each interview between ages 4 and 16. The CBCL assesses the frequency $(0=$ not true to $2=$ often true $)$ of 113 behaviors during the previous six months, which form broadband scales representing internalizing (i.e., withdrawn depression, anxious/depression, somatic complaints) and externalizing (i.e., aggression and delinquency) behavior problems. In addition, the CBCL includes an index of school competence (i.e., performance, special education classes, academic problems, grade repetition). The CBCL has been empirically validated, internationally normed, has extensive evidence of reliability and validity, and includes T-scores for each scale (Achenbach, 1991; Achenbach \& Rescorla, 2001). T-score cut-off values were used in the present study to indicate clinically-elevated problems with school competence between ages 4 and 14. These indicators were summed and dichotomized to indicate whether or not adolescents had clinically elevated problems with school competence at any interview between ages 4 and 14. Continuous raw scores for internalizing and externalizing problems were averaged across the age 4 through 14 interviews to control for prior levels of each domain of problems. In addition, continuous raw scores on internalizing and externalizing problems at age 16 were included as potential mediators (mean T-scores are presented in Table 1 for descriptive purposes).

Reading Achievement. Reading achievement was assessed at the age 16 interview with the Wide Range Achievement Test, Third Edition (WRAT-III) Reading subtest (Wilkinson, 1993). The WRAT-III is a widely used, nationally normed and standardized assessment of academic 
achievement that includes Reading, Arithmetic, and Spelling subtests. The brief subtest for Reading assesses an individual's ability to recognize and pronounce words of increasing difficulty. Standardized scores are calculated based on normative data derived from a national stratified sampling model.

Peer Behaviors. Association with prosocial and deviant peer groups was measured at the age 16 interview using the Risk Behavior of Family and Friends measure (Knight et al., 2008). The items were modified from items included in the Youth Risk Behavior (CDC, 1990) and Monitoring the Future (Johnston, 2010) surveys. Prosocial peer association items assessed how many of the adolescents' close friends (i.e., $0=$ none to $2=$ most) participate in 5 prosocial activities (e.g., sports, school clubs, church, and academics; $\alpha=.78$ in the current sample). Deviant peer association items assessed how many of the adolescents' close friends (i.e., $0=$ none to $2=$ most) engage in 13 risky behaviors, such as substance or alcohol use, drug carrying or dealing, fighting, or weapon carrying ( $\alpha=.85$ in the current sample).

Dropout. At the age 18 interview, adolescents were asked to report: 1) whether or not they were currently going to school, 2) whether or not they had dropped out of school, 3) whether they received a high school or general education diploma, and 4) the highest grade that they had passed or completed. Adolescents who either reported that they had dropped out or who were not currently attending school and had not graduated (i.e., received a diploma or completed grade 12) were considered dropouts.

\section{Data Analysis}

Sample descriptive statistics and missing data patterns were computed using IBM SPSS version 20 (IBM SPSS, 2011). Bivariate correlations and path analyses were performed using Mplus version 7.2 (Muthén \& Muthén, 2012). A theoretical model of the hypothesized pattern of relationships among the constructs was developed a priori (see Figure 1). Bivariate correlations among all variables were computed in order to identify covariates and to confirm hypothesized 
relationships to be specified in the path models, and a logistic regression analysis was performed to determine if any of the individual ACEs variables were independently associated with dropout.

Path Analyses. A path model was tested using a structural equation modeling framework. In addition to the $\chi_{2}$ statistic, which has been found to be overly sensitive to model misfit in large samples (Bentler \& Bonett, 1980), Mplus provides several indicators of overall model fit, including: 1) the Comparative Fit Index (CFI; Bentler, 1990); 2) the Root Mean Square Error of Approximation (Steiger, 1990), and 3) the Weighted Root Mean Residuals (Muthén \& Muthén, 2012). Based on current recommendations (Hu \& Bentler, 1999; Yu, 2002), values greater than .95 indicated excellent model fit for CFI, and values less than .08 for RMSEA and .95 for WRMR indicated acceptable model fit. The fit of individual paths was determined based on their statistical significance. Potential mediation paths were identified first by examining the joint significance test of the paths between ACEs and the mediators (path $a$ ) and the mediators and dropout (path $b$ ), as recommended by MacKinnon and colleagues (2002). The significance of indirect effects $\left(a^{*} b\right)$ was determined using bias-corrected bootstrapped $95 \%$ confidence intervals (CIs) based on 1000 bootstrapped samples, as recommended by Preacher and Hayes (2008). Analyses were adjusted for child sex, actual age in months when the age 18 interview was completed, and family poverty status, caregiver high school graduation, and clinically elevated problems with school competence, and prior internalizing, and externalizing problems between the age 4 and 14 interviews.

\section{Results}

Analyses comparing the adolescents included in the present study to the remainder of the LONGSCAN sample indicated that there were more girls in the analysis sample (56\% vs. $46 \%$ ), $\chi_{2}(1)=13.148, p<.05$, and they did not significantly differ on race/ethnicity, $\chi_{2}(3)=2.212, p>$ .05 , maltreatment allegations, $\chi_{2}(1)=843, p>.05$, poverty status, $\chi_{2}(1)=.275, p>.05$, caregiver high school graduation, $\chi_{2}(1)=.203, p>.05$, or clinically-elevated behavior problems on the 
CBCL, $\chi_{2}(1)=3.385, p>.05$, at the baseline interview. Data were complete for $81 \%$ of the analysis sample and Little's test (1988) of missing data patterns revealed that none of the study variables were associated with any identifiable missing data pattern, $\chi_{2}(43)=21.73, p>.05$. Missing data from within the analysis sample were treated as Missing Completely at Random and Full Information Maximum Likelihood estimation, which has been found to provide unbiased parameter estimates when data are at least Missing at Random (Enders, 2010), was used.

\section{Sample Descriptive Statistics}

In the overall sample, age 16 reading scores were, on average, approximately one-half of a standard deviation below the mean. In addition, a substantial proportion of adolescents had experienced each ACE, and an average of 3.58 ACEs by the age 14 interview. As can be seen in Table 1 , approximately $19.8 \%$ of adolescents $(n=144)$ reported dropping out of school by the age 18 interview, $32.8 \%$ had graduated with a standard diploma, $5.0 \%$ had graduated with a general equivalency diploma, and the remainder were still enrolled in high school. Of the students who were still enrolled, the mean age was 18.40 (ranging from 17.69 to 21.08), mean level of grade attainment was 10.8, and age was not associated with grade attainment, $r=.07, p>.05$.

\section{Preliminary Analyses}

Bivariate correlations among all variables are displayed in Table 2. Importantly, ACEs were significantly and modestly-to-moderately associated with all other variables, with the exception of prosocial and deviant peer behavior at age 16. In addition, school dropout was significantly and modestly-to-moderately associated with all other variables. A binary logistic regression revealed that the individual ACEs significantly improved the model predicting dropout, above and beyond the control variables, $\chi_{2}(8)=18.929, p<.05$, but that neglect was the only ACE that was independently associated with a greater risk of dropout, $\mathrm{b}=.563, p<.05$, OR $=1.75795 \% \mathrm{CI}[1.011,3.052]$. The odds of dropping out were 1.757 times greater for 
adolescents who were neglected during childhood.

\section{Path Analyses}

Tests of Mediation. Figure 2 displays the final path model. Although the model $\chi_{2}$ was statistically significant, all other tests indicated that the model fit the data well, $\chi_{2}(22)=46.716, p$ $<.05 ; \mathrm{CFI}=.976, \mathrm{RMSEA}=.039 ; \mathrm{WRMR}=.685$. More ACEs were significantly associated with poorer reading scores at age $16, \mathrm{~b}=-.791, p<.05,95 \% \mathrm{CI}[-1.427,-.174$,$] and having$ higher levels of externalizing problems, $\mathrm{b}=.353, p<.05,95 \% \mathrm{CI}[.068, .675]$ and higher levels of internalizing problems, $\mathrm{b}=.408, p<.05,95 \%$ CI $[.158, .687]$. More ACEs were not significantly associated with having fewer prosocial peers, $\mathrm{b}=-.005, p<.05,95 \% \mathrm{CI}[-.024$, $.012]$, or more deviant peers, $\mathrm{b}=.002, p<.05,95 \% \mathrm{CI}[-.009, .012]$. School dropout by age 18 was significantly associated with lower age 16 reading scores, $\mathrm{b}=-.011, p<.05,95 \%$ CI [-.019, $.003]$, lower internalizing problems, $\mathrm{b}=-.025, p<.05,95 \% \mathrm{CI}[-.046,-.003]$, and fewer prosocial peers, $\mathrm{b}=-.374, p<.05,95 \%$ CI [-.636, -.113], as well as having more ACEs, $\mathrm{b}=.087, p<.05$, 95\% CI [.032, .135], more deviant peers, $\mathrm{b}=.430, p<.05,95 \%$ CI [.038, .808], and higher externalizing problems, $\mathrm{b}=.024, p<.05,95 \% \mathrm{CI}[.009, .038]$. In particular, the odds of dropping out of school were significantly greater when adolescents had more ACEs $(\mathrm{OR}=1.09)$, lower reading scores $(\mathrm{OR}=1.011)$, higher externalizing problems $(\mathrm{OR}=1.024)$ and more deviant peers $(\mathrm{OR}=1.537)$, and lower internalizing problems $(\mathrm{OR}=1.025)$ and fewer prosocial peers $(\mathrm{OR}=$ $1.453)$.

Significant indirect effects (i.e., mediation) of ACEs on school dropout at age 18 were identified via age 16 reading scores, unstandardized indirect effect $(a b)=.009,95 \%$ CI [.002, $.023]$, externalizing problems, unstandardized indirect effect $(a b)=.008,95 \%$ CI $[.001, .021]$, and internalizing problems, unstandardized indirect effect $(a b)=-.010,95 \%$ CI [-.028, -.002]. This indicated that having poorer reading scores and higher levels of externalizing problems mediated the association between more ACEs and an increased risk for school dropout. On the 
other hand, having more ACEs was associated with higher levels of internalizing problems, which in turn were associated with a lower risk of school dropout.

\section{Discussion}

The purpose of this study was to examine putative pathways to school dropout from childhood adversity through reading achievement, emotional and behavioral problems, and prosocial and deviant peer behaviors in a large prospective sample of adolescents at high risk for adversity. Notably, nearly one in five adolescents in the present study had dropped out by the time of their age 18 interview (mean age 18.4 years), which is substantially higher than the reported national status dropout rate (i.e., 6.6\%-9.3\%; United States Department of Education, 2015). While this rate is concerning, it is considered an underestimate of the number of dropouts in the current sample, as $43.7 \%$ were still enrolled in high school. As noted above, many of these students had not progressed (i.e., $25 \%$ had completed $10_{\text {th }}$ grade or less), indicating that this group was at an elevated risk for dropout and various other factors associated with late graduation (e.g., higher rates of unemployment, poorer health-related outcomes such as higher rates of cigarette smoking; Hull, 2009). Fewer than one-third of participants in this sample had graduated at the time of the age 18 interview, as compared to the nationwide four-year, on-time graduation rate, which rose to $82.3 \%$ in 2014 (United States Department of Education, 2015). Importantly, the present study confirmed previous findings that risk for dropout was independently increased by ACEs. To our knowledge, this study is the first prospective study to explore both the direct and indirect pathways between ACEs and school dropout, and we identified indirect pathways through reading achievement, as well as externalizing and internalizing problems. We discuss each of these findings in more detail below.

Consistent with recent findings, there was a direct relationship between the number of ACEs and high school dropout independent of other risk factors (Giovanelli et al., 2016). This finding is not surprising, as childhood adversity has been found to result in elevated rates of 
academic failure (Dube et al., 2010; Boden et al., 2007; Giovanelli et al., 2016). Also consistent with the previous literature, ACEs were associated with disruptions in multiple domains of adolescent functioning, including poorer reading achievement (Jimenez, Wade, Lin, Morrow, \& Reichman, 2016), as well as emotional (i.e., internalizing; Schilling, Aseltine, \& Gore, 2007) and behavioral problems (i.e., externalizing; Schilling et al., 2007). From a developmental psychopathology perspective, it appears that ACEs contribute to disruptions in multiple developmental processes, which can have cascading effects on multiple domains of functioning, and in turn contribute to dropout. For example, in the present study, having more ACEs from birth to age 14 was associated with having higher levels of externalizing problems and lower reading scores at age 16 , which each independently contributed to an increased risk for high school dropout. This is in line with both research on risk factors for dropout (Bowers et al., 2013), as well as top reasons that students cite for leaving high school (Doll, Eslami, \& Walters, 2013). In sum, these findings are consistent with a life-course perspective of dropout as a complex, dynamic process of academic disengagement that develops over time (Finn, 1989; Bowers \& Sprott, 2012) and suggest that focusing on any single risk factor (e.g., deviant peer association) is unlikely to adequately explain elevated dropout rates among high-risk adolescents.

It was somewhat surprising that higher levels of internalizing problems were associated with a lower risk of dropout, as previous researchers have found that anxious and depressive symptoms are associated with dropout (Fortin et al., 2006; Van Ameringen et al., 2003), and suffering from internalizing problems is generally associated with poorer well-being (Chou, Golik, DeSerisy, \& Comer, in press). Yet our model suggests that higher levels of internalizing problems may lead to lower odds of dropping out in a sample of children at-risk for adversity. In the context of this unexpected finding, the results of the internalizing pathway are unclear and likely represent the need for a more nuanced analysis. For example, previous researchers have noted marked discrepancies between caregiver and adolescent reports of internalizing symptoms 
and have suggested that adolescent reports might more accurately reflect their latent psychopathology (De los Reyes \& Kazdin, 2005). Moreover, specific analysis should be conducted in order to consider the individual components of internalizing problems (i.e., anxiety and depression) separately. While depression and dropout appear to have a positive linear association (Fortin et al., 2006), the literature on the association between anxiety and dropout is mixed, with previous researchers reporting positive, negative, non-significant and even curvilinear associations between anxiety and dropout (DiLalla, Marcus, \& Wright-Phillips, 2004; Duchesne et al., 2008; Vitaro, Brendgen, Larose, \& Trembaly, 2005), and significant associations for girls, but not boys (Sagatun, Heyerdahl, Wentzel-Larsen, \& Lien, 2014). The true association could be masked or inaccurately represented without more complex, fine-grained analysis. For example, previous researchers have suggested that the association between anxiety and dropout could be curvilinear, indicating that lower levels of anxiety could serve a protective role, whereas higher levels of anxiety could be maladaptive (Duchesne, Vitaro, Larose, \& Tremblay, 2008). Future researchers should further explore the complexities of this association more specifically.

We were surprised to find that ACEs were not associated with problematic peer relations; previous studies found that ACEs are linked to deviant peer association (Fergusson \& Horwood, 1999), as well as social maladjustment, with cognitive and emotional processes mediating the relationship between adversities and social outcomes (Schwartz \& Proctor, 2000). However, it is important to note that only peer behaviors were measured in the present study, not peer influences or peer relationship quality, which may be better indicators of the possible pathway between ACEs and dropout related to peer functioning. It is possible that ACEs disrupt appropriate social development in youth causing additional peer conflict and poor peer relations, which in turn increase the odds of dropout. Although they significantly associated with ACEs, deviant and prosocial peer association were independently linked to high school dropout as risk and protective factors, respectively, which is consistent with previous research (Rosenthal, 1998). 


\section{Limitations}

It is important to consider the results of this study in the context of its limitations. First, because this study used previously collected data from a longitudinal study, certain measures (e.g., grades in core courses) were not available and could have provided additional useful information. Moreover, as is the case with any longitudinal study, maintaining engagement among participants over the course of the study was challenging, resulting in missing data. Additionally, those youth and caregivers who did not participate in all waves might have been more at risk for adverse outcomes and were not included in this analysis. We recommend that future studies integrate data from multiple sources, such as administrative school data, in order to most accurately characterize adolescents' school experiences and minimize missing data. Although sex was controlled in all analyses, it should be considered as a possible moderator in future investigations. The timing of this wave of data, approximately age 18 (mean age 18.40), was not ideal for measuring last minute dropout, as well as late graduation. Also, because some of the data collection points were as early as four years of age, the timing of the ACEs may have affected the outcome at age 18. For example, extreme ACEs may have resulted in children in our sample changing households at different points in time. We recommend that future researchers consider the impact of youth's household changes on their pathways to dropout. Additionally, these findings may not generalize to adolescents from the general population, as LONGSCAN was a focused investigation of the population of adolescents at high risk for family violence.

\section{Implications}

Despite these limitations, the findings of this study offer important implications for the prevention of school dropout. In particular, there is likely no singular and adequate target for interventions to prevent high school dropout for at-risk adolescents because there are likely several multifaceted pathways that result in dropout. Successful efforts to prevent dropout 
amongst at-risk adolescents will likely need to leverage change across a complex array of factors, including those that we found to independently contribute to the risk of dropout (e.g., reading achievement, externalizing problems). Perhaps even more importantly, these results underscore the importance of comprehensive personalized intervention models that consider the specific functional impairments that are most substantially impacting adolescents. Fortunately, several relevant intervention models have been developed.

Promising strategies may leverage motivation to engage in services of a varied, personalized nature, such as the Family Check-Up (Dishion \& Kavanagh, 2003). Programs such as these are designed to engage adolescents and their families in an array of services that will address their unique profile of risk factors. Engaging adolescents in services that address academic, behavioral, and emotional impairments is likely to contribute to improved school engagement and reduce the risk of dropout. In cases of more severe functional impairment with serious imminent consequences (e.g., incarceration, child welfare and/or justice-involved youth), intensive intervention models, such as Multisystemic Therapy (MST) or Multidimensional Treatment Foster Care might provide a more adequate level of intensive support (Henggeler \& Schaeffer, 2010; Smith \& Chamberlain, 2010).

\section{Conclusion}

While the association between ACEs and school dropout has been reported among adolescents from the general population (Dube et al., 2010; Boden et al., 2007; Giovanelli et al., 2016), the present study found that this is also true among high-risk adolescents, who have experienced an elevated number of adversities. In addition to the direct association of ACEs with dropout, disruptions in multiple domains of development (e.g., behavioral, academic) as a result of ACEs provide indirect pathways to school dropout. The association between ACEs and dropout is complex. The successful prevention of dropout among adolescents who have 
experienced adversities likely requires a personalized multi-component approach that considers the unique profile of risk and protective factors of the individual. 


\section{References}

Achenbach, T. M. (1991). Integrative Manual for the 1991 CBCL/4-18, YSR, and TRF profiles. Burlington, VT: University of Vermont. Department of Psychiatry.

Achenbach, T. M., \& Rescorla, L. A. (2001). Manual for the ASEBA School-Age Forms \& Profiles. Burlington, VT: University of Vermont, Department of Psychology.

Alexander, K. L., Entwisle, D. R., \& Horsey, C. S. (1997). From First Grade Forward: Early Foundations of High School Dropout. Sociology of Education, 70(2), 87-107. doi: $10.2307 / 2673158$

Balfanz, R., Herzog, L., \& Mac Iver, D. J. (2007). Preventing student disengagement and keeping students on the graduation path in urban middle-grades schools: Early identification and effective interventions. Educational Psychologist, 42(4), 223-235. doi:10.1080/00461520701621079

Barnett, D., Manly, J. T., \& Cicchetti, D. (1993). Defining child maltreatment: The interface between policy and research. In D. Cicchetti \& S. L. Toth (Eds.), Advances in Applied Developmental Psychology: Child Abuse, Child Development and Social Policy. Norwood, NJ: Ablex.

Bender, K. (2010). Why do some maltreated youth become juvenile offenders?: A call for further investigation and adaptation of youth services. Children and Youth Services Review, 32(3), 466-473. doi:10.1016/j.childyouth.2009.10.022

Benson, P. L. (2007). Developmental assets: An overview of theory, research, and practice. In R. K. Silbereisen \& R. M. Lerner (Eds), Approaches to Positive Youth Development, 33-58.

Bentler, P. M., \& Bonett, D. G. (1980). Significance tests and goodness of fit in the analysis of covariance structures. Psychological Bulletin, 88(3), 588.

Bentler, P. M. (1990). Comparative fit indexes in structural models. Psychological Bulletin, 107(2), 238-246.

Bethell, C. D., Newacheck, P., Hawes, E., \& Halfon, N. (2014). Adverse Childhood Experiences: Assessing The Impact On Health And School Engagement And The Mitigating Role Of Resilience. Health Affairs, 33(12), 2106-2115. doi:10.1377/hlthaff.2014.0914

Boden, J. M., Horwood, L. J., \& Fergusson, D. M. (2007). Exposure to childhood sexual and physical abuse and subsequent educational achievement outcomes. Child Abuse \& Neglect, 31(10), 1101-1114. doi:10.1016/j.chiabu.2007.03.022

Bowers, A. J., \& Sprott, R. (2012). Why Tenth Graders Fail to Finish High School: A Dropout Typology Latent Class Analysis. Journal of Education for Students Placed at Risk (JESPAR), 17(3), 129-148. doi:10.1080/10824669.2012.692071 
Bowers, A. J., Sprott, R., \& Taff, S. A. (2013). Do We Know Who Will Drop Out?: A Review of the Predictors of Dropping out of High School: Precision, Sensitivity, and Specificity. The High School Journal, 96(2), 77-100. doi:10.1353/hsj.2013.0000

Bradley, K. A., Bush, K. R., McDonell, M. B., Malone, T., Fihn, S. D., \& Project, A. C. Q. I. (1998). Screening for problem drinking. Journal of General Internal Medicine, 13(6), 379-389.

Brechwald, W. A., \& Prinstein, M. J. (2011). Beyond Homophily: A Decade of Advances in Understanding Peer Influence Processes. Journal of Research on Adolescence: The Official Journal of the Society for Research on Adolescence, 21(1), 166-179. doi:10.1111/j.1532-7795.2010.00721.x

Caraway, K., Tucker, C. M., Reinke, W. M., \& Hall, C. (2003). Self-efficacy, goal orientation, and fear of failure as predictors of school engagement in high school students. Psychology in the Schools, 40(4), 417-427. doi:10.1002/pits.10092

Centers for Disease Control and Prevention (CDC; 2010). Adverse childhood experiences reported by adults --- five states, 2009. MMWR. Morbidity and Mortality Weekly Report, 59(49), 1609-1613.

Centers for Disease Control and Prevention (1990). Youth Risk Behavior Survey. Available at: www.cdc.gov/yrbs. Accessed on [5/17/2016].

Chou, T., Golik, A., DeSerisy, M., \& Comer, J.S. (in press). Disorders of negative affect. In H. Friedman \& A.M. Albano (Eds.), Encyclopedia of Mental Health. Waltham, MA: Academic Press.

Christenson, S. L., Reschly, A. L., Appleton, J. J., Berman, S., Spanjers, D., \& Varro, P. (2008). Best practices in fostering student engagement. Best Practices in School Psychology, 5, 1099-1120.

Christenson, S. L., Sinclair, M. F., Lehr, C. A., \& Godber, Y. (2001). Promoting successful school completion: Critical conceptual and methodological guidelines. School Psychology Quarterly, 16(4), 468.

Cicchetti, D., \& Toth, S. L. (2005). Child maltreatment. Annual Review of Clinical Psychology, 1, 409-438. doi:10.1146/annurev.clinpsy.1.102803.144029

Coddington, R. D. (1972). The significance of life events as etiologic factors in the diseases of children-II a study of a normal population. Journal of Psychosomatic Research, 16(3), 205-213. doi:10.1016/0022-3999(72)90045-1

Cuijpers, P., Smit, F., Unger, F., Stikkelbroek, Y., Ten Have, M., \& de Graaf, R. (2011). The disease burden of childhood adversities in adults: a population-based study. Child Abuse \& Neglect, 35(11), 937-945. doi:10.1016/j.chiabu.2011.06.005

Currie, J., \& Widom, C. S. (2010). Long-term consequences of child abuse and neglect on adult economic well-being. Child Maltreatment, 15(2), 111-120. 
De Los Reyes, A., \& Kazdin, A. E. (2005). Informant discrepancies in the assessment of childhood psychopathology: a critical review, theoretical framework, and recommendations for further study. Psychological Bulletin, 131(4), 483-509. doi:10.1037/0033-2909.131.4.483

Derogatis, L. R. (1993). BSI Brief Symptom Inventory. Administration, Scoring, and Procedures Manual (4th ed.). Minneapolis, MN: National Computer Systems.

DiLalla, L. F., Marcus, J. L., \& Wright-Phillips, M. V. (2004). Longitudinal effects of preschool behavioral styles on early adolescent school performance. Journal of School Psychology, 42(5), 385-401. doi:10.1016/j.jsp.2004.05.002

Dishion, T. J., Eddy, J. M., Haas, E., Li, F., \& Spracklen, K. (1997). Friendships and Violent Behavior During Adolescence. Social Development, 6(2), 207-223. doi:10.1111/j.14679507.1997.tb00102.x

Dishion, T. J., \& Kavanagh, K. (2003). Intervening in adolescent problem behavior: A familycentered approach. New York, NY, US: Guilford Press, 243.

Doll, J. J., Eslami, Z., \& Walters, L. (2013). Understanding Why Students Drop Out of High School, According to Their Own Reports. SAGE Open, 3(4), 2158244013503834. doi: $10.1177 / 2158244013503834$

Drake, B., Jonson-Reid, M., Way, I., \& Chung, S. (2003). Substantiation and recidivism. Child Maltreatment, 8(4), 248-260. doi:10.1177/1077559503258930

Dube, S. R., Cook, M. L., \& Edwards, V. J. (2010). Health-related outcomes of adverse childhood experiences in Texas, 2002. Preventing Chronic Disease, 7(3), A52.

Duchesne, S., Vitaro, F., Larose, S., \& Tremblay, R. E. (2008). Trajectories of Anxiety during Elementary-School Years and the Prediction of High School Noncompletion. Journal of Youth and Adolescence, 37(9), 1134-1146. doi: 10.1007/s10964-007-9224-0

Eckenrode, J., Rowe, E., Laird, M., \& Brathwaite, J. (1995). Mobility as a mediator of the effects of child maltreatment on academic performance. Child Development, 66(4), 1130-1142.

Enders, C. K. (2010). Applied missing data analysis. New York, NY: Guilford Press.

English, D. J., \& the LONGSCAN Investigators. (1997). Modified Maltreatment Classification System (MMCS). Retrieved from http://www.iprc.unc.edu/longscan/.

Fang, X., Brown, D. S., Florence, C., \& Mercy, J. A. (2012). The Economic Burden of Child Maltreatment in the United States And Implications for Prevention. Child Abuse \& Neglect, 36(2), 156-165. doi: 10.1016/j.chiabu.2011.10.006

Felitti, V. J. (2009). Adverse Childhood Experiences and Adult Health. Academic Pediatrics, 9(3), 131-132. doi:10.1016/j.acap.2009.03.001 
Fergusson, D. M., \& Horwood, L. J. (1999). Prospective Childhood Predictors of Deviant Peer Affiliations in Adolescence. The Journal of Child Psychology and Psychiatry and Allied Disciplines, 40(4), 581-592.

Finn, J. D. (1989). Withdrawing From School. Review of Educational Research, 59(2), 117-142. doi:10.3102/00346543059002117

Fortin, L., Marcotte, D., Potvin, P., Royer, É., \& Joly, J. (2006). Typology of students at risk of dropping out of school: Description by personal, family and school factors. European Journal of Psychology of Education, 21(4), 363-383. doi:10.1007/BF03173508

Giovanelli, A., Reynolds, A. J., Mondi, C. F., \& Ou, S.-R. (2016). Adverse Childhood Experiences and Adult Well-Being in a Low-income, Urban Cohort. Pediatrics, 137 (4), e20154016. doi: 10.1542/peds.2015-4016

Henggeler, S. W., \& Schaeffer, C. (2010). Treating serious antisocial behavior using multisystemic therapy. In J. R. Weisz \& A. E. Kazdin (Eds.), Evidence-based psychotherapies for children and adolescents (2nd ed., pp. 259-276). New York, NY US: Guilford Press.

Hildyard, K. L., \& Wolfe, D. A. (2002). Child neglect: developmental issues and outcomes. Child Abuse \& Neglect, 26(6-7), 679-695. doi: 10.1016/S0145-2134(02)00341-1

Hu, L.-t., \& Bentler, P. M. (1999). Cutoff criteria for fit indexes in covariance structure analysis: Conventional criteria versus new alternatives. Structural Equation Modeling, 6(1), 1-55.

Hull, J., (2009). Better late than never? Examining late high school graduates. Center for Public Education. Alexandria, VA: Author.

Hussey, J. M., Marshall, J. M., English, D. J., Knight, E. D., Lau, A. S., Dubowitz, H., \& Kotch, J. B. (2005). Defining maltreatment according to substantiation: Distinction without a difference? Child Abuse and Neglect, 29(5), 479-492. doi:10.1016/j.chiabu.2003.12.005

IBM SPSS. (2011). SPSS for Mac, Release 20.0. Chicago: SPSS Inc., http://www.spss.com.

Jimenez, M. E., Wade, R., Lin, Y., Morrow, L. M., \& Reichman, N. E. (2016). Adverse Experiences in Early Childhood and Kindergarten Outcomes. Pediatrics, 137(2): e20151839. doi:10.1542/peds.2015-1839

Johnston, L. (2010). Monitoring the Future: National Results on Adolescent Drug Use: Overview of Key Findings. DIANE Publishing.

Kendall-Tackett, K. A., \& Eckenrode, J. (1996). The effects of neglect on academic achievement and disciplinary problems: a developmental perspective. Child Abuse \& Neglect, 20(3), $161-169$. 
Knight, E. D., Smith, J. B., Martin, L. M., Lewis, T., \& the LONGSCAN Investigators (2008). Measures for Assessment of Functioning and Outcomes in Longitudinal Research on Child Abuse Volume 3: Early Adolescence (Ages 12 - 14). Accessible at the LONGSCAN web site (http://www.unc.edu/depts/sph/longscan/ )

Kohl, P. L., Jonson-Reid, M., \& Drake, B. (2009). Time to leave substantiation behind: Findings from a national probability study. Child Maltreatment, 14(1), 17-26. doi:10.1177/1077559508326030

Lansford, J. E., Dodge, K. A., Pettit, G. S., \& Bates, J. E. (2016). A Public Health Perspective on School Dropout and Adult Outcomes: A Prospective Study of Risk and Protective Factors From Age 5 to 27 Years. Journal of Adolescent Health. doi:10.1016/j.jadohealth.2016.01.014

Little, R. J. A. (1988). A test of missing completely at random for multivariate data with missing values. Journal of the American Statistical Association, 83, 1198-1202. doi:10.1080/01621459.1988.10478722

Liu, Y., Croft, J. B., Chapman, D. P., Perry, G. S., Greenlund, K. J., Zhao, G., \& Edwards, V. J. (2013). Relationship between adverse childhood experiences and unemployment among adults from five US states. Social Psychiatry and Psychiatric Epidemiology, 48(3), 35769. doi:10.1007/s00127-012-0554-1

Mahoney, J. L. (2014). School Extracurricular Activity Participation and Early School Dropout: A Mixed-Method Study of the Role of Peer Social Networks. Journal of Educational and Developmental Psychology, 4(1), 143. doi:10.5539/jedp.v4n1p143

MacKinnon, D. P., Lockwood, C. M., Hoffman, J. M., West, S. G., \& Sheets, V. (2002). A comparison of methods to test mediation and other intervening variable effects. Psychological Methods, 7(1), 83-104.

Moilanen, K. L., Shaw, D. S., \& Maxwell, K. L. (2010). Developmental cascades: Externalizing, internalizing, and academic competence from middle childhood to early adolescence. Development and Psychopathology, 22(3), 635-653. doi:10.1017/S0954579410000337

Muthén, L. K., \& Muthén, B. O. (2012). Mplus User's Guide (7th ed.). Los Angeles: Muthén \& Muthén.

Musen, L. (2010). Early reading proficiency. Providence, RI: Brown University, Annenberg Institute for School Reform.

Preacher, K. J., \& Hayes, A. F. (2008). Asymptotic and resampling strategies for assessing and comparing indirect effects in multiple mediator models. Behavior Research Methods, 40(3), 879-891. doi: 10.3758/BRM.40.3.879

Porche, M. V., Fortuna, L. R., Lin, J., \& Alegria, M. (2011). Childhood Trauma and Psychiatric Disorders as Correlates of School Dropout in a National Sample of Young Adults. Child Development, 82(3), 982-998. doi:10.1111/j.1467-8624.2010.01534.x 
Pyrooz, D. C. (2014). From Colors and Guns to Caps and Gowns? The Effects of Gang Membership on Educational Attainment. Journal of Research in Crime and Delinquency, 51(1), 56-87. doi:10.1177/0022427813484316

Radloff, L. S. (1977). The CES-D Scale: A self-report depression scale for research in the general population. Applied Psychological Measurement, 1, 385-401. doi:10.1177/014662167700100306

Rosenthal, B. S. (1998). Non-school correlates of dropout: An integrative review of the literature. Children and Youth Services Review, 20(5), 413-433. doi:10.1016/S01907409(98)00015-2

Rowe, E., \& Eckenrode, J. (1999). The timing of academic difficulties among maltreated and nonmaltreated children. Child Abuse \& Neglect, 23(8), 813-832.

Runyan, D. K., Curtis, P. A., Hunter, W. M., Black, M. M., Kotch, J. B., Bangdiwala, S., . . Landsverk, J. (1998). LONGSCAN: A consortium for longitudinal studies of maltreatment and the life course of children. Aggression and Violent Behavior, 3(3), 275285. doi:10.1016/S1359-1789(96)00027-4

Sagatun, A., Heyerdahl, S., Wentzel-Larsen, T., \& Lien, L. (2014). Mental health problems in the 10th grade and non-completion of upper secondary school: the mediating role of grades in a population-based longitudinal study. BMC Public Health, 14, 16. doi:10.1186/14712458-14-16

Schilling, E. A., Aseltine, R. H., \& Gore, S. (2007). Adverse childhood experiences and mental health in young adults: a longitudinal survey. BMC Public Health, 7, 30.

doi:10.1186/1471-2458-7-30

Smith, D. K., \& Chamberlain, P. (2010). Multidimensional treatment foster care for adolescents: Processes and outcomes. In J. R. Weisz \& A. E. Kazdin (Eds.), Evidencebased psychotherapies for children and adolescents (2nd ed., pp. 243-258). New York, NY US: Guilford Press.

Steiger, J. H. (1990). Structural Model Evaluation and Modification - an Interval Estimation Approach. Multivariate Behavioral Research, 25(2), 173-180. doi:10.1207/S15327906mbr2502_4

Straus, M. A., Hamby, S. L., Finkelhor, D., Moore, D. W., \& Runyan, D. (1998). Identification of child maltreatment with the Parent-Child Conflict Tactics Scales: Development and psychometric data for a national sample of American parents. Child Abuse and Neglect, 22(4), 249-270.

Schwartz, D., \& Proctor, L. J. (2000). Community violence exposure and children's social adjustment in the school peer group: The mediating roles of emotion regulation and social cognition. Journal of Consulting and Clinical Psychology, 68(4), 670.

doi:10.1037/0022-006X.68.4.670 
U.S. Department of Education, National Center for Education Statistics. (2015). The Condition of Education 2015 (NCES 2015-144), Status Dropout Rates.

U. S. Department of Health and Human Services. Healthy People 2020. www.healthypeople.gov/ 2020/topicsobjectives2 020/ default. aspx. Accessed March 30, 2015.

Van Ameringen, M., Mancini, C., \& Farvolden, P. (2003). The impact of anxiety disorders on educational achievement. Journal of Anxiety Disorders, 17(5), 561-571. doi:10.1016/S0887-6185(02)002281

Vitaro, F., Brendgen, M., Larose, S., \& Trembaly, R. E. (2005). Kindergarten Disruptive Behaviors, Protective Factors, and Educational Achievement by Early Adulthood. Journal of Educational Psychology, 97(4), 617-629. doi:10.1037/0022-0663.97.4.617

Widom, C. S., Raphael, K. G., \& DuMont, K. A. (2004). The case for prospective longitudinal studies in child maltreatment research: commentary on Dube, Williamson, Thompson, Felitti, and Anda (2004). Child Abuse and Neglect, 28(7), 715-722.

doi:10.1016/j.chiabu.2004.03.009

Wilkinson, G. S. (1993). WRAT3: Wide Range Achievement Test Administration Manual.WideRange, Inc. 15 Ashley Place, Suite 1A. Wilmington, DE

Yu, C. Y. (2002). Evaluating cutoff criteria of model fit indices for latent variable models with binary and continuous outcomes. Doctoral dissertation,. University of California, Los Angeles. 
Table 1. Sample Descriptive Statistics.

\begin{tabular}{ll}
\hline Race/Ethnicity & \\
White [n(\%)] & $186(26 \%)$ \\
Black [n(\%)] & $391(54 \%)$ \\
Hispanic/Latino [n(\%)] & $47(6 \%)$ \\
Mixed/Other [n(\%)] & $104(14 \%)$ \\
Ever had caregiver who did not graduate high school (ages 4-14) [n(\%)] & $347(48 \%)$ \\
Number of interviews with a family income below FPL (ages 4-14) [M (SD)] & $2.36(1.68)$ \\
Ever had clinically elevated school problems (ages 4-14) [n(\%)] & $97(14 \%)$ \\
Mean externalizing problems (ages 4-14) [M(SD)] & $50.45(7.97)$ \\
Mean internalizing problems (ages 4-14) [M(SD)] & $54.39(9.08)$ \\
School dropout by age 18 [n(\%)] & $144(19.8 \%)$ \\
Reading Standard Score at age 16 [M(SD)] & $92.88(15.40)$ \\
Internalizing problems at age 16 [M(SD)] & $49.11(11.85)$ \\
Externalizing problems at age 16 [M(SD)] & $53.21(11.79)$ \\
Prosocial peer association at age 16 [M(SD)] & $1.24(.44)$ \\
Deviant peer association at age 16 [M(SD)] & $.34(.30)$ \\
ACEs [M (SD)] from birth to age 14 & $3.58(2.13)$ \\
Neglect [n(\%)] & $435(60 \%)$ \\
Sexual abuse [n(\%)] & $124(17 \%)$ \\
Physical abuse [n(\%)] & $372(51 \%)$ \\
Emotional maltreatment [n(\%)] & $249(34 \%)$ \\
Witnessed family violence [n(\%)] & $322(44 \%)$ \\
Household member arrested [n(\%)] & $317(44 \%)$ \\
Household member substance use [n(\%)] & $358(49 \%)$ \\
Caregiver mental health problem [n(\%)] & $426(59 \%)$ \\
\hline
\end{tabular}

Note: ACEs = Adverse Childhood Experiences; $M=$ mean; $\mathrm{SD}=$ standard deviation; $\mathrm{T}$-scores are presented for Internalizing and Externalizing to facilitate interpretation

Table 2. Bivariate Correlations Among Study Variables.

\begin{tabular}{lccccccc}
\hline & 1 & 2 & 3 & 4 & 5 & 6 & 7 \\
\hline 1. ACEs ages 0-14 & 1 & - & - & - & - & - & - \\
2. Prosocial peers association & -.042 & 1 & - & - & - & - & - \\
3. Deviant peer association & .028 & $-.042^{*}$ & 1 & - & - & - & - \\
4. Reading achievement & $-.082^{*}$ & $.132^{*}$ & .007 & 1 & - & - & - \\
5. Externalizing problems & $.15^{*}$ & $-.104^{*}$ & $.173^{*}$ & $-.102^{*}$ & 1 & - & - \\
6. Internalizing problems & $.191^{*}$ & $-.117^{*}$ & $.096^{*}$ & $-.103^{*}$ & $.632^{*}$ & 1 & - \\
7. School dropout & $.187^{*}$ & $-.25^{*}$ & $.202^{*}$ & $-.222^{*}$ & $.209^{*}$ & $.077^{*}$ & 1 \\
\hline
\end{tabular}

Note: ACEs $=$ Adverse Childhood Experiences. ${ }^{*} p<.05$ 
Figure 1. Hypothesized path model of mediators of the association between Adverse Childhood Experiences and School Dropout. Light gray curved lines represent concurrent associations among variables. ACEs $=$ adverse childhood experiences.

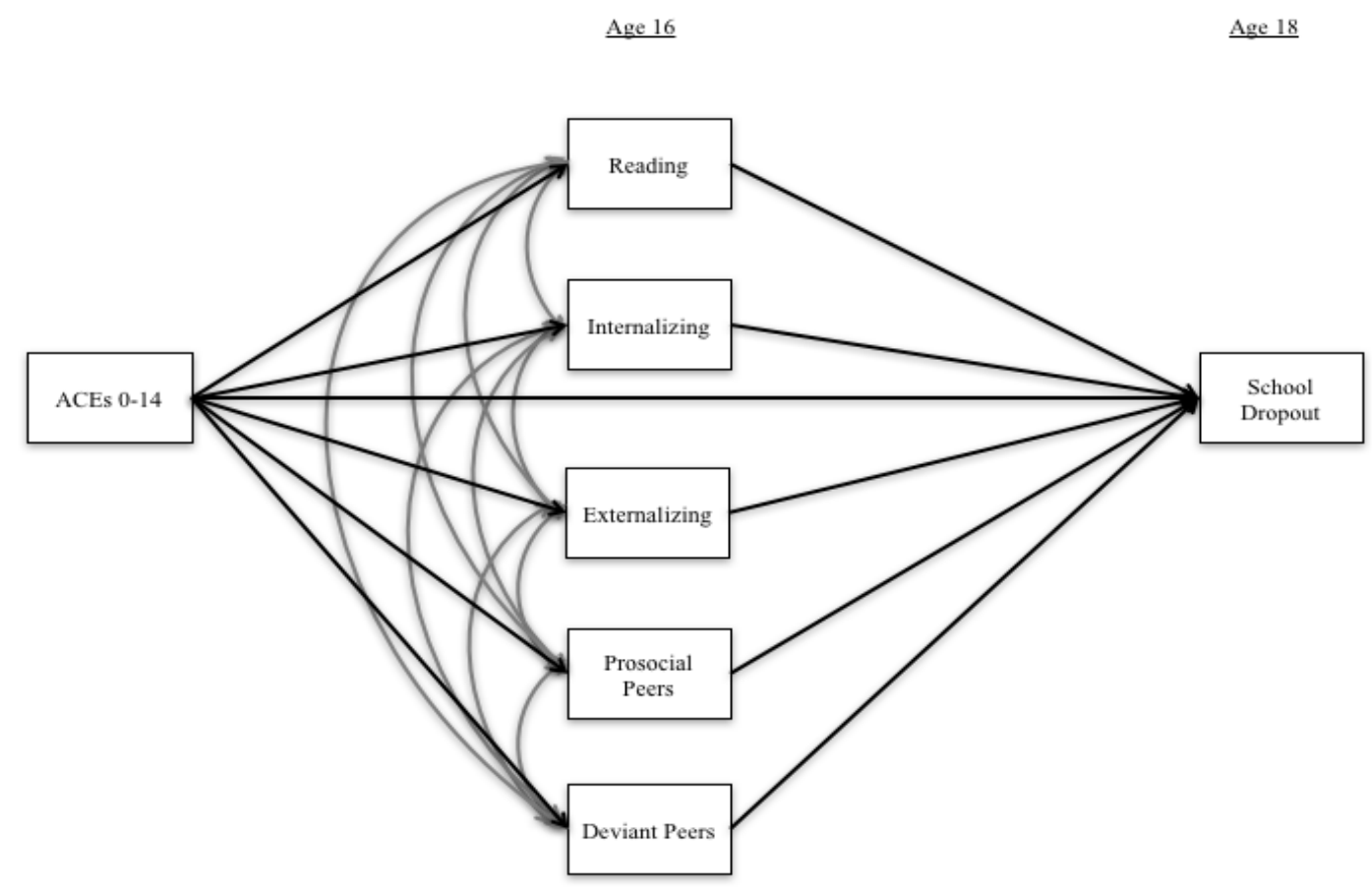


Figure 2. Mediation Model of the Association Between Adverse Childhood Experiences and School Dropout. Broken lines represent hypothesized paths that were not significant. Light gray curved lines represent significant concurrent associations among variables. ACEs $=$ adverse childhood experiences; $\beta=$ standardized path coefficient; OR = odds ratio. ${ }^{*} p<.05$.

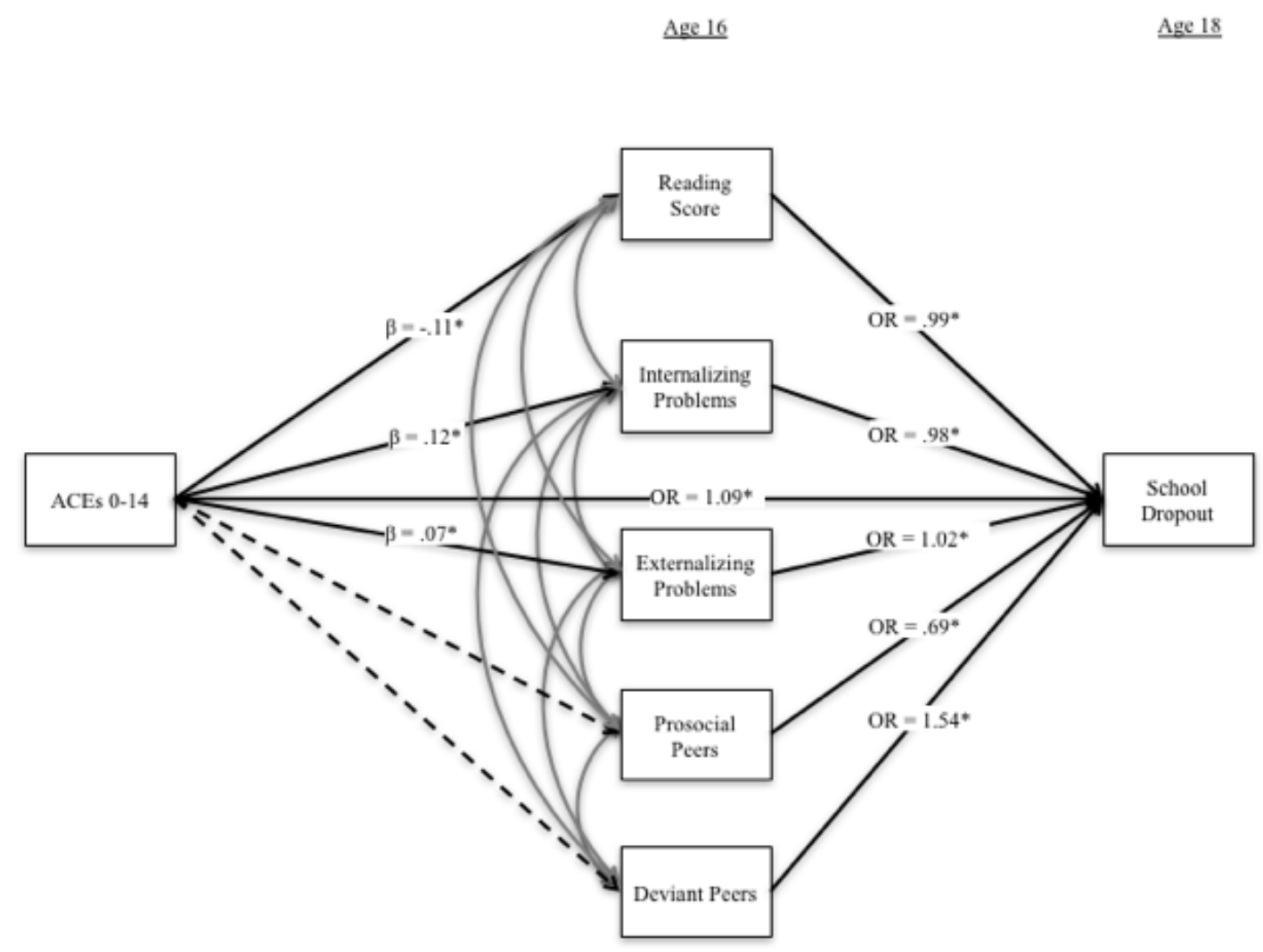


III. CHAPTER 2.

IDENTIFYING PROSPECTIVE RISK FACTORS FOR JUVENILE JUSTICE

INVOLVEMENT IN A SAMPLE OF YOUTH AT-RISK FOR MALTREATMENT

This manuscript is currently in press in Child Maltreatment.

Morrow, A.S., Villodas, M.T. \& Cunius, K. (in press). Identifying Prospective Risk Factors for Juvenile Justice Involvement in a Sample of Youth At-Risk for Maltreatment. Child Maltreatment. 


\begin{abstract}
This study aimed to prospectively identify ecological risk factors for juvenile arrest in a sample of youth at-risk for maltreatment. Chi-squared Automatic Interaction Detector analysis was performed with data from 592 youth from the Longitudinal Studies of Child Abuse and Neglect to identify the optimal combination of age 14 predictors of past-year arrest at age 16. Results extended previous research, which has identified being male, having more conduct disorder symptoms, suspension from school, perceived school importance, witnessing family violence, and having a jailed family member as key risk and protective factors for arrest by identifying important interactions among these risk factors. These interactions differentiate youth at the greatest risk for arrest, which in this sample, were males with greater than two symptoms of conduct disorder who witnessed family violence. These findings suggest that longitudinal and multi-informant data could inform the refinement of actuarial risk assessments for juvenile arrest.
\end{abstract}

\title{
Literature Review
}

Maltreated youth are at-risk for delinquent and criminal behavior, which is a serious yet common outcome. More than 900,000 youth under the age of 18 were arrested in 2015 (Office of Juvenile Justice and Delinquency Prevention (OJJDP), 2017). Juvenile justice involvement is expensive, costing $\$ 148,767$ per case per year on average to confine youth (Petteruti, Schindler, $\&$ Ziendenberg, 2014). It is estimated that rates of prior child welfare involvement for juvenile offenders range from approximately one-third to two-thirds of the population (Halemba, Siegel, Lord, \& Zawacki, 2004; Herz, Ryan, \& Bilchik, 2010). Longitudinal research has established a direct association between maltreatment and delinquent behavior (Thornberry, Henry, Ireland, \& Smith, 2010). Further, maltreatment commonly co-occurs with several other adverse childhood experiences (ACEs), which are interrelated and associated with delinquency (Logan-Green et al., 2017). However, more research is needed to delineate the complex interactions among multiple ecological risk and protective factors to better understand and prevent delinquency among at-risk 
youth. The primary focus of this study is to prospectively identify risk and protective factors for juvenile arrest from multiple ecological contexts among youth at-risk for maltreatment, which could be used to inform the identification of youth at the greatest risk for arrest.

\section{An Ecological Perspective on Juvenile Arrest}

Ecological systems theory (Bronfenbrenner, 1979) is particularly well-suited for the conceptualization of risk and protective factors for juvenile arrest because it considers many factors across contexts within one nested model. The ecological systems model theorizes that more proximal contextual factors exert the most direct influence on individuals, such as individual characteristics, followed by family factors, and increasingly distal influences, such as school/peer and neighborhood/community factors.

Individual factors. A review by Murray and Farrington (2010) noted individual factors such as mental health problems (e.g., Attention Deficit/Hyperactivity Disorder), low school achievement, and low IQ were particularly salient predictors of both conduct disorder and delinquency. Well-established individual risk factors for delinquent outcomes also include male gender, under-controlled temperament (e.g., negative emotionality), and low baseline autonomic arousal (i.e., low resting heart rate; Moffitt \& Caspi, 2001). Mania/hypomania, substance and alcohol use are also all associated with arrest (Green et al., 2016; Harzke et al., 2012). Additionally, a vast majority of justice-involved youth meet the diagnostic criteria for Conduct Disorder (Drerup, Croysdale, \& Hoffmann, 2008; Harkze et al., 2012), with 98\% reporting at least one CD symptom. Further, extensive research indicates that for maltreated youth in particular, internalizing mental health problems (e.g., major depressive disorder), externalizing mental health problems (e.g., disruptive behavior disorders), post-traumatic stress, disengagement from school, and substance abuse problems increase the risk of juvenile delinquency (Bender, 2010). 
Family/Household Factors. Proximal influences in an individual's life, including familial factors (e.g., physical abuse), are strong predictors of delinquency (Lee \& Villagrana, 2015; Murray \& Farrington, 2010). The association between maltreatment and delinquency has been well-characterized in developmental research studies, such as the Cambridge Study in Delinquent Development and the Child Development Project (Bates, Pettit, Dodge, \& Ridge, 1998), which were started in the 1980s (Farrington, 1995; Widom, 1989). These studies were followed by causes and correlates of delinquency studies throughout the 1990s (Thornberry, Huizinga, \& Loeber, 2004), which included the Denver Youth Survey, the Pittsburgh Youth Study, and the Rochester Youth Development Study.

Importantly, household risk factors independently increase the risk for delinquency, including parents' criminal conviction, harsh discipline, inconsistent parenting, mother's mental health problems, years exposed to single parenthood, family conflict, and socioeconomic status (Moffitt \& Caspi, 2001). Given the interrelations among these experiences, researchers have conceptualized the developmental impact of an accumulation of a set of adverse childhood experiences (ACEs; Felitti et al., 1998), including neglect, physical and/or sexual abuse, witnessing family violence, a family member in jail, a caregiver who abuses alcohol or other substances, a caregiver with a mental health problem, or divorced or separated caregivers. Importantly, the interrelated nature of ACEs necessitates the study of all of these factors simultaneously, especially with justice-involved youth (Logan-Green et al., 2017).

Though the association between maltreatment in childhood and delinquency has been well-established (Farrington, 1995; Widom, 1989), the approximately two-thirds of maltreated children are not involved with the juvenile justice system (Widom, 2001). Therefore, ecological domains are best conceptualized as containing both risk and protective factors. Appropriate parental monitoring and warm familial relationships are factors known to promote positive outcomes (Smith, Lizotte, Thornberry, \& Krohn, 1995). 
School/Peer Factors. School-related and peer factors such as deviant peer association and attending schools with high rates of delinquency, are associated with an increased risk for juvenile arrest (Murray \& Farrington, 2010). For example, in the Rochester Youth Development Study, Henry and colleagues (2012) found that five indicators of school engagement (i.e., attendance, course failure, standardized test scores, suspensions, and grade retention) were significantly associated with high school dropout, as well as arrests/police contact at ages 15-16. Additionally, Henry and colleagues (2012) found that high school dropout was a significant mediator of the relationship between school engagement and serious violent crime between the ages 21 and 23 years. Early warning system models developed to predict high school dropout are very useful for predicting delinquency throughout development in at-risk youth (Knight, \& Thornberry, 2012; Smith, Park, Ireland, Elwyn, \& Thornberry, 2012). Indicators of school engagement and peer associations can also be conceptualized as protective factors, as both prosocial peer friendships as well as a positive connection to school life are associated with decreased risk of juvenile arrest (Henry et al., 2012; Smith, et al., 1995).

Neighborhood/community factors. The characteristics of youths' neighborhoods and communities may influence their risk for juvenile arrest by presenting more opportunities for engaging in delinquency. For example, youths living in more disorganized neighborhoods and communities with higher rates of crime are more likely to become involved in delinquency (Leventhal \& Brooks-Gunn, 2000). On the other hand, youths living in communities that are more stable and have a greater sense of collective efficacy are at a lower risk for several negative outcomes, including delinquency (Leventhal \& Brooks-Gunn, 2000).

\section{Actuarial Risk Assessment for Juvenile Justice Involvement}

Actuarial risk assessments (i.e., predominantly used to predict violence/recidivism in the literature) have been conceptualized across a range from involving entirely unstructured clinical judgement to completely structured (actuarial) decision-making (Skeem \& Monahan, 2011). 
Several waves characterize the development of risk assessments in institutional settings, from first-generation assessments relying entirely on clinical judgement, followed by secondgeneration assessments with additive point scales (typically derived without statistical methods/focusing on static risk factors), third-generation assessments with more empirical support and the inclusion of dynamic risk factors, and lastly, fourth-generation assessments which include both risk and protective factors, with a focus on integration of insights into intervention planning (Moon, 2012). Static risk factors are features of an individual's history, such as prior offenses, whereas dynamic risk factors are amenable to change (Moon, 2012). A strength of the literature on actuarial risk assessments is that they have been evaluated extensively, identifying common functional themes to improve prediction accuracy (e.g., in a meta-analysis, all 28 studies include an indicator of prior behavior problems as a risk factor for future institutional violence and/or violent recidivism; Yang, Wong, \& Coid, 2010). However, actuarial risk assessments used to make decisions regarding legal supervision (e.g., incarceration, parole, etc.) have received criticism for several valid reasons, especially perpetuating racial bias (Harcourt, 2008) and gender bias (Schwalbe, Fraser, Day, \& Cooley, 2006). When risk assessments are used to make decisions based on limited data from a single source, they may have less reliable results, potentially leading to increased bias.

Many actuarial assessments relate to recidivism risk in adults (Yang, et al., 2010). However, actuarial risk assessments are currently also used in the child welfare and juvenile justice systems to address the wide-ranging risk and protective factors affecting child safety and delinquency, respectively (Hamilton, Van Wormer, \& Barnoski, 2015; Baird, Wagner, Healy, \& Johnson, 1999). For the child welfare system, current actuarial assessments evaluate risk of overall maltreatment recurrence (e.g., structured decision-making tools to guide decisions on the placement of children in out-of-home care), as well as 24-hour safety (Baird et al., 1999), and for 
the juvenile system, actuarial assessments focus primarily on recidivism and/or violence risk (Davies \& Dedel, 2006; Hamilton et al., 2015; Schwalbe, 2008).

Additionally, an actuarial risk assessment for predicting juvenile offending was developed based on an administrative dataset from the Dutch police, which included records about juveniles who were involved in a criminal offense, but not in the role of a suspect (e.g., involved as a witness; Assink, van der Put, \& Stams, 2016). This actuarial tool is particularly promising because input from administrative police data provided sufficient predictive accuracy of juvenile offenses beyond only recidivism/recurrence (i.e., including first-time offenses, Assink et al., 2016). Nevertheless, it is likely that this assessment could be improved with the inclusion of prospective information from additional data sources other than police records.

\section{The Current Study}

We examined the interactive effects of 31 contextual factors that were assessed up to age 14 for the prediction of past-year juvenile arrest at age 16 in a sample of youth at-risk for maltreatment. In Table 1, we report descriptive statistics for all variables, which were included in the model with the exception of juvenile arrest (i.e., the target outcome). Based on previous empirical evidence and theory, we anticipated that proximal factors would emerge as salient predictors of juvenile arrest: a history of rule-breaking behavior (i.e., conduct disorder symptoms; (Drerup et al., 2008; Harkze et al, 2012); school engagement factors (i.e., both protective strategies and risk behaviors; Henry et al., 2012); and adverse childhood experiences (LoganGreen et al., 2017).

\section{Method}

\section{Sample}

The present study used data collected from 592 adolescents who participated in a multisite consortium of prospective studies, the Longitudinal Studies of Child Abuse and Neglect (LONGSCAN). LONGSCAN included 1354 youth and their caregivers who were recruited to 
participate (at either age four or six years old) across five sites and varied with respect to their levels of risk for family violence. More specifically, the Northwestern and Southwestern sites recruited children who had been reported for abuse and/or neglect, the Eastern site recruited children attending pediatric clinics considered high-risk for maltreatment based on demographic risk factors, and the Southern and Midwestern sites recruited both children that had been reported for maltreatment, as well as children who were considered high-risk for maltreatment (see Runyan et al., 1998, for further description of the overall study design, as well as more details about site-specific recruitment procedures).

Of the 1354 adolescent-caregiver dyads included in the full LONGSCAN sample, dyads who completed caregiver and youth interviews at ages 14 and $16(n=592)$ were included in the current study. Sample descriptive statistics are presented in Table 1. The sample had approximately the same number of males and females (50.3\% and $49.7 \%$, respectively), the adolescents were on average 16.27 years old (standard deviation $[\mathrm{SD}]=.41$ ) at the time of the age 16 interview, and they were racially/ethnically diverse (26\% White, 55\% Black, $6 \%$ Hispanic/Latino, $13 \%$ of another or more than one race/ethnicity), consistent with the demographics of the overall LONGSCAN sample reported (see Results).

\section{Procedures}

LONGSCAN sites used identical data collection, entry, and management protocols. Following institutional review board approval, informed consent was obtained from caregivers, and assent was obtained from the children prior to conducting each interview. Children and their caregivers received a fixed, nominal amount for their participation at each interview. Children and their caregivers were recruited to participate when the children were either 4 or 6 years old and were assessed face-to-face biannually between ages 4 and 16 using developmentally appropriate measures of the children, their caregivers, families, neighborhoods, and schools. Administrative child protective services records for all child participants were reviewed 
continuously and coded for indicators of maltreatment (see information about coding procedures below).

\section{Measures}

Demographic Information. Demographic information about the child-caregiver dyads was collected at each assessment. Child sex, race/ethnicity, and date of birth were assessed at the baseline interview, and family income, number of dependents, and caregiver education were collected at the age 14 interview. An indicator of whether or not families' reported incomes were below the federal poverty level for the year during which they completed the age 14 interview, given their reported number of dependents, was calculated.

Individual Factors. Adolescent Mental Health at age 14. Youth completed the National Institute of Mental Health Diagnostic Interview Schedule for Children (DISC-IV) at age 14 (NIMH DISC-IV, 1997; Shaffer, 2000). The DISC-IV contains more than 2,000 questions designed to assess for symptoms more than thirty psychiatric diagnoses in young adults using an audio computer-assisted self-interview. It has been empirically validated, and the development of the instrument has been extensively described previously (see Shaffer et al., 2000 for complete descriptions of methodological and psychometric testing). Our analyses focused on symptom counts for disorders that have been empirically associated with juvenile arrest, including ADHD, Oppositional Defiant, Conduct, Major Depressive, Bipolar, Post-Traumatic Stress, and substance use disorders, including symptom counts for Marijuana Abuse \& Dependence, Substance Abuse \& Dependence, Nicotine dependence, and Alcohol Abuse and Dependence (Bender, 2010; Harzke et al, 2012; Murray \& Farrington, 2010).

Family/household Risk Factors: We included individual indicators of the presence or absence of eight possible ACEs, which are consistent with those included in prior studies (e.g., Villodas et al., 2016). Specifically, dichotomous indicators of whether or not families experienced 
caregiver mental health problems, family member substance use or incarceration, witnessed family violence, child neglect, and physical, sexual, and emotional abuse between birth until the age 14 interview were constructed and described below.

Child neglect, physical, sexual, or emotional abuse. Child Protective Services (CPS) records were systematically reviewed to identify reports of alleged maltreatment and coded using the Modified Maltreatment Classification System (MMCS; Barnett, Manly, \& Cicchetti, 1993; English \& the LONGSCAN Investigators, 1997). Coders were trained to use the MMCS by experienced coders until they reached $90 \%$ agreement. To further ensure reliability, coders coded a subsample $(\mathrm{n}=109)$ of the CPS narratives and Kappas were high (ranging from .73 for emotional maltreatment to .87 for physical abuse; English \& the LONGSCAN Investigators, 1997). The present study used dichotomous indicators (i.e., $0=$ not alleged, $1=$ alleged) of whether or not adolescents had allegations for each of the 4 maltreatment subtypes (i.e., physical abuse, sexual abuse, neglect, and emotional maltreatment) from birth until the age 14 interview. The decision to use allegations of maltreatment was based on previous findings that children with alleged and substantiated maltreatment are at a similarly increased risk for maltreatment recidivism and mental health and behavioral consequences (Drake, Jonson-Reid, Way, \& Chung, 2003; Hussey et al., 2005; Kohl, Jonson-Reid, \& Drake, 2009).

Caregivers also reported their own aggressive behavior toward their child in the past year on the Conflict Tactics Scales-Parent-Child version (CTSPC; Straus, Hamby, Finkelhor, Moore, \& Runyan, 1998). They completed the severe physical assault scale (3 items; e.g., hit child with fist or kicked hard, threw or knocked child down) at the age 8,12, and 14 interviews, and the extreme physical assault scale (4 items; e.g., grabbed and choked child around the neck, beat child up, burned or scalded child on purpose) at the age 12 and 14 interviews. Although these scales have demonstrated good validity, they tend to show weak evidence of internal consistency because of the relatively low frequency of each of the behaviors (Straus et al., 1998). The 
severe/extreme physical assault scales were combined with the CPS indicator of allegations of physical abuse to form a single indicator of physical abuse from birth to age 14 .

Witnessed family violence. The Life Events Scale is a caregiver-report measure that was adapted by LONGSCAN from Coddington's (1972) Life Event Records to include whether or not the child has experienced any of 30 stressful life events in the past year. At the ages $6,8,10,12$, and 14 interviews, caregivers reported adolescents' experiences of witnessed family violence on five dichotomous indicators of whether or not the child witnessed a family member 1) threatened with a weapon, 2) hit, kicked, or slapped, 3) shot or stabbed, 4) raped or sexually assaulted, or 5) killed or murdered. The History of Witnessed Violence measure is an adolescent-report measure completed at the age 12, and 14 interviews, including seven dichotomous indicators of whether or not the child witnessed during their lifetime any family member 1) hit, kicked, slapped, or beaten up, 2) threatened with a knife, 3) threatened with a gun, 4) stabbed or cut with a weapon, 5) shot, 6) killed, or 7) sexually assaulted. The items from these two scales were combined with an indicator of whether or not family violence between adults in the home was included as a risk factor in CPS records between birth and the age 14 interview based on the MMCS to form a single dichotomous indicator of the presence of witnessed family violence.

Family member substance use. The CAGE (Bradley et al., 1998) alcohol questionnaire is a widely used measure that contains four non-threatening questions about whether or not the caregiver felt they should reduce their drinking, were annoyed or criticized for their drinking, felt guilty about their drinking, or drank first thing in the morning. The scale was administered at the age 4 interview and a dichotomous indicator of whether or not the caregiver endorsed more than 1 item was created. At the age 8 interview, caregivers completed the Caregiver Substance Use scale to assess their current use of illicit drugs, such as marijuana, cocaine, hallucinogens, heroin, stimulants, and tranquilizers. At the age 12 and 14 interviews, adolescents completed the Risk 
Behaviors of Family and Friends self-report measure of whether or not their family members used marijuana, cocaine, methamphetamine, LSD, heroin, or other intravenous drugs. A dichotomous indicator was created to represent the presence of any substance use across the three measures between the age 4 and 14 interviews.

Caregiver mental health. The Center for Epidemiologic Studies Depression (CES-D) scale is a 20-item self-report measure of depressive symptoms experienced by caregivers in the past week (Radloff, 1977). Each item is scored on a 4-point scale ranging from 0 (rarely or none of the time) to 3 (most or all of the time) with a cutoff score of 16 indicating "high depressive symptoms" as recommended by the author. The measure was administered at the age $4,6,12$, and 14 interviews. The Brief Symptom Inventory (Derogatis, 1993) is a 53-item (5-point scale ranging from $0=$ not at all to $4=$ extremely) measure that assesses caregivers' experiences during the previous seven days of nine symptom scales, which were identified through factor analyses: Somatization (seven items), Obsession-Compulsion (six items), Interpersonal Sensitivity (four items), Depression (six items), Anxiety (six items), Hostility (five items), Phobic Anxiety (five items), Paranoid Ideation (five items), and Psychoticism (five items). It was administered to caregivers at the age 8 interview, T-scores were calculated based on the adult non-patient normative data for the measure, and the standard case rule $(\mathrm{T}>63)$ was applied. A dichotomous indicator was created to represent whether or not caregivers were above the clinical cut-off score on any of the BSI scales or on the CES-D at any age.

Family member jailed. One item was included from the Life Events Scale (see description above) at the age $6,8,10,12$, and 14 interviews that assessed whether or not any of the child's family members had been incarcerated in the past year.

Family/household Protective Factors. Parental Monitoring at Age 14. The adolescent's perceived level of monitoring by his/her caregiver was assessed using an adapted adolescent self-report measure at age 14 that was originally developed by Patterson \& 
Stouthamer-Loeber (1984). The five-item abbreviated measure was included in the LONGSCAN measurement protocol to assess parental monitoring of three broad domains, including money, whereabouts, and activities. This measure has been used to assess parental monitoring in multiple studies, including the Child Development Project (Bates, Pettit, Dodge, \& Ridge, 1998) and the Oregon Youth Study (Patterson \& Yoerger, 1993). Specifically, items assessed how much adolescents perceived that their parents really know about who their friends are, where they are at night, how they spend their money, what they do with free time, and where they are most afternoons after school (i.e., $0=$ they don't really know, $1=$ they know A LITTLE about this, $2=$ they know A LOT about this). Internal consistency this measure was acceptable ( $\alpha=.70$ in the current sample).

Quality of parent-youth relationship at Age 14. Adapted from Resnick et al, (1997), the quality of the youth's relationship to his/her parent was assessed using a parent-reported, summed indicator of six items evaluated on five-point likert scale (e.g., how close do you feel to your child?). Significant correlations among relationship quality reported by various individuals (e.g., youth-reported, parent-reported) demonstrate convergent validity of this measure in our sample as well as adequate internal consistency $(\alpha=.74)$.

School/Peer Factors. School Engagement Behaviors at Age 14. Attitudes toward school and school-related behavior problems were assessed at age 14 with a project-developed adolescent self-report measure. Individual items assessed the frequency of homework completion (i.e, never, sometimes, almost always, always, or never get homework), youth's perception of the importance of doing well in school (i.e, not, not very, somewhat, extremely), and if the adolescent had ever thought seriously about dropping out of school (dichotomous response; Yes/No). The aforementioned indicators are valid, aligning with best practices in measuring school engagement both externally (e.g., school suspensions), as well as internally (e.g., perceptions, goals; Christenson et al., 2008). 
Peer Behaviors at age 14. Association with prosocial and deviant peer groups at age 14 was measured using items that were modified from items included in the Youth Risk Behavior (CDC, 1990) and Monitoring the Future (Johnston, 2010) surveys. Prosocial peer association items assessed how many of the adolescents' close friends (i.e., $0=$ none to $2=$ most) participated in 5 prosocial activities (e.g., sports, school clubs, church, academics; $\alpha=.78$ in the current sample). Deviant peer association items assessed how many of the adolescents' close friends (i.e., $0=$ none to $2=$ most) engaged in 13 risky behaviors, such as substance or alcohol use, drug carrying or dealing, fighting, or weapon carrying ( $\alpha=.85$ in the current sample).

Neighborhood/Community Factors. Neighborhood Chaos, Collective Efficacy, and Neighborhood Stability at Age 14. The quality of the adolescents' neighborhoods, as well as its residential stability and organization were assessed using a 30-item caregiver-report measure adapted from previous anthropological investigations of child maltreatment and neighborhood factors (Coulton et al, 1996; \& Sampson et al, 1997). LONGSCAN investigators employed a principal components analysis to derive subscales representing the neighborhood's collective efficacy, chaos, and stability (Knight, Smith, Martin, Lewis, \& the LONGSCAN Investigators, 2008). The neighborhood chaos subscale is made up of 14 items that ask the caregiver about problems in their neighborhood (e.g., "There is graffiti on buildings and walls," "There is open drug activity"). The Collective Efficacy score is made up of 11 items asking the caregiver about neighborhood cohesion, and willingness to intervene (e.g., "People around here help their neighbors," "Neighbors can be trusted"). The neighborhood stability score is made up of 5 items asking the caregiver about people moving in and out of the neighborhood (e.g., "People don't live in neighborhood long," "Most of the people are renters"). All items were scored on a 4-point scale ranging from 1-4 (1 = "Strongly Disagree" to 4="Strongly Agree"). Higher scores indicate higher neighborhood chaos, lower collective efficacy, and lower neighborhood stability.

Outcome variable. Juvenile Arrests at Age 16. One self-report item from the Delinquent 
and Violent Behavior Scale assessed whether or not the adolescent had been arrested in the past year at age 16 (Huizinga, Esbensen, \& Weiher, 1991). Single-item youth self-reports of arrest are a common measurement modality with acceptable test-retest reliability and validity (Huizinga \& Elliot, 1986).

\section{Data Analysis}

Sample descriptive statistics, missing data patterns, and Chi-squared Automatic Interaction Detector (CHAID) analyses were computed using IBM SPSS version 25 (IBM SPSS, 2017). CHAID is useful for identifying the predictors that maximally differentiate a sample into categories of a target variable. In the present study, CHAID was used to prospectively identify the strongest predictors from a set of 31 ecological risk factors that maximally classified youth who had been arrested in the past year at age 16. CHAID is a recursive partitioning method, similar to Classification and Regression Tree analysis. CHAID performs repeated chi-squared analyses with adjusted-significance testing to divide a whole sample into increasingly smaller and more homogenous subgroups in a stepwise fashion. At each step, the sample is divided into more "pure" subgroups by selecting the strongest predictor of the target variable (i.e., juvenile arrest), given the adjusted-significance levels for the predictors included in the model. The purpose of CHAID analysis is to predict outcomes, classify individuals, and/or detect interactions between predictors of an outcome, particularly in the case of multiple predictor variables and a single outcome variable (Kass, 1980). Typically, in CHAID analyses, the whole sample is called the parent node, and all subgroups are called child nodes. Each child node is split on the basis of the next strongest predictor of the outcome within that subgroup until there are either no more predictor variables that significantly differentiate between levels of the criterion or until the child nodes have reached a minimum size ( $\mathrm{n}=10$ in the current study), which are often referred to as terminal nodes. In this way, the combination of predictor variables identified represent a complex interaction. CHAID can also accommodate categorical and continuous predictor variables. In the 
case of categorical variables, CHAID identifies splits that optimally differentiate homogenous subgroups. In the case of continuous predictor variables, CHAID identifies the optimal cutpoint(s) to maximally differentiate subgroups.

\section{Results}

\section{Missing Data}

The 592 youth included in the present study did not significantly differ from the remaining youth in the overall sample on gender, $\chi_{2}(1)=.24, p>.05$, race/ethnicity, $\chi_{2}(6)=.28$, $p>.05$, or maltreatment allegations between birth and the baseline interview. Among the 592 included youth, $3 \%$ were missing data on one variable and Little's test (Little, 1988) of missing data patterns revealed that none of the study variables was significantly related to any discernable pattern of missingness, $\chi_{2}(47)=45.93, p>.05$.

\section{Sample Descriptive Statistics}

In the overall sample of 592 youth, approximately one sixth $(16.7 \%)$ were arrested in the past year at age 16. Adolescents had experienced an average of 3.5 out of eight possible ACEs by the age 14 interview. Between birth and age 14, 50\% of youth had experienced physical abuse, $33 \%$ experienced emotional maltreatment, $16 \%$ had experienced sexual abuse, and $56 \%$

experienced neglect. More than one-half of the youth had a family member who was incarcerated at some time before the age 14 interview (56\%), and one-third of youth had witnessed family violence. Additionally, 58\% of caregivers at the age 14 visit reported family incomes below the federal poverty limit and 39\% reported their education level as less than high school. Lastly, approximately $50 \%$ of the sample was female. With respect to our target outcome, the following variables were significantly correlated for boys, but not for girls: PTSD Symptom Count, $r=.17$, $\mathrm{p}<.05$, alcohol abuse symptoms, $\mathrm{r}=.16, \mathrm{p}<.05$ witnessed family violence, $\mathrm{r}=.13, \mathrm{p}<.05$, caregiver mental health problems, $\mathrm{r}=.13, \mathrm{p}<.05$, family member jailed, $\mathrm{r}=.13, \mathrm{p}<.05$, and childhood sexual abuse, $r=.14, \mathrm{p}<.05$. Conversely, the following variables were significantly 
associated with juvenile arrest for girls, but not for boys: ODD symptoms, $r=.15, \mathrm{p}<.05$, and how often does homework, $\mathrm{r}=-.15, \mathrm{p}<.05$.

\section{Primary predictors and corresponding splits}

The CHAID analysis produced a classification tree (see Figure 1), consisting of 6 splits and 7 terminal notes. The strongest predictor of juvenile arrest was conduct disorder symptom count. In particular, youth with 3 or more symptoms of conduct disorder $(n=300)$ were at a significantly greater risk of arrest than youth with 2 or fewer symptoms $(n=292), \chi_{2}(1)=40.33, p$ $<.05$. Twenty-six percent $(n=79)$ of youth with 3 or more symptoms of conduct disorder at age 14 had been arrested in the past year at age 16 , relative to $7 \%(n=20)$ of youth who had 2 or fewer symptoms. Among youth with 3 or more conduct disorders symptoms, youth who witnessed family violence $(n=116)$ were at significantly greater risk of arrest than youth who had not witnessed family violence $(n=184), \chi_{2}(1)=13.11, p<.05$. Thirty-eight percent $(n=44)$ of youth who had witnessed family violence by 14 had been arrested in the past year at age 16 , relative to $19 \%(n=20)$ of youth who had not. Among youth with 3 or more conduct disorder symptoms, who witnessed family violence, males $(n=73)$ were at a significantly greater risk of arrest than females $(n=43), \chi_{2}(1)=6.25, p<.05$. Forty-seven percent $(n=34)$ of males had been arrested in the past year at age 16 , relative to $23 \%(\mathrm{n}=10)$ of females. Among youth with 3 or more conduct disorder symptoms who did not witness family violence, youth who felt that it was less than "Extremely important" (i.e., 3 or less) to do well in school $(n=54)$ were at a significantly greater risk of arrest than youth who felt it was "Extremely important" (i.e., 4) to do well in school $(n=130), \chi_{2}(1)=10.16, p<.05$. Thirty-three percent $(n=18)$ of youth who felt doing well in school was less important had been arrested in the past year at age 16 , relative to $13 \%(n=10)$ of youth who thought it was extremely important.

Among youth with 2 or fewer conduct disorder symptoms, youth who reported ever being suspended from school $(n=87)$ were at a significantly greater risk for arrest than youth who 
reported that they had never been suspended $(\mathrm{n}=205), \chi_{2}(1)=9.37, p<.05$. Thirteen percent of youth $(\mathrm{n}=12)$ who had ever been suspended from school had been arrested in the past year at age 16 , relative to $3.9 \%(n=8)$ of youth who had not. Finally, among youth who had 2 or fewer conduct disorder symptoms and had never been suspended from school, youth who had a family member in jail from birth to age $14(n=78)$ were at significantly greater risk of arrest than youth who did not $(n=127), \chi_{2}(1)=4.82, p<.05$. Eight percent $(n=6)$ of youth who had a family member in jail had been arrested in the past year at age 16 , relative to $1.6 \%(n=2)$ of youth who had not.

\section{Description of terminal nodes}

One function of CHAID analysis is to identify complex variable interactions that maximally differentiate individuals in different categories of the criterion, (i.e., youth in terminal nodes with either very high or very low arrest rates). The terminal node representing the group with the highest arrest rates at age $16(47 \%)$ included 73 males with 3 or more symptoms of conduct disorder, who had witnessed family violence. This finding indicates that a 3-way interaction between conduct disorder symptoms, witnessed family violence, and gender differentiated the youth who were at the highest risk for being arrested most clearly. Although the rate of arrest among females with the same two risk factors was significantly lower (23\%), it was still higher than the arrest rate in the overall sample. The terminal node with the next highest arrest rate $(33.3 \%)$ included 54 youth with 3 or more conduct disorder symptoms, who did not witness family violence, but reported that they felt school was relatively less important. In other

words, the 3-way interaction between conduct disorder symptoms, witnessed family violence, and school importance also differentiated youth who were at an elevated risk for arrest well. The terminal node in this study that had the lowest arrest rate (1.6\%), contained 127 youth who had 2 or fewer conduct disorder symptoms, reported never being suspended from school, and had never had a family member in jail from birth to age 14 . The 3-way interaction between conduct disorder 
symptoms, school suspension, and family member jailed differentiated youth who were at the lowest risk for arrest most clearly.

\section{Discussion}

Findings from this study underscore the importance of considering the complex interactions among risk factors for juvenile arrest across multiple ecological contexts when dealing with at-risk youth. Notably, approximately one-in-six adolescents in the present study had been arrested in the past year at age 16, which is substantially higher than the reported national prevalence of lifetime arrests for youth of this age (i.e., one-in-nine or 11.0\%; Brame, Turner, Paternoster, \& Bushway, 2012). Our findings support previous research highlighting the increased risk for juvenile justice involvement among maltreated youth (Halemba et al., 2004; Herz, Ryan, \& Bilchik, 2010). Based on the risk factors included in the present study, we differentiated subsets of youth with very high $(47 \%)$ and very low $(2 \%)$ risk of past year juvenile arrests in this at-risk sample. Our findings are consistent with previous research that risk factors from different ecological contexts interact to increase risk for juvenile arrest (Murray \& Farrington, 2010).

Consistent with the extant literature (Drerup et al., 2008; Harzke et al., 2012), the present study found that symptoms of conduct disorder were among the strongest predictors of juvenile arrest, as this individual factor was the first split in our decision tree. Of note, our analysis identified a cut-point of 3 or more symptoms of conduct disorder at age 14, which is consistent with the diagnostic symptom criterion for conduct disorder based on the Diagnostic and Statistical Manual-5 (DSM-5; American Psychiatric Association, 2013). Although expected, these findings reinforce the ecological validity of this clinical cut-point as a clinically meaningful threshold for delineating severe antisocial behavior that is above normative levels during adolescence and is likely to result in juvenile arrest. Additionally, it is not surprising that we found that another individual-level factor, male gender, significantly increased the risk of juvenile 
arrest. It is well established in the literature that boys are at an increased risk for delinquent involvement and arrest than girls (Henry et al., 2012; Smith et al., 2012). Further, male gender is known to moderate externalizing outcomes in high risk youth, such that the association between violence exposure and externalizing symptoms was significantly stronger for males (Evans, Davies, \& DiLillo, 2008). Lastly, it is important to note that an individual-level factor, race, did not emerge as salient in our model. Given concerns that risk assessments have been criticized for increasing racial bias (Harcourt, 2008), our findings buttress previous research suggesting that a focus on empirically-selected, dynamic risk factors is ideal.

The current study also identified important family risk factors, consistent with previous ACEs studies, for juvenile arrest. In line with the existing literature, family violence emerged as a particularly salient risk factor for juvenile arrest among youth with 3 or more CD symptoms (Evans, Davies, \& DiLillo, 2008). Having had a family member in jail also played a role in differentiating youth who were at increased risk for arrest among youth with 2 or fewer CD symptoms.

Lastly, we found that school engagement factors at age 14 (e.g., school suspension and perceived school importance) predicted past-year arrest at age 16. Nearly one-fifth of the sample was contained in a terminal node with the lowest risk for juvenile arrest, which included youth who had 2 or fewer symptoms of conduct disorder, who had never been suspended, and who had not had a family member in jail from birth to age 14 . Furthermore, if youth with elevated CD symptoms did not witness violence, even slightly less positive perceptions of school importance were associated with a nearly one-in-three arrest rate. The association between school engagement and juvenile justice involvement in at-risk youth has also previously been reported in longitudinal studies (Henry et al., 2012; Smith et al., 2012). However, actuarial approaches to conceptualizing juvenile justice prevention in at-risk youth have not previously included this domain of predictors because they relied solely on administrative data from a single source (e.g., 
Assink et al., 2016). Taken together, the results of the present study indicate that school engagement may be an especially pivotal prevention target for youth at-risk for delinquency.

\section{Implications}

A primary aim of the present study was to extend previous research on the additive effects of individual risk and protective factors from an ecological systems perspective by examining the multiplicative effects of risk factors across ecological contexts. The analysis identified interactions between individual, family, and school-related factors that differentiated youth in this sample who were at the greatest risk for juvenile arrest. Although each of these risk factors is an established predictor of delinquency during adolescence (Murray \& Farrington, 2010), it appears that their interactive effects magnify this risk.

ACEs are modifiable household risk factors that could be used to identify youth who are at the greatest risk for developing severe delinquent behaviors and, ultimately, being arrested. Given the well-documented association between ACEs and a variety of physical, psychosocial, and educational problems, including several leading causes of early death (Anda et al., 2006; Brown et al., 2009), prevention of exposure to these adversities and early identification of youth who may have been exposed could facilitate comprehensive family prevention efforts. One particularly effective example of ACEs prevention is SAFECare, which is estimated to save $\$ 16.54$ for every dollar spent on implementation (Lee et al., 2015). More specifically, SafeCare is an evidence-based, in-home child maltreatment prevention program for families at-risk for maltreatment (Casillas, Fauchier, Derkash, \& Garrido, 2016).

Although these findings have identified specific targets for intervention and prevention efforts, they also provide valuable information about intervention and prevention approaches more broadly. For example, these results suggest that multi-modal intervention strategies that directly engage youth, their family members, and perhaps even relevant school stakeholders, could optimally reduce risk for juvenile arrest, as opposed to intervening using a single modality 
or in a single context. For example, some large, urban school districts in the U.S. have specialized offices that integrate administrative data from the educational, juvenile justice, and child welfare systems daily to track the academic progress of youth who are involved with each of those systems (Gonsoulin, Darwin, \& Read, 2012). Integrating administrative data about key variable profiles, such as those identified in the present study, could identify the youth who are at the highest risk for juvenile arrest and have the greatest need for prevention or early intervention.

Using information from early detection systems will facilitate the engagement of youth at the highest risk for juvenile arrest into intervention models that target multiple ecological contexts, such as Multisystemic Therapy (MST) or Multidimensional Treatment Foster Care (Henggeler \& Schaeffer, 2010; Smith \& Chamberlain, 2010). Additionally, less intensive intervention models (i.e., lower burden of attendance) may be indicated for certain youth, as they place less logistical burden on already marginalized families, and provide skills-based support specifically for caregivers (e.g., mindfulness-based parent training; Dumas, 2005). School-based multicomponent interventions, such as Check and Connect could also facilitate improvements in the risk and protective factors highlighted in our model (Sinclair, Christenson, Hurley, \& Evelo, 1997). It will be particularly important for prevention and intervention efforts to integrate multisystem information about risk factors to identify youth at the greatest risk, and for whom multisystemic interventions are warranted.

\section{Limitations}

Several limitations of the present study should be noted. First, because this study used previously collected longitudinal data, some information (e.g., adjudication status) was not available and could have provided additional useful information. Further, typical of any longitudinal study, maintaining engagement throughout the study was challenging, resulting in missing data. Another core limitation to longitudinal research is that risk factors may have changed over time (e.g., due to mobility). We recommend that future researchers consider the 
effects of changes in risk factors on juvenile arrest. The criterion, past-year arrest at age 16, does not account for previous arrests that may have occurred, number of arrests, or the severity of the offense. As CD symptoms were the strongest predictor of juvenile arrest in our analyses, future investigations regarding prevention should consider evaluating risk and protective factors at an earlier point in development than age 14 for optimal early prevention. Additionally, our findings are best positioned to inform risk assessments for boys' arrest, given that models' predictive performance are typically correlated with base rates of arrest (e.g., baseline levels of arrest in our sample was $23.5 \%$ for boys vs. $9.9 \%$ for girls; Schwalbe, 2008). We also did not include femalespecific risk factors for juvenile arrest (e.g., romantic relationships; Javdani, Sadeh, \& Verona, 2011), which future research should consider, as well as conducting studies with predominately female samples. For example, larger-system variables (e.g., neighborhood features) were not present in our decision tree model. When more proximal variables are included, neighborhood characteristics do not distinguish between those arrested and not arrested. This could be explained by their more distal influence on the individual youth outcomes, relative to individual and family-level factors. Alternatively, because disadvantage accounts for a substantial portion of variation in neighborhood variables (Sampson et al., 1997), they may not have emerged as salient due to limited variability in our at-risk sample. Given the large number of predictors, many of which did not emerge as salient interactions, type II error may be a concern in our model. Particularly, our analyses would lead to more accurate predictions if we had a larger sample size (Morgan, Daugherty, Hilchie, \& Carey, 2003). CHAID analyses, along with other recursive partitioning strategies, are prone to model overfit, resulting in findings that tend to reflect the structure of the training dataset too closely and generate less accurate predictions in other samples. Ensemble machine learning methods, such as bagging, boosting, and random forest analysis, which aggregate results across many classifiers may be helpful in future studies to improve the generalizability of a decision tree (Breiman, 2001). Lastly, these findings may not 
generalize to adolescents from the general population of youth at risk for maltreatment, as data were collected through a consortium of studies in five geographic regions of the U.S., rather than a nationally-representative sample. In addition, participants were recruited based the presence of risk for maltreatment and family violence, not using population-based sampling methods.

\section{Conclusion}

The findings of the present study add to the extant literature on the complex interactions among predictors of juvenile arrest across multiple ecological contexts in at-risk youth. Our findings confirm previous research, which has identified being male, having 3 or more conduct disorder symptoms, school suspension, low perceived school importance, witnessed family violence, and having had a family in jail as risk factors for juvenile arrest. Moreover, specific complex interactions among combinations of these risk factors appear to differentiate youth who are at varying levels of risk for arrest during adolescence. Targeting prevention efforts for youth with these combinations of risk factors could contribute to the effective prevention of juvenile arrest among youth in at-risk ecological contexts. Additionally, these findings suggest that longitudinal and multi-informant data could inform the refinement of actuarial risk assessments for juvenile arrest.

\section{References}

Anda, R. F., Felitti, V. J., Bremner, J. D., Walker, J. D., Whitfield, C., Perry, B. D., ... Giles, W. H. (2006). The enduring effects of abuse and related adverse experiences in childhood. A convergence of evidence from neurobiology and epidemiology. European Archives of Psychiatry and Clinical Neuroscience, 256(3), 174-186. doi.org/10.1007/s00406-0050624-4

American Psychiatric Association (2013). Diagnostic and Statistical Manual of Mental Disorders, 5th Edition: DSM-5 (5 edition). Washington, D.C: American Psychiatric Publishing.

Assink, M., van der Put, C. E., \& Stams, G. J. J. M. (2016). The Development and Validation of an Actuarial Risk Assessment Tool for the Prediction of First-Time Offending. International Journal of Offender Therapy and Comparative Criminology, 60(7), 847864. doi:10.1177/0306624X14558204 
Baird, C., \& Wagner, D. (2000). The relative validity of actuarial- and consensus-based risk assessment systems. Children and Youth Services Review, 22(11), 839-871. doi:10.1016/S0190-7409(00)00122-5

Baird, C., Wagner, D., Healy, T., \& Johnson, K. (1999). Risk assessment in child protective services: Consensus and actuarial model reliability. Child Welfare; Arlington, 78(6), 723-48.

Barnett, D., Manly, J. T., \& Cicchetti, D. (1993). Defining child maltreatment: The interface between policy and research. In D. Cicchetti \& S. L. Toth (Eds.), Advances in Applied Developmental Psychology: Child Abuse, Child Development and Social Policy. Norwood, NJ: Ablex.

Bates, J. E., Pettit, G. S., Dodge, K. A., \& Ridge, B. (1998). Interaction of temperamental resistance to control and restrictive parenting in the development of externalizing behavior. Developmental Psychology, 34(5), 982.

Bradley, K. A., Bush, K. R., McDonell, M. B., Malone, T., Fihn, S. D., \& the Ambulatory Care Quality Improvement Project. (1998). Screening for problem drinking. Journal of general internal medicine, 13(6), 379-389. doi:10.1046/j.1525-1497.1998.00118.x

Bender, K. (2010). Why do some maltreated youth become juvenile offenders?: A call for further investigation and adaptation of youth services. Children and Youth Services Review, 32(3), 466-473. doi:10.1016/j.childyouth.2009.10.022

Brame, R., Turner, M. G., Paternoster, R., \& Bushway, S. D. (2012). Cumulative Prevalence of Arrest From Ages 8 to 23 in a National Sample. Pediatrics, 129(1), 21-27. doi:10.1542/peds.2010-3710

Bronfenbrenner, U. (1979). The Ecology of Human Development: experiments by nature and design. Harvard University Press.

Brown, D. W., Anda, R. F., Tiemeier, H., Felitti, V. J., Edwards, V. J., Croft, J. B., \& Giles, W. H. (2009). Adverse Childhood Experiences and the Risk of Premature Mortality. American Journal of Preventive Medicine, 37(5), 389-396. doi: 10.1016/j.amepre.2009.06.021

Casillas, K. L., Fauchier, A., Derkash, B. T., \& Garrido, E. F. (2016). Implementation of evidence-based home visiting programs aimed at reducing child maltreatment: A metaanalytic review. Child Abuse \& Neglect, 53, 64-80. doi: 10.1016/j.chiabu.2015.10.009

Centers for Disease Control and Prevention (1990). Youth Risk Behavior Survey. Available at: www.cdc.gov/yrbs. Accessed on [3/2/2018].

Coddington, R. D. (1972). The significance of life events as etiologic factors in the diseases of children-II a study of a normal population. Journal of Psychosomatic Research, 16(3), 205-213. doi:10.1016/0022-3999(72)90045-1 
Coulton, C. J., Korbin, J.E. \& Su, M. (1996). Measuring neighborhood context for young children in an urban area. American Journal of Community Psychology, 24, 5-31.

Christenson, S. L., Reschly, A. L., Appleton, J. J., Berman, S., Spanjers, D., \& Varro, P. (2008). Best practices in fostering student engagement. Best Practices in School Psychology, 5, 1099-1120.

Davies, G., \& Dedel, K. (2006). Violence Risk Screening in Community Corrections. Criminology \& Public Policy, 5(4), 743-769. doi: 10.1111/j.1745-9133.2006.00405.x

Drerup, L.C., Croysdale, A., \& Hoffmann, N.G. (2008). Patterns of behavioral health conditions among adolescents in a juvenile justice system. Professional Psychology: Research and Practice, 39, 122-128.

Derogatis, L. R. (1993). BSI Brief Symptom Inventory. Administration, Scoring, and Procedures Manual (4th ed.). Minneapolis, MN: National Computer Systems.

Drake, B., Jonson-Reid, M., Way, I., \& Chung, S. (2003). Substantiation and recidivism. Child maltreatment, 8(4), 248-260. doi:10.1177/1077559503258930

Dube, S. R., Felitti, V. J., Dong, M., Giles, W. H., \& Anda, R. F. (2003). The impact of adverse childhood experiences on health problems: evidence from four birth cohorts dating back to 1900. Prev Med, 37(3), 268-277. doi:10.1016/S0091-7435(03)00123-3

Dumas, J. E. (2005). Mindfulness-based parent training: Strategies to lessen the grip of automaticity in families with disruptive children. Journal of Clinical Child and Adolescent Psychology, 34(4), 779-791. doi: 10.1207/s15374424jccp3404_20

English, D. J., \& the LONGSCAN Investigators (1997). Modified Maltreatment Classification System (MMCS). Retrieved from http://www.iprc.unc.edu/longscan/.

Evans, S. E., Davies, C., \& DiLillo, D. (2008). Exposure to domestic violence: A meta-analysis of child and adolescent outcomes. Aggression and Violent Behavior, 13(2), 131-140.

Farrington, D. P. (1995). The development of offending and antisocial behaviour from childhood: Key findings from the Cambridge Study in Delinquent Development. Journal of Child Psychology and Psychiatry and Allied Disciplines, 36(6), 929-964.

Felitti, V. J., Anda, R. F., Nordenberg, D., Williamson, D. F., Spitz, A. M., Edwards, V., ... Marks, J. S. (1998). Relationship of childhood abuse and household dysfunction to many of the leading causes of death in adults. The Adverse Childhood Experiences (ACE) Study. American Journal of Preventive Medicine, 14(4), 245-258.

Gonsoulin, S., Darwin, M. J., \& Read, N. W. (2012). Providing Individually Tailored Academic and Behavioral Support Services for Youth in the Juvenile Justice and Child Welfare Systems. Washington, DC: National Evaluation and Technical Assistance Center for Children and Youth Who Are Neglected, Delinquent, or At-Risk (NDTAC). 
Green, K. M., Musci, R. J., Johnson, R. M., Matson, P. A., Reboussin, B. A., \& Ialongo, N. S. (2016). Outcomes associated with adolescent marijuana and alcohol use among urban young adults: A prospective study. Addictive Behaviors, 53, 155-160. doi: 10.1016/j.addbeh.2015.10.014

Halemba, G. J., Siegel, g. C., Lord, R. D., \& Zawacki, S. (2004). Arizona dual jurisdiction study final report. National Center for Juvenile Justice. Retrieved from http://www.cwla.org/programs/juvenilejustice/AZDualJurStudy.pdf

Hamilton, Z., Van Wormer, J., Barnoski, R. (2015). PACT Validation and Weighting Results Technical Report. Spokane, W.A.; Washington Association of Juvenile Court Administrators.

Harcourt, B. E. (2008). Against Prediction: Profiling, Policing, and Punishing in an Actuarial Age. Chicago, IL: University of Chicago Press.

Harske, A.J., Baillargeon, J., Baillargeion, W., Henry, J., Olvera, R.L., Torrealday, O., Penn, J.V., \& Parikh, R. (2012). Prevalence of psychiatric disorders in the Texas juvenile correctional system. Journal of Correctional Health Care, 18, 143-157. doi: $10.1177 / 1078345811436000$

Henggeler, S. W., \& Schaeffer, C. (2010). Treating serious antisocial behavior using multisystemic therapy. In J. R. Weisz \& A. E. Kazdin (Eds.), Evidence-based psychotherapies for children and adolescents (2nd ed., pp. 259-276). New York, NY US: Guilford Press.

Henry, K. L., Knight, K. E., \& Thornberry, T. P. (2012). School Disengagement as a Predictor of Dropout, Delinquency, and Problem Substance Use during Adolescence and Early Adulthood. Journal of Youth and Adolescence, 41(2), 156-166. doi:10.1007/s10964-0119665-3

Herz, D. C., Ryan, J. P., \& Bilchik, S. (2010). Challenges facing crossover youth: An examination of juvenile-justice decision making and recidivism. Family Court Review, 48(2), 305-321.

Huizinga, D., \& Elliott, D. S. (1986). Reassessing the reliability and validity of self-report delinquency measures. Journal of Quantitative Criminology, 2(4), 293-327. doi:10.1007/BF01064258

Huizinga, D., Esbensen, F., and Weiher, A.W. (1991). Are there multiple paths to delinquency? Journal of Criminal Law and Criminology: 82(1).

Hussey, J. M., Marshall, J. M., English, D. J., Knight, E. D., Lau, A. S., Dubowitz, H., \& Kotch, J. B. (2005). Defining maltreatment according to substantiation: Distinction without a difference? Child Abuse \& Neglect, 29(5), 479-492. doi:10.1016/j.chiabu.2003.12.005

IBM Corp. (2017). IBM SPSS Statistics for Windows, Version 25.0. Armonk, NY: IBM Corp. 
Javdani, S., Sadeh, N., \& Verona, E. (2011). Expanding our lens: Female pathways to antisocial behavior in adolescence and adulthood. Clinical psychology review, 31(8), 1324-1348. doi:10.1016/j.cpr.2011.09.002

Johnston, L. (2010). Monitoring the Future: National Results on Adolescent Drug Use: Overview of Key Findings. DIANE Publishing.

Kass, G. V. (1980). An Exploratory Technique for Investigating Large Quantities of Categorical Data. Journal of the Royal Statistical Society. Series C (Applied Statistics), 29(2), 119127. doi:10.2307/2986296

Knight, E. D., Smith, J. B., Martin, L. M., Lewis, T., \& the LONGSCAN Investigators (2008). Measures for Assessment of Functioning and Outcomes in Longitudinal Research on Child Abuse Volume 3: Early Adolescence (Ages 12-14). Accessible at the LONGSCAN web site (http://www.iprc.unc.edu/longscan/).

Kohl, P. L., Jonson-Reid, M., \& Drake, B. (2009). Time to leave substantiation behind: Findings from a national probability study. Child maltreatment, 14(1), 17-26. doi:10.1177/1077559508326030

Lee, S.-Y., \& Villagrana, M. (2015). Differences in risk and protective factors between crossover and non-crossover youth in juvenile justice. Children and Youth Services Review, 58, 18 27. doi:10.1016/j.childyouth.2015.09.001

Leventhal, T., \& Brooks-Gunn, J. (2000). The neighborhoods they live in: The effects of neighborhood residence on child and adolescent outcomes. Psychological Bulletin, 126(2), 309-337. doi.org/10.1037//0033-2909.126.2.309

Little, R.J.A. (1988). A test of missing completely at random for multivariate data with missing values. Journal of the American Statistical Association, 83(404), 1198-1202. doi:10.1080/01621459.1988.10478722

Logan-Greene, P., Tennyson, R. L., Nurius, P. S., \& Borja, S. (2017). Adverse Childhood Experiences, Coping Resources, and Mental Health Problems among Court-Involved Youth. Child \& Youth Care Forum, 46(6), 923-946. doi: 10.1007/s10566-017-9413-2

Moffitt, T. E., \& Caspi, A. (2001). Childhood predictors differentiate life-course persistent and adolescence-limited antisocial pathways among males and females. Development and Psychopathology, 13(2), 355-375.

Moon, J. (2012). Risk and Needs Assessment Instruments. In Encyclopedia of Community Corrections (pp. 398-399). Thousand Oaks: SAGE Publications, Inc. doi:10.4135/9781452218519

Murray, J., \& Farrington, D. P. (2010). Risk factors for conduct disorder and delinquency: key findings from longitudinal studies. Canadian Journal of Psychiatry. Revue Canadienne De Psychiatrie, 55(10), 633-642. doi:10.1177/070674371005501003 
Office of Juvenile Justice and Delinquency Prevention OJJDP Statistical Briefing Book. Online. Available: http://www.ojjdp.gov/ojstatbb/crime/qa05101.asp?qaDate=2015. Released on March 27, 2017.

Patterson, G. R., \& Yoerger, K. (1993). Developmental models for delinquent behavior. In Mental disorder and crime (pp. 140-172). Thousand Oaks, CA, US: Sage Publications, Inc.

Petteruti, A., Schindler, M., \& Ziedenberg, J. (2014). Sticker Shock: Calculating the Full Price Tag for Youth Incarceration. Washington, D.C.: Justice Policy Institute.

Radloff, L. S. (1977). The CES-D Scale: A self-report depression scale for research in the general population. Applied Psychological Measurement, 1, 385-401. doi:10.1177/014662167700100306

Resnick, M. D., Bearman, P. S., Blum, R. W., Bauman, K. E., Harris, K. M., Jones, J., ... Udry, J. R. (1997). Protecting Adolescents From Harm: Findings From the National Longitudinal Study on Adolescent Health. JAMA, 278(10), 823-832. doi: 10.1001/jama.1997.03550100049038

Runyan, D. K., Curtis, P. A., Hunter, W. M., Black, M. M., Kotch, J. B., Bangdiwala, S., . . . Landsverk, J. (1998). LONGSCAN: A consortium for longitudinal studies of maltreatment and the life course of children. Aggression and Violent Behavior, 3(3), 275285. doi:10.1016/S1359-1789(96)00027-4

Sampson, R. J., Raudenbush, S. W., \& Earls, F. (1997). Neighborhoods and violent crime: A multilevel study of collective efficacy. Science, 27(7), 918-924.

Schwalbe, C. S., Fraser, M. W., Day, S. H., \& Cooley, V. (2006). Classifying Juvenile Offenders According to Risk of Recidivism: Predictive Validity, Race/Ethnicity, and Gender. Criminal Justice and Behavior, 33(3), 305-324. doi :10.1177/0093854806286451

Schwalbe, C. S. (2008). A Meta-Analysis of Juvenile Justice Risk Assessment Instruments: Predictive Validity by Gender. Criminal Justice and Behavior, 35(11), 1367-1381. doi:10.1177/0093854808324377Shaffer D., Fisher, P., Lucas, C.P., Dulcan, M.K., \& Schwab-Stone, M.E. (2000). NIMH Diagnostic Interview Schedule for Children Version IV (NIMH DISC-IV): Description, differences from previous versions, and reliability of some common diagnoses. Journal of the American Academy of Child and Adolescent Psychiatry, 39(1),28-38.

Sinclair, M. F., Christenson, S. L., Evelo, D. L., \& Hurley, C. M. (1998). Dropout prevention for youth with disabilities: Efficacy of a sustained school engagement procedure. Exceptional Children, 65(1), 7.

Skeem, J. L., \& Monahan, J. (2011). Current Directions in Violence Risk Assessment. Current Directions in Psychological Science, 20, 1, 38-42. doi: 10.1177/0963721410397271 
Smith, D. K., \& Chamberlain, P. (2010). Multidimensional treatment foster care for adolescents: Processes and outcomes. In J. R. Weisz \& A. E. Kazdin (Eds.), Evidencebased psychotherapies for children and adolescents (2nd ed., pp. 243-258). New York, NY US: Guilford Press.

Smith, C., Lizotte, A. J., Thornberry, T. P., \& Krohn, M. D. (1995). Resilient youth: identifying factors that prevent high-risk youth from engaging in delinquency and drug use. Current Perspectives on Aging and the Life Course, 4, 217-247.

Smith, C. A., Park, A., Ireland, T. O., Elwyn, L., \& Thornberry, T. P. (2012). Long-Term Outcomes of Young Adults Exposed to Maltreatment: The Role of Educational Experiences in Promoting Resilience to Crime and Violence in Early Adulthood. Journal of Interpersonal Violence, 0886260512448845. doi:10.1177/0886260512448845

Smith, C., \& Thornberry, T. P. (1995). The Relationship Between Childhood Maltreatment and Adolescent Involvement in Delinquency. Criminology, 33(4), 451-481. doi:10.1111/j.1745-9125.1995.tb01186.x

Straus, M. A., Hamby, S. L., Finkelhor, D., Moore, D. W., \& Runyan, D. (1998). Identification of child maltreatment with the Parent-Child Conflict Tactics Scales: Development and psychometric data for a national sample of American parents. Child Abuse \& Neglect, 22(4), 249-270. doi:10.1016/S0145-2134(97)00174-9

Thornberry, T. P., Henry, K. L., Ireland, T. O., \& Smith, C. A. (2010). The Causal Impact of Childhood-Limited Maltreatment and Adolescent Maltreatment on Early Adult Adjustment. Journal of Adolescent Health, 46(4), 359-365. doi:10.1016/j.jadohealth.2009.09.011

Thornberry, T. P., Huizinga, D., \& Loeber, R. (2004). The causes and correlates studies: Findings and policy implications. Juvenile Justice, 9, 3.

Villodas, M. T., Cromer, K. D., Moses, J. O., Litrownik, A. J., Newton, R. R., \& Davis, I. P. (2016). Unstable child welfare permanent placements and early adolescent physical and mental health: The roles of adverse childhood experiences and post-traumatic stress. Child Abuse \& Neglect, 62, 76-88. doi: 10.1016/j.chiabu.2016.10.014

Walker, S. C., Bishop, A. S., Nurius, P. S., \& Logan-Greene, P. (2016). The Heterogeneity of Treatment Needs for Justice-Involved Girls: A Typology Using Latent Class Analysis. Criminal Justice and Behavior, 43(3), 323-342. doi: 10.1177/0093854815615162

Widom, C. S. (1989). Child abuse, neglect, and adult behavior: Research design and findings on criminality, violence, and child abuse. American Journal of Orthopsychiatry, 59(3), 355367. doi:10.1111/j.1939-0025.1989.tb016

Widom, C. S. (2001). Child Abuse and Neglect. In S.O. White (Ed.), Handbook of Youth and Justice (pp. 31-47). New York, NY: Kluwer Academic/Plenum Publishers.

Wiig J, Spatz Widom C., \& Tuell J. (2003). Understanding child maltreatment \& juvenile delinquency. Washington DC: CWLA Press. 
Yang, M., P, C., \& Coid, J. (2010). The efficacy of violence prediction: A meta-analytic comparison of nine risk assessment tools. Psychological Bulletin, 136(5), 740-767. doi:10.1037/a0020473 
Table 1. Descriptive Statistics

\begin{tabular}{|c|c|}
\hline & $\begin{array}{c}\text { Full Sample } \\
(n=592)\end{array}$ \\
\hline Past-year arrest at age $16[\mathrm{n}(\%)]$ & $99(16.7 \%)$ \\
\hline \multicolumn{2}{|l|}{ Neighborhood/Community Factors } \\
\hline Neighborhood chaos [M (SD)] & $1.91(.54)$ \\
\hline Collective efficacy [M (SD)] & $2.84(.56)$ \\
\hline Neighborhood stability [M (SD)] & $1.97(.63)$ \\
\hline \multicolumn{2}{|l|}{ School/Peer Factors } \\
\hline \multicolumn{2}{|l|}{ School engagement behaviors } \\
\hline Endorsed the highest level of school importance[n(\%)] & $467(79 \%)$ \\
\hline Endorsed previous suspension(s) [n(\%)] & $320(54 \%)$ \\
\hline Endorsed HW always/almost always complete [n(\%)] & $469(79 \%)$ \\
\hline Endorsed thoughts of dropping out $[\mathrm{n}(\%)]$ & $47(8 \%)$ \\
\hline \multicolumn{2}{|l|}{ Peer behaviors } \\
\hline Deviant peer association & $.20(.25)$ \\
\hline Prosocial peer association & $1.29(.40)$ \\
\hline \multicolumn{2}{|l|}{ Family Factors } \\
\hline Parental monitoring $[M(\mathrm{SD})]$ & $1.63(.37)$ \\
\hline Quality of parent-youth relationship & $4.35(.49)$ \\
\hline Living below the Federal Poverty Line (Y/N) & $344(58 \%)$ \\
\hline Caregiver mental health problem, birth to age $14[\mathrm{n}(\%)]$ & $349(59 \%)$ \\
\hline Family member substance use, birth to age $14[\mathrm{n}(\%)]$ & $89(15 \%)$ \\
\hline Family member incarcerated, birth to age $14[\mathrm{n}(\%)]$ & $270(46 \%)$ \\
\hline Witnessed family violence, birth to age $14[\mathrm{n}(\%)]$ & $195(33 \%)$ \\
\hline Neglect, birth to age $14[\mathrm{n}(\%)]$ & $195(33 \%)$ \\
\hline Physical abuse, birth to age $14[\mathrm{n}(\%)]$ & $296(50 \%)$ \\
\hline Sexual abuse, birth to age $14[\mathrm{n}(\%)]$ & $95(16 \%)$ \\
\hline Emotional abuse, birth to age $14[\mathrm{n}(\%)]$ & $195(33 \%)$ \\
\hline \multicolumn{2}{|l|}{ Individual Factors } \\
\hline \multicolumn{2}{|l|}{ Gender } \\
\hline Female $[\mathrm{n}(\%)]$ & $294(50 \%)$ \\
\hline \multicolumn{2}{|l|}{ Race/ethnicity } \\
\hline White $[\mathrm{n}(\%)]$ & $153(26 \%)$ \\
\hline Black $[\mathrm{n}(\%)]$ & $327(55 \%)$ \\
\hline Hispanic/Latino $[\mathrm{n}(\%)]$ & $36(6 \%)$ \\
\hline Mixed/Other [n(\%)] & $76(13 \%)$ \\
\hline \multicolumn{2}{|l|}{ Adolescent mental health symptom counts } \\
\hline Attention Deficit/Hyperactivity Disorder $[M(\mathrm{SD})]$ & $5.18(4.85)$ \\
\hline Oppositional Defiant Disorder [M(SD)] & $2.97(2.83)$ \\
\hline Conduct Disorder $[M(\mathrm{SD})]$ & $3.59(3.69) 88$ \\
\hline Major Depressive Disorder [M(SD)] & $(3.88)$ \\
\hline Marijuana Abuse \& Dependence $[M(\mathrm{SD})]$ & $3.88(3.88)$ \\
\hline Substance Abuse \& Dependence $[M(\mathrm{SD})]$ & $.08(.60)$ \\
\hline Nicotine Dependence [M (SD)] & $.04(58)$ \\
\hline Alcohol Abuse \& Dependence $[M(\mathrm{SD})]$ & $.09(.65)$ \\
\hline Post-Traumatic Stress Disorder [M (SD)] & $.07(.64)$ \\
\hline \multirow[t]{2}{*}{ Mania/Hypomania $[M(\mathrm{SD})]$} & $.82(2.64)$ \\
\hline & $3.74(2.70)$ \\
\hline
\end{tabular}

Note: ACEs = Adverse Childhood Experiences; HW=Homework; $\mathrm{M}=$ mean; $\mathrm{SD}=$ standard deviation 
Figure 1. Classification Tree Predicting Past-year Arrests at Age 16

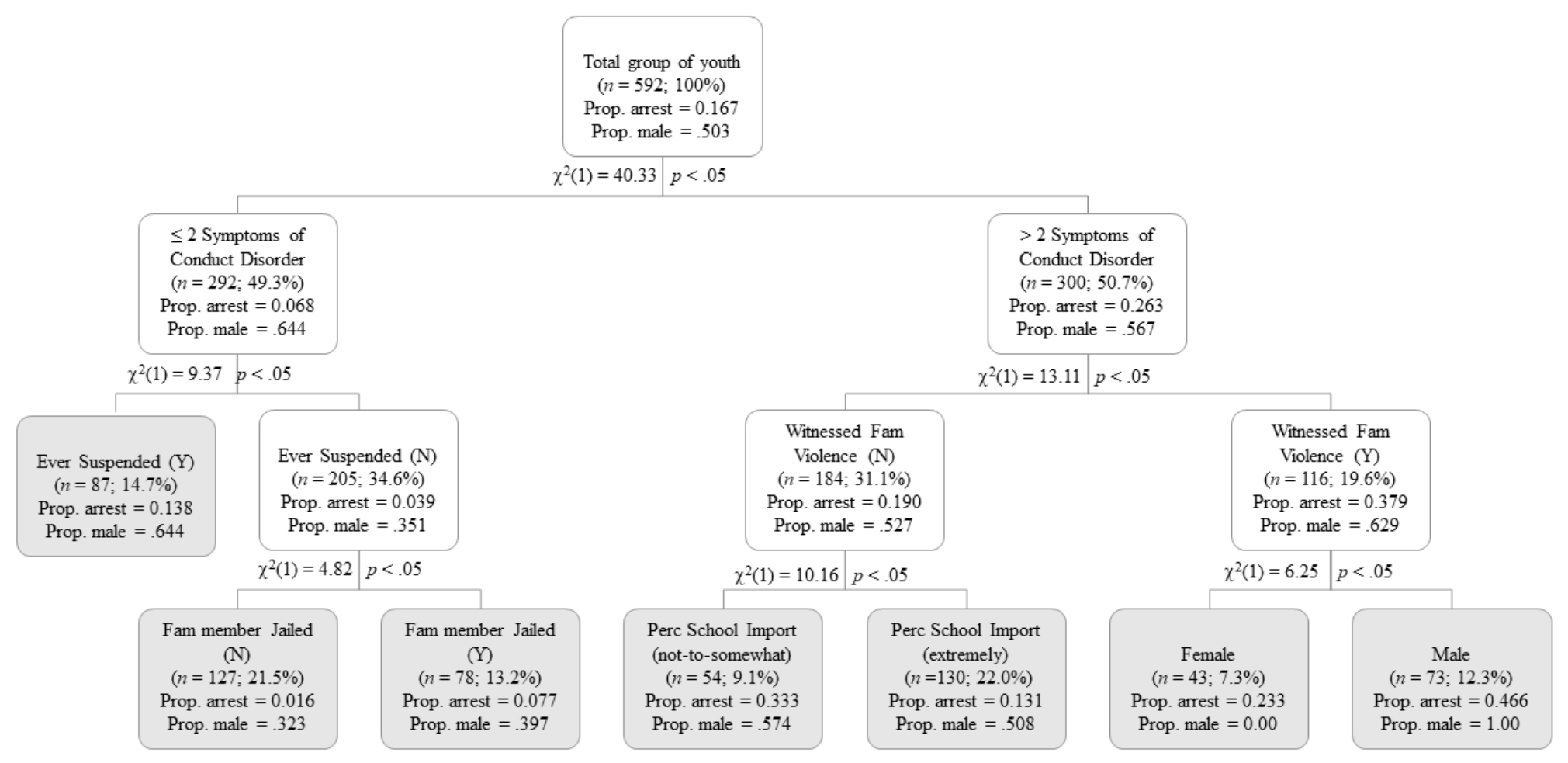

Note: The terminal nodes (shaded in grey) represent the 7 "risk groups" in which youth have similar scores on predictor variables at age 14, thus the same risk for juvenile arrest at age 16. $n(\%)=$ the number and percentage of juveniles that are classified in each tree node; Prop. arrest $=$ Proportion arrested in the past year at age 16; Prop. male $=$ Proportion males; Fam. Member Jailed= Binary Indicator of Ever had a family member jailed from birth to age 14; Perc. School Import; Perceived School Importance; Witnessed Fam Violence=Binary Indicator of Witnessed Family Violence from birth to age 14 


\section{CHAPTER 3.}

\section{MIXED-METHOD EXAMINATION OF LATINX TEACHERS' PERCEPTIONS OF DAILY BEHAVIORAL REPORT CARD INTERVENTIONS TO SUPPORT STUDENTS WITH ADHD}

This manuscript will be submitted to Administration and Policy in Mental Health, and thus adheres to its use of APA 6th Edition formatting guidelines.

Morrow, A.S., Villodas, M.T., Frazier, S., Raiker, J.S., Liriano, M.M, English, A., Lozano, C., Campez, M., Lesperance, S., \& Little, K. (in preparation). Mixed-method Examination of Latinx Teachers' Perceptions of Daily Behavioral Report Card Interventions to Support Students with ADHD. 


\begin{abstract}
Daily behavioral report cards are an efficacious intervention for children with ADHD, yet there is little information on Latinx teachers' perceptions about ADHD and preferences related to behavioral treatment. The purpose of our convergent, mixed-method study found that Latinx teachers' ( $\mathrm{n}=23$ ) Daily Report Card (DRC) completion rates (80\%) were comparable to previous studies with predominantly non-Latinx white teachers and students. Qualitative findings expanded quantitative trends; thematic analyses revealed two overarching themes, that (1) teachers' attitudes toward behavioral interventions matter a great deal, and that (2) teachers' perceived behavioral control over DRC implementation depends a lot on the environment.
\end{abstract}

\title{
Literature Review
}

"For me, I feel you have to establish [authority] from, the beginning, from the first day at school... 'You can't smile 'til Christmas type' thing. You need to almost make them see-make it seem you are a no-nonsense person. This is how it is. This is how it goes. You cannot stray from here, until you come back from Christmas and they know this is how it goes, this is the way it's done. ... [The students] eventually see you as a human, like oh, she does have teeth." -Teacher 19, completed Daily Report Card three days per week

Attention-deficit hyperactivity disorder (ADHD) is a neurodevelopmental disorder that affects approximately $8 \%$ of schoolchildren worldwide (Danielson et al., 2018) and is associated with estimated educational, health care, and juvenile justice costs of $\$ 14,576$ per individual, annually (Pelham, Foster, \& Robb, 2007). Symptoms include hyperactivity, impulsivity and inattention, which are associated with serious impairments in classroom behavior, peer functioning and academic achievement (Harpin, 2005; Loe \& Feldman, 2007). Symptoms may be particularly impairing for uninsured children and children of color, including Latinx children, who have a disproportionately high rate of unmet need for mental health care (Merikangas et al,, 2011). Researchers have found that Latinx children who meet criteria for ADHD are less likely to 
receive a diagnosis than non-Latinx, white children, and less likely to receive treatment than nonLatinx white children as well (Eiraldi \& Diaz, 2010). Yet there is a dearth of information regarding treatment for ADHD among Latinx students and factors that may contribute to the disparity in care. School-based interventions present a promising opportunity to engage Latinx students in mental health services, by reducing barriers to care. The primary aim of our convergent, mixed-method study is to examine Latinx teachers' perceptions of the feasibility and acceptability of a behavioral consultation intervention, with particular focus on the Daily Report Card (DRC), for Latinx students with ADHD.

\section{Behavioral Treatment Recommended as First-line Treatment for ADHD}

A growing cadre of researchers have highlighted the gap between scientific knowledge and widespread adoption of best practices in real world settings across a number of health care specialties (Balas \& Boren, 2000; Khoury et al., 2007; Westfall, 2007). Research progresses through several phases, a cycle that ultimately culminates in the implementation of new findings to improve outcomes at the level of a population health impact (e.g., see a conceptual model in Figure 1; Khoury et al., 2007; Westfall \& Mensah, 2018). The field of ADHD treatment is certainly plagued by the issue of slow translation of research to practice, with less than a third of students with ADHD receiving the first-line intervention today (behavioral treatment; DuPaul, Chronis-Tuscano, Danielson, \& Visser, 2018). We clarify that behavior therapy is recommended as the first-line of treatment for children under the age of six, and for children six years and older, either medication and/or behavior therapy is recommended, but "preferably both" should be prescribed (American Academy of Pediatrics, Subcommittee on ADHD, 2011). Taken together, the American Academy of Pediatrics (2011) recommends that children with ADHD of all ages should receive behavior therapy. Neither the discovery of the core symptoms of ADHD nor the foundational principles of behavioral treatment are new, as both were established over 100 years ago (e.g., Still, 1902; Watson, 1913). That is, an early example of research on ADHD is Sir 
George Still's (1902) description of 20 clinical cases of what he called a "defect of moral control." Still (1902) proposed the concept of a syndrome marked by an impairing pattern of behavior characterized by impulsivity/immediate self-gratification. Contemporaneous research on behavior modification elucidated a theory on how to predict and control behavior (Watson, 1913). Watson (1913) put forth the notion that the systematic development of paired associations and the use of reinforcement techniques are powerful tools to change behavior.

Around 50 years later, Constance Hanf (1968) applied Watson's (1913) core tenets of behaviorism to modifying disruptive/impulsive behavior in children. Hanf's program of research influenced the development of several gold-standard behavioral interventions for ADHD (Kaehler, Jacobs, \& Jones, 2016). Next, initial results of a landmark randomized clinical trial, the Multimodal Treatment Study of Children with ADHD (MTA), revealed that medication treatment was superior to gold-standard behavioral treatment after a 14-month period (MTA Cooperative Group, 1999). Re-analyses disconfirmed initial findings, indicating no significant differences between medication, behavioral treatment, or their combination after a 6-to-8 year period (Molina et al., 2009). Finally, a sequential, multiple assignment, randomized trial found that beginning with behavioral treatment for ADHD (vs. medication) led to lower rates of observed classroom rule violations during the school year and cost less money for a school year of treatment (Page et al., 2016; Pelham et al., 2016). In sum, ADHD is a well characterized neurodevelopmental disorder (APA, 2013) with a rich history of clinical research culminating in the establishment of behavioral interventions as a leading treatment (Kaehler, Jacobs, \& Jones, 2016). The long, winding road to translate Still (1902) and Watson's (1913) insights into actionable steps for practicing clinicians (with demonstrated efficacy and effectiveness) illustrates the need for research to accelerate the pace. A brief review of translational research in the field of ADHD treatment is included in Table 1. 


\section{Disparities Reflect Both Limitations to the Science and Challenges Moving Science to Routine Practice}

Behavioral Treatment for Students with ADHD is Efficacious, But is it Effective?

Behavioral teacher consultation is an efficacious treatment for students with ADHD, with the first controlled trial demonstrating efficacy of behavior modification to treat ADHD in the classroom established over forty years ago (O’Leary, Pelham, Rosenbaum, \& Price, 1976). The previous literature, including meta-analytic findings from multiple randomized controlled trials, has documented strong support for school-based behavioral treatment for ADHD in predominantly non-Latinx white samples (Evans, Owens, \& Bunford, 2014; Fabiano et al., 2009; Pyle \& Fabiano, 2017; Sheridan, Bovaird, et al., 2012; Sheridan, Holmes, Coutts, \& Smith, 2012). Following the convention in the aforementioned literature, we will adhere to the term "schoolbased" mental health services to describe mental health interventions delivered at schools within our paper. A leading treatment, behavioral teacher consultation, aims to align teachers' behavior management strategies with best practices, building knowledge and skills in evidence-based behavioral classroom management for students with ADHD (e.g., classroom rules, positive reinforcement, and contingency management; Coles, Owens, Serrano, Slavec, \& Evans, 2015). Improvements in these target skills lead to changes in teachers' behavior, as well as subsequent improvements in child performance (Coles et al., 2015; Owens et al., 2017). Importantly, the goal of changing teachers' behavior aligns with adult behavior change theory (e.g., Theory of Planned Behavior; Azjen, 1991), as teachers' implementation of behavioral techniques relies on underlying changes in their knowledge, attitudes, and beliefs (Coles et al., 2015; Owens et al., 2017). Consultation meetings with teachers typically include the development of an individualized behavior chart, commonly referred to as the Daily Report Card (DRC; Volpe \& Fabiano, 2013). The DRC typically includes a set of operationalized behavioral targets (e.g., "leaves seat 4 or fewer times"), which are typically titrated downward over time as the child's 
behavior improves (Volpe \& Fabiano, 2013). Teachers provide in vivo feedback to their student on progress with target behaviors, and typically the student receives daily contingent positive reinforcement for his or her success in meeting goals. Of note, interventions leveraging behavioral principles and involving a consultant, a teacher, and target student(s) are sometimes called collaborative consultation, conjoint behavioral consultation, or in certain cases, coaching (Cappella et al., 2012; Pfiffner, Barkley, \& DuPaul, 2006; Sheridan \& Kratochwill, 2007)—we will refer to the intervention as behavioral teacher consultation within our paper.

Challenges Moving Science to Routine Practice. In addition to the paucity of research on behavioral consultation among Latinx teachers and students, it is important to note that there has been mixed evidence in the literature beginning decades ago regarding teachers' acceptability of behavioral strategies to manage ADHD in the classroom (Rapport, Murphy, \& Bailey, 1982; Rosen, O’Leary, \& Conway, 1985; Atkins, Pelham, \& White, 1989). Reasons behind the slow pace of translation of ADHD treatment research to practice fall within interacting domains ranging between the characteristics of the intervention itself, to the inner setting, outer setting, characteristics of the individuals involved in implementation, and process factors (i.e., constructs of the Consolidated Framework for Intervention Research; CFIR; Damschroder et al., 2009). For example, one teacher refused to participate in certain components of behavioral treatment because of her perception of its intrusiveness in classroom activities (Atkins et al., 1989). Information on characteristics such as ethnicity/race of teachers participating in these case studies was not available. In a nationally recruited sample of teachers' acceptability of behavioral treatment (i.e., the Daily Report Card; DRC), only $12 \%$ of teachers responded and there was no information available about their ethnic/racial background (Chafouleas, Riley-Tillman, \& Sassu, 2006). Further, concerns regarding teachers' apparent lack of enthusiasm for behavioral strategies have been conceptualized as "resistance" (Witt, 1986). Witt (1986) noted that teachers may not want to use an intervention only because it is effective; other factors important to teachers' decision- 
making processes include time and resources required, theoretical orientation of the intervention, and ecological intrusiveness. In a survey examining resistance to behavioral interventions among teachers, few variables related to improved engagement. However, teachers reported higher intentions to attend consultation meetings when working with consultants who spent more hours located on the premises of the school (vs. less hours), a feature of the inner setting (Gonzalez, Nelson, Gutkin, \& Shwery, 2004).

\section{A Dearth of Information on Behavioral Treatment among Latinx Teachers and Students}

There is little information about the implementation of school-based treatments for ADHD among Latinx students, teachers, and communities. Notably, one-in-five teachers at highpoverty schools identifies as Latinx (National Center for Education Statistics; NCES, 2016); currently, there is a need for inclusive research to adequately represent diverse stakeholders' views. Although previous trials have not found differences in the overall outcomes of ethnic minority and non-ethnic minority children whose teachers received behavioral teacher consultation, differences between specific ethnic minority groups have not been investigated because of a lack of diversity in the samples (Sheridan, Eagle, \& Doll, 2006). Additionally, recruitment for school-based mental health research trials has been problematic (Sheridan, Holmes, Smith, \& Moen, 2016), with ethnic minorities displaying high rates of enrollment refusal (Fung, Guo, Jin, Bear, \& Lau, 2016). In a sample of predominantly ethnic minority teachers working in schools that served predominantly Latinx students, teachers were reluctant to participate in a study of behavioral consultation, with less than a third of teachers expressing interest (Cappella et al., 2012). Those teachers who did not consent cited reasons such as a lack of perceived need for support and insufficient time. In the only large, randomized trial of behavioral teacher consultation with a sample including Latinx teachers and students, teachers' classroom organization and behavior management practices, as well as children's behavioral regulation failed to significantly improve in quantitative analyses (Cappella et al., 2012). Analysis of 
qualitative data revealed that mental health program staff were concerned about the defensiveness and skepticism of teachers, and perceived that teachers were not receptive to the support they were offering (Cappella, Jackson, Bilal, Hamre, \& Soulé, 2011). Program and school staff stated concerns with the intervention's relevance for ethnic minorities (e.g., teachers requested that video materials include more minorities) and reported that they felt that the intervention model was outdated (Cappella et al., 2011). Several previous efforts to implement behavioral teacher consultation with ethnic minority populations have focused on predominantly African-American communities (Becker, Darney, Domitrovich, Keperling, \& Ialongo, 2013; Hershfeldt, Pell, Sechrest, Pas, \& Bradshaw, 2012; Shernoff, Lakind, Frazier, \& Jakobsons, 2014). Notably, intervention-driven improvements in teachers' implementation of classroom management strategies resulted from a seven-year iteratively-adapted trial which incorporated feedback from community-based stakeholders, including teachers (Becker et al., 2013). Therefore, the current evidence demonstrates that adaptation to evidence-based interventions may be necessary to reach ethnic/racial minority communities.

\section{What We Know and What We Don't Know}

There is a gap in the literature surrounding Latinx teachers' perceptions and beliefs about $\mathrm{ADHD}$ and preferences related to behavioral treatment. We will briefly review the emerging literature on this topic among Latinx parents of children with ADHD, given that there may be some similarities between parents and teachers of youth with ADHD. Research has demonstrated that Latinx parents differ from their Caucasian counterparts in their perceptions and beliefs about ADHD and preferences related to behavioral treatment (Eiraldi \& Diaz, 2010; Gerdes, Lawton, Haack, \& Schneider, 2014; Paidipati, Brawner, Eiraldi, \& Deatrick, 2017). For example, researchers have found that acculturation and cultural values are associated with Latinx parents' beliefs about the cause of ADHD, as low acculturated families were more likely to endorse sociological or spiritual causes than a biological etiology (Lawton, Gerdes, Haack, \& Schneider, 
2014). Specifically, Latinx parents hold beliefs about the etiology of ADHD that may lead to blaming themselves, citing perceived causes such as low parental motivation and divorce (Gerdes et al., 2014). Further, Latinx parents have also reported feeling shame because members of their support system thought the child's behavior was the parents' fault (Perry, Hatton, \& Kendall, 2005). These varying perceptions of ADHD shape how Latinx parents' seek help for and address their children's concerns (Eiraldi \& Diaz, 2010). Previous research indicated that certain core behavioral strategies (e.g., selective ignoring in public settings) were perceived as unacceptable among Latinx parents (Calzada, Basil, \& Fernandez, 2013; Paidipati et al., 2017). Additionally, researchers have explored preferences for treatment among Latinx parents, who reported that they were not interested in "white" parenting classes. They reported that, because of their previous experiences, they found these classes to be pejorative (Cardona et al., 2009). Latinx parents also strongly preferred to address cultural issues in treatment, such as living between two cultures, which were not addressed in previous treatment protocols (Parra Cardona et al., 2012).

Notably, research indicating that cultural differences affect ADHD treatment among Latinx families has been conducted exclusively with parents, and little information is known about Latinx teachers' views of ADHD or behavioral treatment. Further, Latinx individuals are a heterogeneous population, representing a wide variety of national origins, racial identities, and social classes (González Burchard et al., 2005). As Latinx parents’ beliefs about ADHD are related to ranging acculturation and cultural values (Lawton et al., 2014), dimensions of Latinx cultural values and/or experiences of acculturation could impact Latinx teachers' perceptions of behavioral interventions as well. Given that so little is known on this topic, mixed-method designs may be a strategic approach to close the science-to-practice gap (Palinkas et al., 2011). Of note, employing mixed-method research designs as an initial step in the exploration of the feasibility and acceptability of established interventions among diverse cultural groups has been successful across a wide array of interventions and cultures (Barrera \& Castro, 2006; Domenech 
Rodríguez \& Bernal, 2012). In addition to mixed-method paradigms, we also argue that the systematically selected levels of the CFIR are helpful to guide the translation of research findings on ADHD treatment into practice (Damschroder et al., 2009).

\section{The Present Study}

Given the identified gaps in the literature on ADHD treatment, the purpose of the present study was to offer an evidence-based, behavioral consultation intervention to Latinx teachers and students and use a convergent, mixed-method design to examine (1) feasibility, (2) acceptability, and (3) perceptual, practical/logistical, individual, and cultural factors that may influence them. We employed both quantitative methods as well as qualitative methods to measure each aim.

\section{Method}

\section{Participants}

Setting. The current study was conducted in a Title I, bilingual public elementary school in a large southeastern metropolitan area, with $86 \%$ of the students qualifying for free- or reduced-priced lunch. The student body is $98 \%$ Latinx, approximately half of the students are English language learners, and among them are many recent or first-generation immigrants from Central American and Caribbean nations.

Partnership history. Our clinical research team initiated collaboration with the partnering school approximately two and a half years before the start of the current study. Since that time, our team has offered school-based mental health services at no or low cost for students with ADHD and their families. Services included behavioral parent training and behavioral teacher consultation.

Participants. Twenty-three teachers (100\% Hispanic, 96\% female) in grades one to five participated. Our sample was highly educated (61\% with Master's degrees), and highly experienced (years taught; $M=21.48, S D=8.56$ ). Full descriptive statistics of teachers' demographics are presented in Table 2. Teachers were invited to participate in behavioral 
consultation if they had one or more students in their class referred for services, and $100 \%$ of teachers elected to participate. Out of 34 total teachers at the school, 23 were invited to participate (i.e., 11 teachers did not have students in their class who were referred for services, which took place during the spring of the previous school year). Of the 23 teachers who participated in consultation meetings, $100 \%$ also participated in quantitative and qualitative data collection. Students were referred to our team through a collaborative relationship with the school counselor, as well as based on parent and teacher report of ADHD symptoms on the Disruptive Behavior Disorders Questionnaire: (Pelham, Gnagy, Greenslade, \& Milich, 1992). Clinical interviews were used to further investigate ADHD symptoms, as well as to evaluate functional impairment in multiple domains. All students' files were reviewed by the clinical supervisor to establish a diagnosis of ADHD. Of the 48 1st through 5th grade students referred for behavioral services, $71 \%$ were boys, the mean age was eight years $(\mathrm{SD}=1.4)$, and all but two students were Latinx. Half of the families reported speaking Spanish at home, and $45 \%$ reported total family incomes below $\$ 30,000$. Characteristics of students enrolled are presented in Table 3.

\section{Procedures}

All study procedures were approved by the university Institutional Review Board (\#103799) and partnering school district Research Review Committee. All procedures adhered to the APA ethical guidelines (American Psychological Association, 2010).

Teacher consultation. The evidence-based behavioral consultation intervention (Volpe \& Fabiano, 2013) offered to teachers was previously evaluated in several randomized clinical trials, employing an individualized, daily behavior chart procedure called the Daily Report Card (Coles, Owens, Serrano, Slavec, \& Evans, 2015; Fabiano et al., 2010; MTA Cooperative Group, 1999; Watabe, Stewart, Owens, Andrews, \& Griffeth, 2013). Between four and eight meetings are recommended, employing functional behavior analytic principles to (1) identify problem behaviors, (2) develop/implement behavioral target goals, and (3) iteratively evaluate and adapt a 
student's individualized goals. For example, individualized, operationalized target behaviors included goals such as remaining in seat/area. Students' behavioral targets were titrated via a changing criterion design (Hartman and Hall, 1976), and students' daily performance was rewarded via a menu of reinforcers (e.g., screen time) if approximately $80 \%$ or more of a student's daily behavioral goals were successfully completed. See Appendix 1 for an outline of the behavioral consultation curriculum. See Figure 2 for an example of a Daily Report Card. Postbaccalaureate and graduate student consultants delivered the intervention, in person, during approximately 20 -minute consultation meetings occurring once or twice per month, scheduled at the teachers' convenience before and after school, as well as during breaks in the day.

Behavioral Consultants. Graduate student and post-baccalaureate trainees $(N=5)$ were enrolled in a Clinical Psychology doctoral program $(N=3)$, School Psychology/Mental Health Counseling master's program $(\mathrm{N}=1)$, or currently applying to graduate school $(N=1)$. All consultants were female; two consultants were non-Hispanic/white, one was non-Hispanic/black, and two were Hispanic/white. Two of the five consultants were first-generation Americans, one was a second-generation American, and two were not descended from recent immigrants. Consultants were supervised by a non-Hispanic/white male clinical psychology faculty member with over ten years of clinical research experience with externalizing behavior disorders and traditionally underserved populations (e.g., Hispanic/Latino youth). Consultants were assigned an average of five teachers on their caseload $(S D=1.85$, range $=2-7)$ and they worked with teachers throughout the 2017-2018 school year (from approximately September through June on a rolling basis).

Training and Supervision of Behavioral Teacher Consultants. Behavioral teacher consultants were instructed to familiarize themselves with an intervention procedural manual prior to the first training/supervision group meeting. Throughout the school year, 60-minute group supervision meetings were conducted once-to-twice per month and facilitated by the 
clinical supervisor (fourth author). Structured, agenda-driven group supervision meetings were designed to provide ongoing feedback to consultants regarding their caseload (similar to the clinical supervision needs identified by previous teacher consultant teams; Schoenwald, Mehta, Frazier \& Shernoff, 2013; Shernoff et al., 2014). In addition to the intervention manual, consultants received session outlines with detailed agendas, sessions/materials checklists, templates of behavioral intervention materials (e.g., examples of developmentally appropriate DRCs), as well as templates of data collection, tracking, and graphing templates. Despite a primary focus on the session content from the behavioral teacher consultant protocol (Volpe \& Fabiano, 2013), consultants were prepared to discuss matters or concerns raised by teachers; sessions with teachers (and subsequent discussions in group supervision) therefore encompassed topics such as psychoeducation regarding ADHD, as well as the principles of behavioral treatment broadly (e.g., positive reinforcement). Training/supervision also included brief information on the history of the university-school partnership, rationale and design of the current study protocol, and information regarding research-related procedures (e.g., collection of permanent products, behavioral consultation logs including the time of day, duration, and location of meetings). In order to best facilitate the management of difficult cases, behavioral rehearsals were also included throughout supervision as needed.

Surveys and Semi-Structured Interview Protocol. Teachers were invited to complete semi-structured interviews and an online survey, and they earned gift cards for their participation in either/both elements of the study. Following the completion of their final behavioral consultation meeting, teachers completed post-treatment data collection. Surveys were administered via REDCap software, and they were completed during the last three weeks of the school year. Semi-structured interviews were also completed between the teachers' final consultation meeting and the end of the school year. All interviews were conducted in the teachers' classrooms. Teacher interviews lasted 26 minutes on average ( $S D=7.23$ minutes, range 
$=15-43$ minutes). Following prior qualitative work assessing intervention acceptability with teachers in Title I schools, the first author facilitated all semi-structured interviews to reduce possible effects of interviewer style and bias (Shernoff et al., 2014; Shernoff, Lekwa, Reddy, \& Coccaro, 2017).

\section{Quantitative Measures}

Quantitative and qualitative measures and analyses were guided by the Consolidated Framework for Intervention Research (Damschroder et al., 2009) as well as definitions of terms delineated in Proctor and colleagues' (2011) guidelines for implementation outcome research. Throughout the behavioral consultation intervention, permanent products were collected to assess feasibility, described further below.

Feasibility. We collected administrative data throughout the study pertaining to possible enrollment refusal, dropout from consultation services, and adherence throughout the intervention. Enrollment refusal and dropout were defined as any teacher who declines to participate initially, or else discontinues their participation after consenting and prior to the completion of treatment. Adherence was measured through the evaluation of permanent products, including documented participation in consultation meetings and copies of completed DRCs. Specifically, we randomly selected one referred child per classroom, and we calculated the percentage of business days that the teachers completed the Daily Report Card to facilitate comparisons with previous research (Fabiano et al., 2010).

Acceptability. We also assessed intervention satisfaction using the Intervention Rating Profile-10 (IRP-10; Power, Hess, \& Bennett, 1995). The IRP-10 a six-point Likert scale ranging from "strongly disagree" to "strongly agree," with reference to statements about the extent to which an intervention is beneficial. One reason we selected the IRP-10 is to facilitate comparisons with previous research on DRC acceptability in a nationally recruited sample, also reported on a 1-to-6 Likert-scale (Chafouleas et al., 2006). We evaluated IRP-10 responses with 
respect to the DRC tool itself as well as the DRC consultation meetings separately. We used project-developed Likert-scale surveys to measure teachers' consumer preferences, including interest in modifications to format or content (Metzler, Sanders, Rusby, \& Crowley, 2012). On a scale from 1 ("Not at all Interested") to 5 ("Extremely Interested") teachers rated their preferences for getting information about new strategies or recommendations to inform their work with students with behavior and/or attention problems: attending formal trainings/workshops, reading materials (i.e., books, newsletters), meetings with a consultant, through website(s) online/an application (i.e., an app); from other teachers, through trial and error, and through email.

Potential Factors Associated with Feasibility and Acceptability. We evaluated factors possibly associated with engagement outcomes including practical/logistical barriers, individual characteristics, and cultural factors, described below. With respect to the CFIR, we focused on the levels of characteristics of individuals and inner setting:

Characteristics of individuals. We collected background information on the teachers, including demographics, training level, and years of experience.

Teachers' beliefs about behavioral strategies. We assessed teachers' beliefs about ADHD and classroom management strategies with an 18-item measure that has been used previously in behavioral teacher consultation studies (Owens et al., 2017). Each item is scored on a 6-point scale ranging from 0 ("strongly agree") to 6 ("strongly disagree"). This measure assesses teachers' beliefs including the reasons why children misbehave (e.g., "children often misbehave just to cause me stress"), attitudes toward behavioral strategies, (e.g., "rewarding children reduces their own internal motivation to behave appropriately"), and related factors.

Quality of Teacher Work Life Survey. Teacher stress was evaluated with the Quality of Teacher Work Life Survey (Pelsma, Richard, Harrington, \& Burry, 1989), a 36-item questionnaire assessing self-reported work-related stress and satisfaction. Teachers rated items on 
a 5-point scale ranging from 1 ("low") to 5 ("high") on both the extent to which each causes stress and the extent to which they are satisfied with each. Items included: salaries, job security, class sizes, support from administration, state/federal requirements generated by law, etc.

Acculturation Rating Scale for Mexican Americans-II. We measured behavioral acculturation with an adaptation of the Acculturation Rating Scale for Mexican Americans-II that extends the use of the scale for Latinx individuals broadly (Cuellar, Arnold, \& Maldonado, 1995; Gerdes, Lawton, Haack, \& Hurtado, 2013). The 30-item measure with adequate test-retest reliability and internal consistency assesses orientation to the Latinx and Anglo cultures, on a 5point Likert scale, ranging from 1 (not at all) to 5 (extremely often or almost always). There are two subscales: the Latinx Orientation Subscale (LOS; 17 items) and the Anglo Orientation Subscale (AOS; 13 items). Subscales measure orthogonal, bicultural orientations. Sample LOS items include, "I speak Spanish." and "My thinking is done in the Spanish language" Sample AOS items include, "I associate with Anglos." and "My thinking is done in the English language."

Latina/o Values Scale. We assessed teachers' adherence to traditional Latinx cultural values with the Latina/o Values Scale (Kim, Soliz, Orellana, \& Alamilla, 2009), a 35-item scale with adequate test-retest reliability and internal consistency (coefficient alpha $=.89$ ). More specifically, the two-week test-retest reliability of the Latino Values Scale resulted in a stability coefficient of .78 (Kim et al., 2009). Using a 4-point scale ranging from 1 ("strongly disagree") to 4 ("strongly agree"), teachers rated adherence to cultural values including familism, respect, affection, trust, congeniality, dignity, and cultural pride.

Inner setting. We assessed organizational health with the Organizational Health Inventory for Elementary Schools (OHI-E; Hoy, Tarter, \& Kottkamp, 1991), a 37-item survey assessing teachers' perceptions of organizational school health. Items were rated from 1 ("rarely") to 4 ("very frequent"), on five factor-derived subscales: The OHI-E yields an averaged 
total score and five subscale scores: institutional integrity (integrity of educational program; not vulnerable to outside forces); collegial leadership (principal's behavior is supportive, open/sets clear expectation); resource influence (principal's ability to obtain material resources); teacher affiliation (sense of friendliness, enthusiasm/connection for the school); academic emphasis (academic "press," students' expectations of high achievement). The OHI-E also generates an overall index of school health (total/averaged subscale scores). Lastly, the factor structure of the OHI-E has been investigated among teachers working in low income schools, with the factor structure remaining similar to the original study sample (Mehta, Atkins, \& Frazier, 2013).

\section{Qualitative Measures}

Semi-Structured Interview Protocol. Semi-structured interviews were designed to examine the perceived feasibility and the acceptability of behavioral consultation, as well as potentially associated factors. Open-ended questions elicited general information about acceptability ('Please tell me about your use of DRC with students in your classroom”) and feasibility (e.g., "To what extent was the DRC feasible, given the current demands and resources of teaching?"). Probes followed to encourage elaboration and clarification (e.g., “To what extent did you find the DRC helpful (or not) in managing students' off-task or disruptive behavior?";

“'To what extent did you find the DRC resulted in student improvement?'”). Informed by the CFIR, additional open-ended questions explored potential influences on feasibility and acceptability such as values (e.g., "To what extent does the spirit of the DRC (based on principles of behavioral reinforcement) align with your values?"). Within each CFIR construct intervention characteristics, inner setting, outer setting, characteristics of individuals, and process, we selected at least one qualitative prompt (Damschroder et al., 2009); see Appendix A for a CFIR-annotated Semi-Structured Interview Guide. 


\section{Data Analytic Plan}

The mixed methods data analytic plan included the following steps: simultaneous (1) descriptive quantitative analysis and multivariate analysis and (2) thematic analysis of the qualitative data, followed by (3) synthesis of quantitative and qualitative findings. Though we gathered both quantitative and qualitative strands of data, the open trial design and depth of the qualitative analyses highlight the prominence of our qualitative data (i.e., "QUAL + quan;" Palinkas et al., 2011).

Quantitative Analysis. Quantitative data (i.e., electronic surveys, permanent products such as daily report cards and documentation of consultation meetings) were analyzed with SPSS (V 25; IBM Corp., 2017). Descriptive statistics for all study variables, as well as bivariate correlations among selected study variables were performed.

Qualitative Analysis. Interviews were audio-recorded, professionally transcribed verbatim, double-checked against recordings for accuracy, and analyzed using Dedoose software, a qualitative data analysis program (Lieber, 2009). Thematic analyses were guided by Braun and Clarke's (2006) framework, with the following steps: (1) familiarization with data, (2) initial code generation (3 identifying themes, (4) reviewing and revising themes, (5) defining and naming themes, and (6) producing a final report. The qualitative coding team (all female) was comprised of one doctoral student (first author) and two bachelor-level research assistants. The qualitative coding team was comprised of one doctoral student (first author, non-Latinx white) and two BA level research assistants (one non-Latinx white, one Latinx white second generation American). First, the coding team began to code interviews to familiarize themselves with the corpus, using the Consolidated Framework for Intervention Research (CFIR) codebook as a starting point (Damschroder et al., 2009). The CFIR was selected because of its relevance in rapid iterations of implementation research to improve line-level efforts (Keith, Crosson, O’Malley, Cromp, \& Taylor, 2017). Second, through an initial round of open coding, a project-developed list of sub- 
codes was created. Throughout the process, the team leveraged a codebook, including operational definitions of thematic codes, inclusion and exclusion criteria, and example text to clarify the team's emerging insights. Weekly consultation was used to review and renegotiate thematic codes as the codebook evolved throughout ongoing, iterative qualitative analyses. Agreement between qualitative coders was monitored throughout the process and resolved via weekly consultation. Thematic codes, sub-themes, and overarching themes were conceptualized as the outputs of these analyses. That is, operational definitions of sub-codes frequently and iteratively changed throughout the coding process. Frequency counts (illustrated in Table 4) represent the number of times teachers expressed/cited a thematic sub-code. In sum, these qualitative analyses ultimately represent a constructivist epistemological perspective (i.e., multiple realities exist/each research effort may bring about varying interpretations). Yet mixed-method research allows for a dynamic approach, as synthesis with quantitative findings may lend toward the positivist paradigm at some junctures (i.e., single reality exists/identifying causal relationships through quantitative analysis; Doyle, Brady, \& Byrne, 2009).

Synthesis of qualitative and quantitative results. Lastly, the descriptive quantitative findings were merged with the results of the qualitative thematic analysis using a joint display table (i.e., Table 5; Fetters, Curry, \& Creswell, 2013). Joint display facilitates the convergence of quantitative and qualitative data in a highly visual manner, allowing for comparisons across data collection modalities (Fetters et al., 2013). That is, we developed a table in which each row presented both quantitative (e.g., implementation outcomes) and qualitative (e.g., most commonly cited thematic code) information in order to highlight each teacher's performance in the intervention and corresponding frequently cited qualitative code describing about his/her experience. After integrating quantitative and qualitative analyses, the coding team reviewed findings and drew inferences regarding the triangulation of quantitative and qualitative data regarding various implementation outcome trends (Seale, 1999). Specifically, our team reviewed 
our findings with respect to quantitative and qualitative findings regarding feasibility; the joint display table is designed to include the most critical quantitative indicators of feasibility/intervention engagement (e.g., session attendance), which demonstrate the extent to which outcomes align with qualitative findings (i.e., thematic codes cited). Further, our joint display table was similarly designed to include the most critical indicators of acceptability (i.e., IRP-10 scores), also paired with the qualitative findings (i.e., thematic codes cited).

\section{Results}

As described above, we followed Braun and Clarke's (2006) method for thematic analysis; the overarching themes that emerged from the process are described in Figure 3, as well as in the text below. In order to best facilitate the integration/synthesis of our quantitative and qualitative findings, we discuss each of our specific aims below with respect to the quantitative results as well as the emergent themes most-related to each aim. Many themes cut across several aims.

Feasibility. Quantitative Results. All 23 teachers (100\%) who were invited participated in both behavioral consultation, as well as semi-structured interviews. Of more than 500 students enrolled at the elementary school, 48 students were referred for behavioral services. Teachers completed DRCs for the majority of students who were referred (i.e., 36 of 48 referred students; $75 \%$ ). That is, 12 students were referred for services, yet their teachers declined to develop a DRC for them. They instead elected to complete a DRC for other student(s) in that child's class. Reasons reported for electing not to complete a DRC for these students included: the teacher reported that the child did not demonstrate a functional impairment at the time (children were referred for treatment/assessed during the spring preceding the school year our study was conducted); the student was currently responding well to stimulant medication and he/she did not require more treatment currently; and the teacher reported that he/she accommodates the child's symptoms without a current need to intervene (e.g., a hyperactive child was allowed to move 
around often). Teachers attended an average of 4.6 behavioral consultation meetings ( $S D=2.18$, Range $=1-9)$, and behavioral consultation meetings were brief ( $M=22.9$ minutes; $S D=7.1)$. A substantial number of teachers cancelled or "no showed" to meetings at least once ( 8 of 23 teachers; 35\%), resulting in approximately one in ten meetings being rescheduled. Teachers completed daily report cards for 2.39 students in their class (Range $=1-6 ; S D=1.41)$. Several teachers completed a DRC for only one student $(N=7)$, and for teachers completing DRCs for more than one student $(N=16)$, we randomly selected one student; teachers completed daily report cards consistently, about four days per week $(M=80.3 \%, S D=12.0 \%)$. For teachers completing DRCs for two or more students $(N=16)$, we also randomly selected a second student; teachers completed daily report cards consistently for these students as well $(M=73.6 \%$; $S D$ $=10.6 \%$ ). With respect to acceptability, teachers indicated on the Intervention Rating Profile-10 that they "slightly agree" to "agree" that the DRC is beneficial $(M=4.86, S D=.57)$. For further information on individual-level feasibility indicators, see Table 5. Aggregate descriptive statistics regarding the location and time of day of consultative meetings are presented in Table 6 .

Additionally, several very brief interactions occurred between teachers and behavioral consultants (especially those who were employed daily in the school building); all consultative interactions/meetings lasting longer than five minutes were logged. Teacher-level descriptive statistics regarding the number and duration of consultative meetings are presented in Table 5. Interestingly, individual-level descriptive statistics (i.e., Table 5) also reveal that teacher number 17 attended only one meeting, yet completed a DRC four out of five days per week. She communicated information about behavior target titration via her co-teacher (i.e., instead of via in person meetings with the consultant.

Feasibility. Qualitative Results. With respect to feasibility, an overarching theme (\#1) emerged that perceived behavioral control of DRC completion depends a lot on the environment. First, we discuss subtheme (\#1.1: High self-efficacy). All teachers ( $n=23)$ cited high self-efficacy 
when assessing their own competence, citing reasons such as the simplicity of the DRC. For example, one teacher described several reasons for high self-efficacy:

"The way that you guys set it up [the DRC] is very simple. I just circle and initial and that's it. [...] You guys make it very simple for us to be able to do it and not be a problem or taking away time from our regular instruction. [...] I've been doing [the DRC] for already quite some time and I think I've mastered the way. Some years is easier than others, some years the information is more accurate than others because of the number of DRCs that I have to fill out, that, like I said, has an important role in how accurate. [...] I can say that I'm pretty knowledgeable. You guys always give us [...] a mini training [in the beginning of the year] just to remind us of how it is done. I've been doing it already for three, four years, five years maybe." -Teacher 22

Another teacher characterized behavior management skills as the norm at their elementary school, as such a high percentage of teachers have many years' experience $(M=21.48, S D=8.56)$ and advanced training. Additionally, teachers in our sample endorsed that they valued the Latinx cultural value, "respect for authority" ( $M=3.0$ out of $4, S D=0.9)$.

"I think the majority of the teachers here in our school were such senior teachers, we've been here for so long, that we've got it pretty well down pat when it comes to discipline. I think most teachers [here] have something that is [in place to manage classroom behavior]-whether it's my paper clips or [...] the DRC. I mean, I think we're pretty good there. " -Teacher 21

Lastly, within the subtheme 1.1 (high self-efficacy), a frequently cited thematic code included that teachers were familiar with/have helpful ideas about design quality/packaging. For example, one teacher suggested a salient idea: to create a rubber stamp version of the DRC. Another teacher recommended creating something "to put in our 'sub' folders for when we're not here," such as a one-page fact sheet to educate substitute teachers about the DRC.

Next, we discuss subtheme (\#1.2: Low controllability). All but one teacher ( $n=22)$ identified the central problem to implementing DRCs in Title I schools as the lack of available resources (e.g., time). Three teachers discussed the way lack of time plays a major role in the feasibility of DRC implementation: 
"It is difficult. I'm not gonna lie. Having a conference [i.e., meeting with a behavioral consultant about DRCs], an extra conference, it does take [time] because especially, you're talking about our planning time." Teacher 3

"I don't wanna say it's time consuming [to fill out the DRC], but it is something that has to be done every day. It's not right off the top of your head, "Oh you guys did a great job today." You know what I'm saying? It's not oral. You do have to take a moment to think how was this child all day that he was with me? Sometimes it's not black and white. You know what I mean? [Teachers] have to be observant. They have to pay attention to what the child does all through the day [...] Oh my God. I know for a fact that there are teachers that have three or four [DRCs] at one time. I think that would be insane." - Teacher 10

"I mean I think for both entities always the hardest thing is trying to get a teacher to sit down with you guys to talk to you. That's just like scheduling cuz there's always something going on. [...] It might just be our school, but there's always something going on." -Teacher 6

Students enrolled in the elementary school often lacked resources at home, noted two teachers.

Considering that the DRC is typically defined as a daily home-school note, concerns about

limited resources at home/limited interest in communication from parents stand out:

"To be quite honest with you, when it comes to the [English as a Second Language] (ESL) population, you have to give that assimilation period, so I don't think there's much you can do [...]. Until [the child's parents] finish their struggle, I don't think they can worry about-they're trying to figure out where they're gonna live, where their work is, where the money is coming from -I don't think they're consumed with this little paper that tells 'em if their child stood up three times today or something to that effect." Teacher 12

"I have a few of my own students [who] have been failing my class [...], and I've reached out to parents, calls, tried to make conferences, emails, written them notes in their homework agenda, and I receive nothing back. I know that [these students] could do so much more, but since they don't get the reinforcement at home, there's only so much I can do as an educator" -Teacher 9

Several teachers championed the accessibility of the consultants as a solution to difficulty scheduling 20-minute, biweekly meetings. That is, having consultants who are "always here" onsite was what teachers perceived that made the DRC work: 
"[The behavioral consultant] was very much on top of it. We met probably either every month, or every three weeks. I know it was often enough for us to adjust and to be able to act quickly and sometimes we're formal, sometimes we're informal meetings. If I would catch her in the hallway, I would say, "Yes, everything is okay." Or 'No, we need to do this.'." Teacher 22

'I don't remember [how many meetings were cancelled.] I know that meeting every once in awhile is not bad just to stay in touch, [to say] "Okay, [the DRC's] working. It's not working. What's going on?" Even though if something were to occur or there was something very important-you guys were very accessible-we would go see you."

-Teacher 5

The perception that consultants were so ever-present and highly flexible even made one teacher feel guilty:

"No, I feel bad for you guys. You're always trying to chase us. If I were to change something, it's probably the way that we have to be more available for you guys, 'cause I know that's a very difficult thing. Teachers are probably saying, 'Oh, not today.' [...] You adjust to my schedule, and you always have." -Teacher 21

Acceptability. Quantitative Results. With respect to acceptability, teachers indicated on the Intervention Rating Profile-10 that they "slightly agree" to "agree" that the DRC is beneficial $(M=4.86, S D=.57)$. For further information on individual-level teachers' acceptability ratings, see

Table 5. In addition, aggregate statistics on teachers' consumer preferences are presented in Table 7.

Acceptability. Qualitative Results. With respect to acceptability, an overarching theme (\#2) emerged that attitudes toward the DRC matter a great deal. We discuss subtheme (\#2.1:

Mixed success with the DRC is the norm; it depends on which student(s) we are talking about). Most teachers implemented the DRC for more than one student $(n=16)$ during the school year. All teachers $(n=23)$ cited highly variable results, with differences depending on student response to the DRC. One teacher compared two students who used the DRC, noting two very different outcomes: 
"For example, last year we had [child's name redacted]. He did what he wanted anyway. There was no true consequence at home for him and he knew this, so having the DRC whether we filled it out, [...] wasn't as beneficial. Some students take it. This particular student has a little bit more sense of responsibility. He's a little bit more noble as far as that's concerned. It's just that he can't control himself. I think a child like [redacted] could have probably controlled himself a little bit better if he had more consequences at home for his actions." -Teacher 23

Perhaps baseline rates of maladaptive behavior are related to the differential effectiveness for students, a teacher noted:

"Yes. DRC, I think it's, a very good tool for some students, not for others. There are some students that really work for it just to be rewarded at the end of the week. When there is constantly a misbehavior, there's sometimes that even if they get unsatisfactory at the very beginning of the day, I see that they give up at the middle of the day when I get them. [...] That's what I see a difference that some [children say], "Okay, I already got unsatisfactory," it turns 'em off. You know what I'm saying? As far as the DRC, again, it works for some, but not for others." -Teacher 13

Implementing a DRC for an entire school year without any perceivable positive effect was

painful, for one teacher. However, she noted that she saw the benefits of the DRC in general:

"The DRCs, historically, I find they do work. They're effective, and I've seen improvement in their overall behavior. This year, in particular, just because of this specific child [this year], I find that [the DRC has] become more of a nuisance because it's just one more thing for him to ask me about. I'm glad [the audiorecorder's] not recording my facial expressions [while I'm describing this]. Overall, I do see the value in [the DRC], and I do recognize that it is a tool. It's just this one child it hasn't been as effective for." -Teacher 17

Potentially Associated Factors. Quantitative Results. In addition, unadjusted bivariate correlations among selected study variables are displayed in Table 8. Of note, few variables were significantly correlated. Both teacher self-report of stress and satisfaction were positively associated with DRC completion rates, $r=.43, p<.05$. and $, r=.53, p<.05$., respectively. Teacher self-report of stress and satisfaction were significantly positively associated, $r=.07, p<$ .05 . The number of years teaching experience was positively associated with the number of DRC meeting held, $r=.45^{*}, p<.05$. Although not statistically significant, there was positive trend 
toward a bivariate association between the number of years teaching experience and Anglo orientation on the ARSMA-II, $r=.50, p>.05$. The total number of DRC meetings was also positively associated with the number of students with a DRC in the classroom, $r=.62, p<.05$.

In addition, we evaluated teachers' aggregate perceptions of organizational health with the OHI-E (Hoy et al., 1991). The overall index of organizational school health fell into the very high/healthy range, with subscale scores mostly in the very high range (teacher affiliation; collegial leadership; resource influence), followed by institutional integrity in the high range. Academic emphasis fell within in the low range.

Potentially Associated Factors. Qualitative Results. With respect to factors potentially associated with feasibility and acceptability, the subtheme (\#2.2) is particularly relevant, positive attitudes toward the DRC include that it is effective and aligns with real life/values. Teachers unanimously expressed positive attitudes toward the DRC ( $n=23)$, noting that positive reinforcement really works in their eyes. Reviewing data/graphs during behavioral consultation meetings confirmed for one teacher that the DRC affected change:

"Well, I like how it's consistent, how you follow it through with the graphs, how we have meetings, how the parents are totally informed, are involved in this. You have meetings with them, how you discuss all the changes, all the positive changes that have been made, all the problem behaviors that have decreased, that's awesome. Definitely, I like the DRC. It's helpful, and I think it's been effective in my case." -Teacher 2

Another teacher noted the salience of reinforcers selected by students enrolled in the program, noting powerful motivators likely caused success with the DRC:

"I've seen wonderful, wonderful things happen with students this year and the years past. It keeps them on track. It redirects their behavior. They're consciously making a conscious effort to follow through. They want their [token economy reinforcers] on Friday. They want that, so I would say, for the most part, it's effective for students." -Teacher 4 
Some teachers even described the DRC as "perfect" reflecting its close alignment with their core values. The vast majority of teachers reported examples of extremely positive attitudes toward the DRC ( $n=19)$. For example, one teacher explained:

"[The DRC] aligns perfectly [with my values], because you get what you work for. If you work hard, there's positive consequences; if you don't, then that's life. You're not gonna get everything. I'm not one of these people that everybody's a winner. You work, and work leads you to luxuries, and advantages that other people, who don't work, don't lead you to. There's consequences. Just like, I always tell my students that, 'Your reputation gets there before you do. You have to be aware. Not everybody's a winner. You have to learn how to lose, and then grow from your mistakes.' The DRC does that. You grow from your mistakes. Maybe on that Friday, you didn't get [weekly end-of-week reinforcement]. That's what you worked for. You have to be responsible for your actions." - Teacher 14

A second teacher confirmed that the DRC both aligns with her values, as well as works well to improve student performance because of effective reinforcers:

"Oh, it definitely fits in [with my values]. I wish everybody could be on a DRC. That would be great because that would be a great control of the classroom or getting them all to work. There were some kids that were not in your program that wanted the DRC. They just wanted it. I don't know why because they didn't participate in [weekly end-of-week reinforcement], but they just thought that it was cool to have a DRC. [...] The advantage of the DRC is that they were way more motivated to do whatever you were giving them, or they were more conscientious of how many points they had, how many points they needed to participate in [weekly end-of-week reinforcement]. They really knew that."-Teacher 18

Next, we discuss subtheme (\#2.3): negative attitudes toward the DRC include poor acceptability of successive approximation and overreliance on extrinsic motivators. While all teachers said something positive about the DRC, many also expressed concerns $(n=19)$. One teacher used a striking analogy to illustrate why the behavioral principle of successive approximation was completely unacceptable to her:

"You're supposed to behave good all the time. All the time. In the cafeteria, you need to sit and eat and that's it. [...] It's like a thief steals $\$ 500$ the first time, and then, the second time, he only stole \$100. You're still a thief. Sorry to break it to you. [...] In my head, that bothers me for some reason. I get it that you need to be, like, 'good job [when children's behavior improves],' but if they do something bad, [...] I'm not going to be, like, 
"well, at least they were [less bad than last time]-no. No. You behaved horrible in recess and now, you're going to be in time out." -Teacher 16

Successive approximation is inherently unfair to well-behaved students, noted one teacher:

"I guess-if I have to reward her for something that the other ones were expected to do, and then she's rewarded for doing the same thing that they are, but they don't get rewarded, I've seen that been an issue in other years. [...] The rest of the class thought it was unfair. [...] It was just between him and I at that point, and nobody else really needed to know. You could tell that they had a problem with it. [...] I did see that the rest of them questioned a little bit." -Teacher 19

Cognitive distortions about expected behavior (e.g., "should" statements) echo throughout negative comments about the DRC; several $(n=14)$ noted that teachers should not have to reward every little accomplishment, because students should do certain things without being rewarded.

For example, one teacher described her views on how students are supposed to behave:

“Again, I don't know. Sometimes I just feel that with the DRC there's too many chances maybe, and I think the children, the students, don't take it as seriously when they get those Nos, because they might say, "Oh, well, I got one No," but they shouldn't be getting any Nos. I don't think the academic part should be included in their DRC. I think what they do, their on-task behavior, that they're doing the work that they're supposed to, that they do the work over the weekend or from one night to the next. That should be counted, not whether it was they did 80 percent of it. It's expected to do 100 percent. I don't think there should be a percentage that they're allowed to do because then it's very easy. "Oh, I didn't have time." "I didn't understand." "I felt sick," and they stop. "Why didn't you finish it?" Oh, their mothers write a note. They got a headache. "Did you have the headache the entire six hours form the time you got home till when you went to bed?" They can't answer that, of course. It just shows-because lots of times, especially for me. I begin home-learning activity in the classroom, and then it becomes what they did not finish, and they should finish 100 percent of it." $\quad$-Teacher 20

"Should" statements also encompassed teacher behavior, such as the well-known adage early career teachers often hear from colleagues "Don't smile before Christmas" (Dorsey, 1997; Roberts, 2010; Wallinger, 1997). One teacher described how she internalized this advice about classroom management:

For me, I feel you have to establish [authority] from, the beginning from the first day at school. If you let them walk over all over you from the first 
day of school, it's gonna be like that all year[...] You can't smile 'til Christmas type thing. You need to almost make them see-make it seem you are a no-nonsense person. This is how it is. This is how it goes. You cannot stray from here, until you come back from Christmas and they know this is how it goes, this is the way it's done. This is the way we're gonna do it. Don't stray from that. Then you can be like, okay, so now I can be your friend. They eventually see you as a human, like oh, she does have teeth." Teacher 19

One teacher clarified exactly why it makes perfect sense to hold simultaneous positive and negative attitudes toward the DRC (i.e., is effective/unappealing). That is, she described sometimes the DRC only worked because of extrinsic motivation:

"The disadvantage to the DRC is sometimes that's the only reason why they do things. The only reason why she'll stop talking is because now she's gonna not get the point for her DRC, or she'll get too many points on her DRC, instead of an inner self control like, 'Okay, I need to stop this for me, not because I'm not gonna get the points. [...] I need to do this because this is just the way I should be acting in class.' -Teacher 11

Negative perceptions about an overreliance on extrinsic motivation were sometimes practical.

When it was not feasible to implement extrinsic motivation, one teacher highlighted that the improvements in behavior did not generalize:

"[The DRC only] worked during the time he was here [in class]. Then as soon as they go to a special area or cafeteria where the same level of supervision is not there, then that's where the-some of the issues occurred, most of the issues occurred. Because here he was accountable. He knew that I was watching him. Everywhere else, maybe they weren't as stern as I was, maybe they weren't on the eagle eye like I call it, but-that's where the issues are coming. I think he was smart enough to know when he could and when he couldn't. Then there was no penalty for that section of the time that he did get in trouble as long as he met the goal then he was okay for Fridays. That became a little bit of a power play. He and I butted heads a lot. I did see that he would try play the system." -Teacher 19

Importantly, we offered flexible options for teachers who held negative attitudes toward various components of the DRC intervention. For example, with two teachers who reported that diffuse praise/positivity for expected behavior was not acceptable, consultants minimized the positivity of the formatting on the DRC. Typically, teachers circled "yes" or a happy face when DRC goals were met, yet we re-formatted these teachers' DRC with neutral, yet informational dichotomous 
indicators to deliver feedback regarding earning rewards after the school day (i.e., satisfactory vs. unsatisfactory).

\section{Discussion}

The purpose of our convergent, mixed-method study was to examine the feasibility and acceptability of behavioral consultation with Latinx teachers and students, as well as potentially associated factors. To our knowledge, our study is the first to examine Latinx teachers' perceptions about ADHD and preferences related to behavioral treatment, including the DRC. Within respect to implementation outcomes such as feasibility, we found that Latinx teachers' DRC completion rates were comparable to previous studies with predominantly non-Latinx white teachers and students (Fabiano et al., 2010; Owens, Murphy, Richerson, Girio, \& Himawan, 2008). Quantitative indicators of acceptability were also similar to previous research conducted (Chafouleas et al., 2006), with teachers in our study reporting that the DRC was somewhat beneficial to students. Notably, meetings attended were considerably shorter than certain evidence-based interventions (e.g., Sheridan, Ryoo, Garbacz, Kunz, \& Chumney, 2013) and teachers completed DRCs for more than two students in their class on average. Qualitative findings expanded upon these trends; two overarching themes emerged, that (1) teachers' attitudes toward behavioral interventions matter a great deal, and that (2) teachers' perceived behavioral control over intervention engagement depends a lot on the environment. We discuss each of these findings in more detail below.

Quantitative findings revealed that more experienced teachers were more likely to demonstrate high engagement in our intervention, attending more meetings and completing DRCs for a higher number of students in their class than teachers with fewer years of experience. This finding may suggest that the DRC is an intervention better-suited to teachers with more experience/improved classroom management skills (as they typically develop over time). Both teacher self-report of stress and satisfaction were positively associated with DRC completion 
rates. Perhaps engagement in the DRC represents a fulfilling, meaningful endeavor, yet taxing on most already over-burdened teachers. Furthermore, as discussed above, quantitative data included that teachers in our study exhibited comparable rates of DRC completion (80\%) to those in previous studies (e.g., 73\%; Fabiano et al., 2010; 77\%, Owens, Murphy, Richerson, Girio, \& Himawan, 2008). In addition, despite excellent DRC completion rates of approximately four out of five school days per week, DRC acceptability rates fell between "slightly agree" and "agree," ( $M=4.86$ on a 6-point scale, $S D=.57)$ indicating that the intervention was perceived to benefit students to some extent. That is, teachers implemented the DRC well. Yet on average, teachers endorsed that they less than "agree" that the intervention is beneficial. Perhaps acceptability ratings reflect teachers' somewhat ambivalent attitudes toward the DRC.

Qualitative analyses illuminated how disparate quantitative findings might be explained. Considering the framework of the theory of planned behavior more broadly (Ajzen, 1991), both attitudes and perceived behavioral control affect behavior via intentions. Therefore, one could assume that ambivalent attitudes toward the DRC would suppress completion rates, or that variable perceived behavioral control of the DRC would also lead to decreased completion rates. However, it is puzzling that the third pillar of the Theory of Planned Behavior (Azjen, 1991) perceived behavioral norms (or a proxy) did not emerge in either quantitative or qualitative analyses as significant/salient. That is, we measured several cultural values and background characteristics, as well as included semi-structured interview prompts regarding culture. Yet teachers in our sample completed the DRC at high daily rates. Perhaps disparate quantitative and qualitative findings could be explained by our overarching themes; (1) teachers' attitudes toward the DRC matter a great deal, and ambivalence toward the DRC was normative, and (2) that perceived behavioral control of the DRC depends a lot on the environment. Ambivalence toward the DRC typically signified that teachers felt the DRC worked for one student, but not another. In fact, teachers often noted that the DRC works very well for certain students. Because 
the majority of teachers implemented the DRC for more than one student, perhaps they completed the DRC for multiple students even though there were certain students included in the group who failed to respond. Further, teachers reported that their perceived behavioral control of the DRC wavered with the difficult-to-control, under-resourced environment - yet nearly every teacher reported that they had very high self-efficacy in qualitative interviews. It is also possible that high self-efficacy with the DRC was the norm in our sample because advanced behavior management skills is consistent with Latinx cultural values (e.g., respect for authority) as way to maintain order.

\section{Clinical Implications}

Our findings suggest that direct persuasion (or seeking "buy-in") may be unlikely to affect teachers' behavior and engagement in behavioral consultation/implementation of the DRC under certain circumstances. Attitudes are long-held beliefs toward a stimulus (Perloff, 2016), direct persuasion to change an attitude can result in accumulating "sustain talk," (i.e., speech elaborating on the reasons why to refrain from behavior change; (Miller \& Rollnick, 2012), and a teacher who is provoked by an attempt at direct persuasion might therefore solidify their negative attitude(s) toward the DRC. More important than the valence of teachers' attitudes, the overarching qualitative theme that encompassed each attitude highlighted that teachers' attitudes matter a great deal. A foundation for building rapport with teachers should therefore acknowledge teachers' longstanding attitudes as valuable, rather than primarily a set of beliefs that fuel "resistance." Further, teachers in our study expressed a logical framework for their perceived behavioral control over implementing the DRC (i.e., the perception of the ease/difficulty of a particular behavior; Ajzen, 1991). Teachers expressed high self-efficacy and concerns with low controllability, meaning that they were well-prepared, yet that was not always enough. A behavioral consultant focused on increasing the preparedness of the teacher to implement the 
DRC might overlook factors completely beyond the teachers' control, such as lack of time for scheduled meetings in an under-resourced environment.

In addition, teachers' concerns with low controllability extended beyond the availability of resources at school; teachers $(n=10)$ often noted concerns that the DRC did not work because of the lack of resources in the home lives of their students. Teachers in our study commented on how economically disadvantaged elementary school students may have unfettered access to rewarding stimuli in their "unstructured" homes, or that parent support, or "follow through" was absent. In an era of increasing access to highly palatable, processed food and/or electronics “screen" time (Bucksch et al., 2016; Kearney, 2010), teachers' concerns that the DRC does not work for students with low socioeconomic status therefore is logical because of the behavior analytic concept of motivating operation (Michael, 1982, 1993). Motivating operation refers to the phenomenon that stimuli vary in the strength of their reinforcing qualities based on environmental characteristics, among other factors (Michael, 1982, 1993). For example, if an unsupervised child has constant access to electronic screens during the hours of the day spent at home before his or her parents return from work (thus becoming satiated with the stimulus), earning 10 minutes of screen time at school as a privilege/reward for good school day behavior would be ineffective. Previous studies of the daily report card among teachers serving low income students found that many parents were not involved in DRC implementation, nor did many teachers find communication with parents effective (Watabe et al., 2013). More research is needed to elucidate how rewarding stimuli in children's homes affects DRC response, as well as possibly moderating effects of family income on intervention outcomes. Additionally, an overall organizational school health index on the OHI-E fell in the very high range, yet academic emphasis was low in our sample (Hoy et al., 1991). The lack of resources at home may have also affected academic "press"/students' achievement orientation. Importantly, academic press is associated with achievement, and the effect is largest among low-SES schools (Shouse, 1996). 
Hamilton and colleagues (2008) proposed that "flexibility within fidelity" is critical to deliver personalized evidence-based interventions. Our work highlights several instances in which we offered flexible options for teachers in the context of an evidence-based intervention: minimizing the positivity of the formatting on the DRC (i.e., typically requiring teachers to circle "yes" or a happy face when goals are met) with neutral, yet informational dichotomous indicators to deliver feedback regarding earning rewards after the school day; using a ticket/token system vs. a typical behavior chart version of the DRC; and communicating information about behavior target titration via co-teacher (i.e., instead of in person meetings, as one teacher only attended one meeting yet completed a DRC four out of five days per week). Typically, refusal to complete a behavior chart, aversion to positive social reinforcement, or the preference to only attend one meeting for an entire school year would be conceptualized as "poor engagement." Considering the overarching theme that attitudes matter a great deal, comments opposing certain core elements of positive reinforcement and/or the DRC were taken very seriously (e.g., "you can't smile 'til Christmas"). Rather than explaining the benefits of social reinforcement, for example, our team selected to modify the DRC to increase teachers' engagement (e.g., neutral indicators of "satisfactory"/"unsatisfactory" vs. circling "YES"). Although we may have succeeded in increasing teachers' engagement/DRC completion rates (or at least maintaining the rates from efficacy trials in a community-based setting), more information is needed regarding child-level outcomes of these modifications, as effect sizes may be attenuated by changing these elements of the procedure. In addition, teachers suggested helpful, flexible strategies for future dissemination and implementation efforts, such as the use of a rubber stamp version of the DRC (to facilitate implementation with multiple students per class/reduce paperwork burden), as well as the use of a one-page fact sheet to educate substitute teachers/increase their participation. Please see Figures 4-6 for a photograph of a rubber stamp "DRC" prototype, and Figures 7-8 for an example of a one-page fact sheet developed for substitute teachers. 
Lastly, the engagement successes of our implementation efforts are at the level of day-today follow-through on the completion of the daily report card. Teachers attended brief meetings though with consultants regarding the care/management of multiple students in their classes, yet more than a third of our sample attended only three or fewer meetings throughout the entire school year. The minimum number of recommended meetings for the evidence-based protocol we set out to follow is four, with up to eight meetings required as needed (Volpe \& Fabiano, 2013). Of note, similar behavioral teacher consultation protocols achieved successful outcomes with two to three 30-minute meetings (Pfiffner, Villodas, Kaiser, Rooney, \& McBurnett, 2013). Clearly, our mode of intervention delivery is incompatible with the most common, dominant model in clinical practice of one-on-one, in person meetings lasting approximately one hour (Christensen, Grossman, \& Hwang, 2009). For example, would behavioral teacher consultants be reimbursed for the time they spent driving to schools? Would consultants be able to bill enough credits to economically justify the school visit? Or, if an in-house therapist is assigned to implement behavioral teacher consultation (e.g., school social worker, counselor), how would these tasks fit into an already over-burdened schedule? Further, an interesting sub-theme in our qualitative analyses highlighted that teachers appreciated when consultants were "always here" onsite, buttressing previous research that teacher engagement intentions are positively associated with the number of hours behavioral consultants spend located on the premises of the school (Gonzalez et al., 2004). Possible innovations to existing treatment delivery models could include leveraging paraprofessionals to implement the intervention (Atkins, Rusch, Mehta, \& Lakind, 2016; Rusch, Walden, Gustafson, Lakind, \& Atkins, 2018). In addition, several evidence-based interventions to improve student engagement, such as Check \& Connect, operate via a tiered hierarchy of clinicians and paraprofessionals (e.g., City Year volunteers supervised by school counselor/psychologist; Christenson et al., 2008; Sinclair, Christenson, Lehr, \& Anderson, 2003). In addition to paraprofessionals, other indigenous, onsite staff members such as masters-level 
learning support professionals (e.g., social workers) have implemented behavioral consultation successfully as well (Pfiffner et al., 2011). Future efforts should emphasize the use of onsite staff members to implement day-to-day components of behavioral teacher consultation.

\section{Research Implications}

Future studies are needed (1) to explore the quantitative relationship between cultural factors and DRC implementation outcomes among a larger sample of Latinx teachers and students (2) to gather more information on perceived behavioral norms of DRC implementation in this population, as well as prospective intentions to use the DRC. For example, Fishman, Beidas, Reisinger, and Mandell (2018) used the theory of planned behavior framework, and they found that intentions predicted teachers' use of psychosocial interventions in a low income school. Broadly speaking, culturally adapted mental health care is more effective for Latinx individuals, as a recent meta-analytic study of more than twenty years of literature found that culturally-adapted mental health treatments resulted in significantly more favorable outcomes for ethnic minorities, including Latinx individuals, relative to unadapted interventions (Hall, Ibaraki, Huang, Marti, \& Stice, 2016). Cultural adaptation involves tailoring mental health interventions to better fit with the cultural context (Smith, Rodríguez, \& Bernal, 2011), systematically addressing barriers to successful treatment, such as inadequate acceptability and feasibility (Castro, Barrera, \& Holleran Steiker, 2010). We conceptualize our study as only a preliminary step toward in the line of research (Barrera \& Castro, 2006), demonstrating the promise of behavioral consultation for Latinx teachers and students. Additional, larger studies are needed to more adequately investigative the quantitative associations between cultural variables and implementation outcomes, between-group differences, etc.

Further, continued research on the implementation of DRCs with Latinx students is the logical next step for several reasons. Latinx youth are less likely to use specialty mental health services than their non-Latinx white counterparts (Hough et al., 2002); given the nature of these 
mental health care disparities for Latinx youth, integrating mental health care in schools could increase access to care by mitigating barriers such as stigma, low perceived need for treatment, financial limitations, and transportation (Mojtabai et al., 2011); and there is initial evidence that ethnic/racial minority parents prefer for their children to receive school-based mental health care, and are considerably more likely to access treatment offered at school than in a clinic (Jaycox et al., 2010). Further, in a predominantly Latinx sample of parents recruited from a Title I school, participants reported that having existing, ongoing relationships with school staff was critically important for their engagement in mental health services provided by the school (Langley, Santiago, Rodríguez, \& Zelaya, 2013). Our study therefore buttresses previous support for the promise of school-based interventions among Latinx students, as implementation outcomes demonstrated adequate engagement overall.

\section{Limitations}

The findings of our study should be considered in the context of its limitations. First, the sample was not randomly selected, and the small number of participants $(n=23)$ drawn from only one school limits the strength of the conclusions that can be drawn from quantitative findings in particular. Therefore, our findings may lack generalizability for several reasons. Teachers in our study were unique because teacher turnover was almost nonexistent. The majority of Title I schools suffer from the inverse; high turnover (Darling-Hammond \& Sykes, 2003). Further, several methodological concerns arose throughout our study, with strengths and weakness to each decision we took. First, in order to develop a strong community partnership and collaboratively identify needs, we began working with the school more than two years before the present study was conducted. Though the strength of the partnership was helpful to create a bond, the period of time before we requested data collection is not described by our current analyses. It is possible that enthusiasm for the DRC would have been lower at the beginning of the partnership. In addition, consultants were university students, which has been previously shown to lead to better 
outcomes than more indigenous and sustainable staff members (e.g., school personnel;

community providers; Curtis et al., 2004).

Summary and Conclusion

Our convergent, mixed-method study examined the feasibility and acceptability of behavioral consultation among Latinx teachers $(n=23)$, as well as potentially associated factors. Latinx teachers' DRC completion rates (80\%) were comparable to previous studies with predominantly non-Latinx white teachers and students (Fabiano et al., 2010; Owens, Murphy, Richerson, Girio, \& Himawan, 2008). Quantitative indicators of acceptability were also similar to previous research conducted (Chafouleas et al., 2006). Thematic analyses revealed two overarching themes, that (1) teachers' attitudes toward behavioral interventions matter a great deal, and that (2) teachers' perceived behavioral control over DRC implementation depends a lot on the environment. Findings highlight the importance of stakeholders' perspectives in translating research to routine practice.

\section{References}

Alegria, M., Atkins, M., Farmer, E., Slaton, E., \& Stelk, W. (2010). One size does not fit all: taking diversity, culture and context seriously. Administration and Policy in Mental Health, 37(1-2), 48-60. doi.org/10.1007/s10488-010-0283-2

Atkins, M.S., Pelham, W.E., \& White, K.J. (1989). Hyperactivity and attention deficit disorders. In M. Hersen (Ed.), Psychological aspects of developmental and physical disabilities: A casebook (pp. 137-156). California: Sage Publications.

Ault-Brutus, A. A. (2012). Changes in Racial-Ethnic Disparities in Use and Adequacy of Mental Health Care in the United States, 1990-2003. Psychiatric Services, 63(6), 531-540. doi.org/10.1176/appi.ps.201000397

Balas, E. A., \& Boren, S. A. (2000). Managing clinical knowledge for health care improvement. Yearbook of Medical Informatics 2000: Patient-Centered Systems. Retrieved from https://augusta.openrepository.com/augusta/handle/10675.2/617990

Barrera, M., \& Castro, F. G. (2006). A Heuristic Framework for the Cultural Adaptation of Interventions. Clinical Psychology: Science and Practice, 13(4), 311-316. https://doi.org/10.1111/j.1468-2850.2006.00043.x 
Baumann, A. A., Domenech Rodríguez, M. M., Amador, N. G., Forgatch, M. S., \& ParraCardona, J. R. (2014). Parent Management Training-Oregon Model (РМТОтм) in Mexico City: Integrating Cultural Adaptation Activities in an Implementation Model. Clinical Psychology: A Publication of the Division of Clinical Psychology of the American Psychological Association, 21(1), 32-47. doi.org/10.1111/cpsp.12059

Becker, K. D., Darney, D., Domitrovich, C., Keperling, J. P., \& Ialongo, N. S. (2013). Supporting Universal Prevention Programs: A Two-Phased Coaching Model. Clinical Child and Family Psychology Review, 16(2), 213-228. doi.org/10.1007/s10567-013-0134-2

Bernal, G., Bonilla, J., \& Bellido, C. (1995). Ecological validity and cultural sensitivity for outcome research: Issues for the cultural adaptation and development of psychosocial treatments with Hispanics. Journal of Abnormal Child Psychology, 23(1), 67-82. doi.org/10.1007/BF01447045

Blanco, C., Patel, S. R., Liu, L., Jiang, H., Lewis-Fernández, R., Schmidt, A. B., ... Olfson, M. (2007). National Trends in Ethnic Disparities in Mental Health Care: Medical Care, 45(11), 1012-1019. doi.org/10.1097/MLR.0b013e3180ca95d3

Bussing, R., Zima, B. T., Gary, F. A., \& Garvan, C. W. (2003). Barriers to detection, helpseeking, and service use for children with ADHD symptoms. The Journal of Behavioral Health Services \& Research, 30(2), 176-189.

Calzada, E. J., Basil, S., \& Fernandez, Y. (2013). What Latina mothers think of evidence-based parenting practices: A qualitative study of treatment acceptability. Cognitive and Behavioral Practice, 20(3), 362-374.

Cappella, E., Hamre, B. K., Kim, H. Y., Henry, D. B., Frazier, S. L., Atkins, M. S., \& Schoenwald, S. K. (2012). Teacher consultation and coaching within mental health practice: Classroom and child effects in urban elementary schools. Journal of Consulting and Clinical Psychology, 80(4), 597. doi.org/10.1037/a0027725

Cappella, E., Jackson, D. R., Bilal, C., Hamre, B. K., \& Soulé, C. (2011). Bridging mental health and education in urban elementary schools: Participatory research to inform intervention development. School Psychology Review, 40(4), 486.

Cardona, J. P., Holtrop, K., Córdova, D., Escobar-Chew, A. R., Horsford, S., Tams, L., ... Fitzgerald, H. E. (2009). "Queremos aprender”: Latino immigrants' call to integrate cultural adaptation with best practice knowledge in a parenting intervention. Family Process, 48(2), 211-231.

Castro, F. G., Barrera, M., \& Holleran Steiker, L. K. (2010). Issues and Challenges in the Design of Culturally Adapted Evidence-Based Interventions. Annual Review of Clinical Psychology, 6, 213-239. doi.org/10.1146/annurev-clinpsy-033109-132032

Chafouleas, S. M., Riley-Tillman, T. C., \& Sassu, K. A. (2006). Acceptability and Reported Use of Daily Behavior Report Cards Among Teachers. Journal of Positive Behavior Interventions, 8(3), 174-182. doi.org/10.1177/10983007060080030601 
Coles, E. K., Owens, J. S., Serrano, V. J., Slavec, J., \& Evans, S. W. (2015). From consultation to student outcomes: The role of teacher knowledge, skills, and beliefs in increasing integrity in classroom management strategies. School Mental Health, 7(1), 34-48. http://dx.doi.org.ezproxy.fiu.edu/10.1007/s12310-015-9143-2

Cuellar, I., Arnold, B., \& Maldonado, R. (1995). Acculturation Rating Scale for Mexican Americans-II: A Revision of the Original ARSMA Scale. Hispanic Journal of Behavioral Sciences, 17(3), 275-304. doi.org/10.1177/07399863950173001

Darling-Hammond, L.. and Sykes, G.. (2003). Wanted: A national teacher supply policy for education: The right way to meet the "Highly Qualified Teacher" challenge. Education Policy Analysis Archives, 11(33). Retrieved [3/3/2019] from http://epaa.asu.edu/epaa/v11n33/.

Danielson, M. L., Bitsko, R. H., Ghandour, R. M., Holbrook, J. R., Kogan, M. D., \& Blumberg, S. J. (2018). Prevalence of Parent-Reported ADHD Diagnosis and Associated Treatment Among U.S. Children and Adolescents, 2016. Journal of Clinical Child \& Adolescent Psychology, 47(2), 199-212. doi.org/10.1080/15374416.2017.1417860

Domenech Rodríguez, M. M., Baumann, A. A., \& Schwartz, A. L. (2011). Cultural adaptation of an evidence based intervention: from theory to practice in a Latino/a community context. American Journal of Community Psychology, 47(1-2), 170-186. doi.org/10.1007/s10464-010-9371-4

Domenech Rodríguez, M. M., \& Bernal, G. (2012). Bridging the gap between research and practice in a multicultural world. In G. Bernal \& M. M. Domenech (Eds.), Cultural adaptations: Tools for evidence-based practice with diverse populations (pp. 265-287). Washington, DC, US: American Psychological Association.

Domenech-Rodriguez, M., \& Wieling, E. (2004). Developing culturally appropriate, evidencebased treatments for interventions with ethnic minority populations. Voices of Color: First Person Accounts of Ethnic Minority Therapists, 313-333.

Dorsey, S. W. (1997). The seven deadly sins of first-year teachers. Choral Journal, 38(4), 17.

DuPaul, G. J., Chronis-Tuscano, A., Danielson, M. L., \& Visser, S. N. (2018). Predictors of Receipt of School Services in a National Sample of Youth With ADHD. Journal of Attention Disorders, 1087054718816169. doi.org/10.1177/1087054718816169

Eiraldi, R., \& Diaz, Y. (2010). Use of Treatment Services for Attention-Deficit/Hyperactivity Disorder in Latino Children. Current Psychiatry Reports, 12(5), 403-408. doi.org/10.1007/s11920-010-0139-1

Evans, S. W., Owens, J., \& Bunford, M. N. (2014). Evidence-Based Psychosocial Treatments for Children and Adolescents with Attention-Deficit/Hyperactivity Disorder. Journal of Clinical Child and Adolescent Psychology: The Official Journal for the Society of Clinical Child and Adolescent Psychology, American Psychological Association, Division 53, 43(4), 527-551. doi.org/10.1080/15374416.2013.850700 
Fabiano, G. A., Pelham, W. E., Jr, Coles, E. K., Gnagy, E. M., Chronis-Tuscano, A., \& O'Connor, B. C. (2009). A meta-analysis of behavioral treatments for attentiondeficit/hyperactivity disorder. Clinical Psychology Review, 29(2), 129-140. doi.org/10.1016/j.cpr.2008.11.001

Fabiano, G. A., Vujnovic, R. K., Pelham, W. E., Waschbusch, D. A., Massetti, G. M., Pariseau, M. E., ... Volker, M. (2010). Enhancing the Effectiveness of Special Education Programming for Children With Attention Deficit Hyperactivity Disorder Using a Daily Report Card. School Psychology Review, 39(2), 219-239.

Fetters, M. D., Curry, L. A., \& Creswell, J. W. (2013). Achieving Integration in Mixed Methods Designs-Principles and Practices. Health Services Research, 48(6pt2), 2134-2156. doi.org/10.1111/1475-6773.12117

Fung, J., Guo, S., Jin, J., Bear, L., \& Lau, A. (2016). A Pilot Randomized Trial Evaluating a School-Based Mindfulness Intervention for Ethnic Minority Youth. Mindfulness, 7(4), 819-828. doi.org/10.1007/s12671-016-0519-7

Gerdes, A. C., Lawton, K. E., Haack, L. M., \& Hurtado, G. D. (2013). Assessing ADHD in Latino Families Evidence for Moving Beyond Symptomatology. Journal of Attention Disorders, 17(2), 128-140. doi.org/10.1177/1087054711427396

Gerdes, A. C., Lawton, K. E., Haack, L. M., \& Schneider, B. W. (2014). Latino parental help seeking for childhood ADHD. Administration and Policy in Mental Health, 41(4), 503513. doi.org/10.1007/s10488-013-0487-3

Glasgow, R.E. \& Rabin, B (2014). New and Future Directions in Implementation Science: Some Things to Consider in Your Next Grant or Two. Oral presentation given at the Colorado Health Outcomes Program/Department of Family Medicine, University of Colorado. Retrieved from:

http://www.ucdenver.edu/academics/colleges/medicalschool/programs/crisp/traini ng/Documents/CRISPSeminar_GlasgowRabin_1.13.14_archive\%20version.pptm

Gonzalez, J. E., Nelson, J. R., Gutkin, T. B., \& Shwery, C. S. (2004). Teacher Resistance to School-Based Consultation with School Psychologists: A Survey of Teacher Perceptions. Journal of Emotional and Behavioral Disorders, 12(1), 30-37. doi.org/10.1177/10634266040120010401

Hall, G. C. N., Ibaraki, A. Y., Huang, E. R., Marti, C. N., \& Stice, E. (2016). A meta-analysis of cultural adaptations of psychological interventions. Behavior Therapy, 47(6), 993-1014.

Hanf C. (1968). Modifying problem behaviors in mother-child interaction: Standardized laboratory situations. Paper presented at the Association of Behavior Therapies; Olympia, WA.

Harpin, V. A. (2005). The effect of ADHD on the life of an individual, their family, and community from preschool to adult life. Archives of Disease in Childhood, 90(suppl 1), i2-i7. doi.org/10.1136/adc.2004.059006 
Hartmann, D. P., \& Hall, R. V. (1976). The changing criterion design. Journal of Applied Behavior Analysis, 9(4), 527-532.

Hershfeldt, P. A., Pell, K., Sechrest, R., Pas, E. T., \& Bradshaw, C. P. (2012). Lessons Learned Coaching Teachers in Behavior Management: The PBISplus Coaching Model. Journal of Educational and Psychological Consultation: The Official Journal of the Association for Educational and Psychological Consultants, 22(4), 280-299. doi.org/10.1080/10474412.2012.731293

Hough, R. L., Hazen, A. L., Soriano, F. I., Wood, P., McCabe, K., \& Yeh, M. (2002). Mental health services for Latino adolescents with psychiatric disorders. Psychiatric Services (Washington, D.C.), 53(12), 1556-1562.

Hoy, W. K., Tarter, C. J., \& Kottkamp, R. B. (1991). Open schools, healthy schools: Measuring organizational climate. Corwin Press.

Humes, K. R., Jones, N. A., \& Ramirez, R. R. (n.d.). Overview of Race and Hispanic Origin: 2010. Washington, D.C: United States Census Bureau.

Jaycox, L. H., Cohen, J. A., Mannarino, A. P., Walker, D. W., Langley, A. K., Gegenheimer, K. L., ... Schonlau, M. (2010). Children's mental health care following Hurricane Katrina: a field trial of trauma-focused psychotherapies. Journal of Traumatic Stress, 23(2), 223231. doi.org/10.1002/jts.20518

Kaehler, L. A., Jacobs, M., \& Jones, D. J. (2016). Distilling Common History and Practice Elements to Inform Dissemination: Hanf-Model BPT Programs as an Example. Clinical Child and Family Psychology Review, 19(3), 236-258. doi.org/10.1007/s10567-0160210-5

Khoury, M. J., Gwinn, M., Yoon, P. W., Dowling, N., Moore, C. A., \& Bradley, L. (2007). The continuum of translation research in genomic medicine: how can we accelerate the appropriate integration of human genome discoveries into health care and disease prevention? Genetics in Medicine: Official Journal of the American College of Medical Genetics, 9(10), 665-674. doi.org/10.1097GIM.0b013e31815699d0

Kim, B. S. K., Soliz, A., Orellana, B., \& Alamilla, S. G. (2009). Latino/a Values Scale: Development, Reliability, and Validity. Measurement and Evaluation in Counseling and Development, 42(2), 71-91. doi.org/10.1177/0748175609336861

Langley, A., Santiago, C. D., Rodríguez, A., \& Zelaya, J. (2013). Improving Implementation of Mental Health Services for Trauma in Multicultural Elementary Schools: Stakeholder Perspectives on Parent and Educator Engagement. The Journal of Behavioral Health Services \& Research, 40(3), 247-262. doi.org/10.1007/s11414-013-9330-6

Lawton, K. E., Gerdes, A. C., Haack, L. M., \& Schneider, B. (2014). Acculturation, Cultural Values, and Latino Parental Beliefs About the Etiology of ADHD. Administration and Policy in Mental Health and Mental Health Services Research, 41(2), 189-204. doi.org/10.1007/s10488-012-0447-3 
Lê Cook, B., Zuvekas, S. H., Carson, N., Wayne, G. F., Vesper, A., \& McGuire, T. G. (2014). Assessing Racial/Ethnic Disparities in Treatment across Episodes of Mental Health Care. Health Services Research, 49(1), 206-229. doi.org/10.1111/1475-6773.12095

Loe, I. M., \& Feldman, H. M. (2007). Academic and Educational Outcomes of Children With ADHD. Ambulatory Pediatrics, 7(1, Supplement), 82-90. doi.org/10.1016/j.ambp.2006.05.005

Matos, M., Torres, R., Santiago, R., Jurado, M., \& Rodríguez, I. (2006). Adaptation of parentchild interaction therapy for Puerto Rican families: a preliminary study. Family Process, $45(2), 205-222$.

Mejia, A., Leijten, P., Lachman, J. M., \& Parra-Cardona, J. R. (2016). Different Strokes for Different Folks? Contrasting Approaches to Cultural Adaptation of Parenting Interventions. Prevention Science. doi.org/10.1007/s11121-016-0671-2

Mehta, T. G., Atkins, M. S., \& Frazier, S. L. (2013). The Organizational Health of Urban Elementary Schools: School Health and Teacher Functioning. School mental health, 5(3), 144-154. doi:10.1007/s12310-012-9099-4

Metzler, C. W., Sanders, M. R., Rusby, J. C., \& Crowley, R. N. (2012). Using Consumer Preference Information to Increase the Reach and Impact of Media-Based Parenting Interventions in a Public Health Approach to Parenting Support. Behavior Therapy, 43(2), 257-270. doi.org/10.1016/j.beth.2011.05.004

Miller, W. R., \& Rollnick, S. (2012). Motivational Interviewing, Third Edition: Helping People Change (Third Edition edition). New York, NY: The Guilford Press.

Moilanen, K. L., Shaw, D. S., \& Maxwell, K. L. (2010). Developmental cascades: externalizing, internalizing, and academic competence from middle childhood to early adolescence. Development and psychopathology, 22(3), 635-653.

Mojtabai, R., Olfson, M., Sampson, N. A., Jin, R., Druss, B., Wang, P. S., ... Kessler, R. C. (2011). Barriers to mental health treatment: results from the National Comorbidity Survey Replication. Psychological Medicine, 41(8), 1751-1761. doi.org/10.1017/S0033291710002291

Molina, B. S., Hinshaw, S. P., Swanson, J. M., Arnold, L. E., Vitiello, B., Jensen, P. S., ... Abikoff, H. B. (2009). The MTA at 8 years: prospective follow-up of children treated for combined-type ADHD in a multisite study. Journal of the American Academy of Child \& Adolescent Psychiatry, 48(5), 484-500.

National Center for Education Statistics, U. S. D. of E. (2010). Schools and Staffing Survey (SASS); Public School Teacher, BIE School Teacher, and Private School Teacher Data Files, 2007-08. Washington, D.C: National Center for Education Statistics.

O'Leary, K. D., Pelham, W. E., Rosenbaum, A., \& Price, G. H. (1976). Behavioral treatment of hyperkinetic children. An experimental evaluation of its usefulness. Clinical Pediatrics, 15(6), 510-515. doi.org/10.1177/000992287601500603 
Owens, J. S., Coles, E. K., Evans, S. W., Himawan, L. K., Girio-Herrera, E., Holdaway, A. S., ... Schulte, A. C. (2017). Using Multi-component Consultation to Increase the Integrity with Which Teachers Implement Behavioral Classroom Interventions: A Pilot Study. School Mental Health, 1-17. doi.org/10.1007/s12310-017-9217-4

Page, T. F., Pelham, W. E., Fabiano, G. A., Greiner, A. R., Gnagy, E. M., Hart, K. C., ... Pelham, W. E. (2016). Comparative Cost Analysis of Sequential, Adaptive, Behavioral, Pharmacological, and Combined Treatments for Childhood ADHD. Journal of Clinical Child and Adolescent Psychology: The Official Journal for the Society of Clinical Child and Adolescent Psychology, American Psychological Association, Division 53, 45(4), 416-427. doi.org/10.1080/15374416.2015.1055859

Perloff, R. M. (2016). The dynamics of persuasion: communication and attitudes in the twentyfirst century. Routledge.

Paidipati, C. P., Brawner, B., Eiraldi, R., \& Deatrick, J. A. (2017). Parent and Family Processes Related to ADHD Management in Ethnically Diverse Youth. Journal of the American Psychiatric Nurses Association, 23(2), 90-112. doi.org/10.1177/1078390316687023

Palinkas, L. A., Aarons, G. A., Horwitz, S., Chamberlain, P., Hurlburt, M., \& Landsverk, J. (2011). Mixed method designs in implementation research. Administration and Policy in Mental Health, 38(1), 44-53. doi.org/10.1007/s10488-010-0314-z

Parra Cardona, J. R., Domenech-Rodriguez, M., Forgatch, M., Sullivan, C., Bybee, D., Holtrop, K., ... Bernal, G. (2012). Culturally Adapting an Evidence-Based Parenting Intervention for Latino Immigrants: The Need to Integrate Fidelity and Cultural Relevance. Family Process, 51(1), 56-72. doi.org/10.1111/j.1545-5300.2012.01386.x

Parra-Cardona, J. R., López-Zerón, G., Villa, M., Zamudio, E., Escobar-Chew, A. R., \& Rodríguez, M. M. D. (2017). Enhancing Parenting Practices with Latino/a Immigrants: Integrating Evidence-Based Knowledge and Culture According to the Voices of Latino/a Parents. Clinical Social Work Journal, 45(1), 88-98. doi.org/10.1007/s10615-016-0589-y

Pelham Jr., W. E. P., Fabiano, G. A., Waxmonsky, J. G., Greiner, A. R., Gnagy, E. M., III, W. E. P., ... Murphy, S. A. (2016). Treatment Sequencing for Childhood ADHD: A MultipleRandomization Study of Adaptive Medication and Behavioral Interventions. Journal of Clinical Child \& Adolescent Psychology, 45(4), 396-415. doi.org/10.1080/15374416.2015.1105138

Pelham, W. E., Foster, E. M., \& Robb, J. A. (2007). The economic impact of attentiondeficit/hyperactivity disorder in children and adolescents. Ambulatory Pediatrics: The Official Journal of the Ambulatory Pediatric Association, 7(1 Suppl), 121-131. doi.org/10.1016/j.ambp.2006.08.002

Pelsma, D. M., Richard, G. V., Harrington, R. G., \& Burry, J. M. (1989). The Quality of Teacher Work Life Survey: A measure of teacher stress and job satisfaction. Measurement and Evaluation in Counseling and Development. Retrieved from http://psycnet.apa.org.ezproxy.fiu.edu/psycinfo/1989-24635-001 
Perry, C. E., Hatton, D., \& Kendall, J. (2005). Latino Parents' Accounts of Attention Deficit Hyperactivity Disorder. Journal of Transcultural Nursing, 16(4), 312-321. doi.org/10.1177/1043659605278938

Proctor, E., Silmere, H., Raghavan, R., Hovmand, P., Aarons, G., Bunger, A., ... Hensley, M. (2011). Outcomes for Implementation Research: Conceptual Distinctions, Measurement Challenges, and Research Agenda. Administration and Policy in Mental Health, 38(2), 65-76. doi.org/10.1007/s10488-010-0319-7

Pyle, K., \& Fabiano, G. A. (2017). Daily Report Card Intervention and Attention Deficit Hyperactivity Disorder: A Meta-Analysis of Single-Case Studies. Exceptional Children, 83(4), 378-395. doi.org/10.1177/0014402917706370

Rapport, M. D., Murphy, H. A., \& Bailey, J. S. (1982). Ritalin vs. response cost in the control of hyperactive children: a within-subject comparison. Journal of Applied Behavior Analysis, 15(2), 205-216. doi.org/10.1901/jaba.1982.15-205

Resnicow, K., Soler, R., Braithwaite, R. L., Ahluwalia, J. S., \& Butler, J. (2000). Cultural sensitivity in substance use prevention. Journal of Community Psychology, 28(3), 271290. doi.org/10.1002/(SICI)1520-6629(200005)28:3<271::AID-JCOP4>3.0.CO;2-I

Roberts, T. L. (2010). You can smile! Classroom management tips. Middle Ground, 13(3), 18.

Rogers, C. R., \& Farson, R. (1957). Active listening. Chicago. IL: Industrial Relations Center of The University of Chicago.

Rosen, L. A., O'Leary, S. G., \& Conway, G. (1985). The withdrawal of stimulant medication for hyperactivity: Overcoming detrimental attributions. Behavior Therapy, 16(5), 538-544. doi.org/10.1016/S0005-7894(85)80032-0

Sheridan, S. M., Bovaird, J. A., Glover, T. A., Garbacz, S. A., Witte, A., \& Kwon, K. (2012). A Randomized Trial Examining the Effects of Conjoint Behavioral Consultation and the Mediating Role of the Parent-Teacher Relationship. School Psychology Review, 41(1).

Sheridan, S. M., Eagle, J. W., \& Doll, B. (2006). An examination of the efficacy of conjoint behavioral consultation with diverse clients. School Psychology Quarterly, 21(4), 396417. doi.org/10.1037/h0084130

Sheridan, S. M., Holmes, S. R., Coutts, M. J., \& Smith, T. E. (2012). Preliminary Effects of Conjoint Behavioral Consultation in Rural Communities. CYFS Working Paper No. 2012-8. Nebraska Center for Research on Children, Youth, Families and Schools.

Sheridan, S. M., Holmes, S. R., Smith, T. E., \& Moen, A. L. (2016). Complexities in Field-Based Partnership Research: Exemplars, Challenges, and an Agenda for the Field. In S. M. Sheridan \& E. Moorman Kim (Eds.), Family-School Partnerships in Context (pp. 1-23). Cham: Springer International Publishing. Retrieved from http://link.springer.com/10.1007/978-3-319-19228-4_1 
Shernoff, E. S., Lakind, D., Frazier, S. L., \& Jakobsons, L. (2014). Coaching Early Career Teachers in Urban Elementary Schools: A Mixed-Method Study. School Mental Health, 7(1), 6-20. doi.org/10.1007/s12310-014-9136-6

Shernoff, E. S., Lekwa, A. J., Reddy, L. A., \& Coccaro, C. (2017). Examining Teachers' Attitudes and Experiences with Coaching to Inform Research-Based Practice: An Iterative Developmental Design Study. Journal of Educational and Psychological Consultation, O(0), 1-27. doi.org/10.1080/10474412.2016.1255850

Smith, T. B., Rodríguez, M. D., \& Bernal, G. (2011). Culture. Journal of Clinical Psychology, 67(2), 166-175. doi.org/10.1002/jclp.20757

Still, G.F. (1902). Some abnormal psychical conditions in children: the Goulstonian lectures. Lancet (1), 1008-1012.

IBM Corp. (2017). IBM SPSS Statistics for Windows, Version 25.0. Armonk, NY: IBM Corp.

The MTA Cooperative Group. (1999). A 14-month randomized clinical trial of treatment strategies for attention-deficit/hyperactivity disorder. The MTA Cooperative Group. Multimodal Treatment Study of Children with ADHD. Archives of General Psychiatry, 56(12), 1073-1086.

Villatoro, A. P., Morales, E. S., \& Mays, V. M. (2014). Family Culture in Mental Health HelpSeeking and Utilization in a Nationally Representative Sample of Latinos in the United States: The NLAAS. The American Journal of Orthopsychiatry, 84(4), 353-363. doi.org/10.1037/h0099844

Volpe, R. J., \& Fabiano, G. A. (2013). Daily behavior report cards: an evidence-based system of assessment and intervention.

Wallinger, L. M. (1997). Don't smile before Christmas: The role of humor in education. NASSP Bulletin, 81(589), 27-34.

Wang PS, Lane M, Olfson M, Pincus HA, Wells KB, \& Kessler RC. (2005). Twelve-month use of mental health services in the united states: Results from the national comorbidity survey replication. Archives of General Psychiatry, 62(6), 629-640. doi.org/10.1001/archpsyc.62.6.629

Watson, J. B. (1913). Psychology as the behaviorist views it. Psychological Review, 20(2), 158. doi.org/10.1037/h0074428

Westfall, J. M., \& Mensah, G. A. (2018). T4 Translational Moonshot: Making Cardiovascular Discoveries Work for Everyone. Circulation Research, 122(2), 210-212. doi.org/10.1161/CIRCRESAHA.117.312273

Witt, J. C. (1986). Teachers' resistance to the use of school-based interventions. Journal of School Psychology, 24(1), 37-44. doi.org/10.1016/0022-4405(86)90040-3 
Woodward, A. M., Dwinell, A. D., \& Arons, B. S. (1992). Barriers to mental health care for hispanic americans: A literature review and discussion. The Journal of Mental Health Administration, 19(3), 224-236. /doi.org/10.1007/BF02518988 
Table 1. The Slow Pace of Translation from Science to Practice in the Field of ADHD Treatment

\begin{tabular}{crl}
\hline Phase & Year & Discovering practical solutions: a long journey \\
\hline T0 & 1902 & Sir George Still (1902): Described 20 cases of 'defect of moral control' \\
T1 & 1913 & John B. Watson (1913): "Psychology as the Behaviorist Views it" \\
T1/T2 & 1968 & Constance Hanf (1968): "Modifying problem beh. in mother-child interactions" \\
T2 & 1999 & Main Findings (1999): Multimodal Treatment Study of Children with ADHD \\
T3 & 2008 & Atkins et al. (2008): “Teacher Key Opinion Leaders...” \\
T4 & 2018 & Danielson et al. (2018): Only 30\% (lifetime) children w/ ADHD received beh. parent training \\
\hline
\end{tabular}

Note: Phase $=$ Phase of translational research (Westfall \& Mensah, 2018) 
Table 2. Characteristics of Participating Teachers

\begin{tabular}{|c|c|c|}
\hline & $\begin{array}{c}\text { Full Sample } \\
(n=23)\end{array}$ & $M(S D)$ \\
\hline \multicolumn{3}{|l|}{ Demographic Variables } \\
\hline Age in years & & $\begin{array}{c}38.65 \\
(17.94)\end{array}$ \\
\hline \multicolumn{3}{|l|}{ Gender } \\
\hline Female & $22(96 \%)$ & \\
\hline \multicolumn{3}{|l|}{ Race } \\
\hline White & $23(100 \%)$ & \\
\hline Black & $0(0 \%)$ & \\
\hline Mixed race/other & $0(0 \%)$ & \\
\hline \multicolumn{3}{|l|}{ Ethnicity } \\
\hline Hispanic/Latino & $23(100 \%)$ & \\
\hline \multicolumn{3}{|l|}{ Educational Background } \\
\hline Bachelors Degree (BA/BS) & $9(39 \%)$ & \\
\hline Masters Degree, (MA/MS) & $10(44 \%)$ & \\
\hline Masters Degree, ((Ed.S/Ed.M/Ed.D) & $4(17 \%)$ & \\
\hline \multicolumn{3}{|l|}{ Acculturation } \\
\hline Anglo Orientation Scale & & $4.30(0.33)$ \\
\hline Latina/o Orientation Scale & & $3.07(0.62)$ \\
\hline \multicolumn{3}{|l|}{ Latino/a Values Scale } \\
\hline Cultural Pride & & $2.59(0.22)$ \\
\hline Simpatia & & $2.53(0.44)$ \\
\hline Familialismo & & $3.23(0.62)$ \\
\hline Espiritismo & & $2.14(0.57)$ \\
\hline Overall/Total Score & & $2.65(0.21)$ \\
\hline \multicolumn{3}{|l|}{ Years of Teaching Experience } \\
\hline Overall & & $21.48(8.56)$ \\
\hline At this current Elementary School $[M(\mathrm{SD})]$ & & $14.48(4.89)$ \\
\hline \multicolumn{3}{|l|}{ Quality of Teacher Work Life Survey Scores } \\
\hline Satisfaction & & $3.58(0.50)$ \\
\hline Stress & & $3.76(0.57)$ \\
\hline \multicolumn{3}{|c|}{ Survey of Teachers' Negative Beliefs About Behavioral Strategies* } \\
\hline Average across 24 items & & $2.78(0.49)$ \\
\hline
\end{tabular}

Note: *Teachers’ Negative Beliefs about Behavioral Strategies = Project-developed measure (e.g.,

"Learning about new behavioral interventions is not worth my time"), Likert scale ranging from 1, Strongly

Disagree, to 6 Strongly Agree 
Table 3. Characteristics of Students Enrolled

\begin{tabular}{|c|c|c|}
\hline & $\begin{array}{l}\text { Full Sample } \\
\qquad(n=48)\end{array}$ & $M(S D)$ \\
\hline Age in years & & $8.38(1.39)$ \\
\hline \multicolumn{3}{|l|}{ Gender } \\
\hline Male & $35(71 \%)$ & \\
\hline \multicolumn{3}{|l|}{ Race } \\
\hline White & $46(96 \%)$ & \\
\hline Black & $0(0 \%)$ & \\
\hline Other & $2(4 \%)$ & \\
\hline \multicolumn{3}{|l|}{ Ethnicity } \\
\hline Hispanic/Latino & $47(98 \%)$ & \\
\hline \multicolumn{3}{|l|}{ Language Spoken in the Home } \\
\hline Spanish & $17(41 \%)$ & \\
\hline English & $20(48 \%)$ & \\
\hline Both English and Spanish & $4(9 \%)$ & \\
\hline Other & $1(2 \%)$ & \\
\hline \multicolumn{3}{|l|}{ Marital Status of Parent/Caregiver } \\
\hline Married & $19(45 \%)$ & \\
\hline Currently Single/Unmarried & $23(55 \%)$ & \\
\hline \multicolumn{3}{|c|}{ Educational Attainment of Parent/Caregiver } \\
\hline High School & $8(19 \%)$ & \\
\hline Some College & $10(24 \%)$ & \\
\hline Associates Degree & $10(24 \%)$ & \\
\hline Bachelors Degree & $7(17 \%)$ & \\
\hline Masters Degree & $2(5 \%)$ & \\
\hline Advanced Degree (JD, MD, Ph.D.) & $1(2 \%)$ & \\
\hline Technical Degree/Certificate & $4(9 \%)$ & \\
\hline \multicolumn{3}{|l|}{ Family Income } \\
\hline Less than $\$ 19,999$ & $11(26 \%)$ & \\
\hline Between $\$ 20,000-\$ 29,999$ & $8(19 \%)$ & \\
\hline Between $\$ 30,000-\$ 39,999$ & $4(10 \%)$ & \\
\hline Between $\$ 40,000-\$ 49,999$ & $8(19 \%)$ & \\
\hline Between $\$ 50,000-\$ 59,999$ & $1(2 \%)$ & \\
\hline Between $\$ 60,000-\$ 69,999$ & $3(7 \%)$ & \\
\hline Above $\$ 70,000$ & $7(17 \%)$ & \\
\hline \multicolumn{3}{|c|}{ Parent Disruptive Behavior Disorders Rating (\# of Symptoms) } \\
\hline ADHD-Inattention & & $5.54(2.62)$ \\
\hline ADHD-Hyperactive/Impulsive & & $4.70(3.00)$ \\
\hline Oppositional Defiant Disorder & & $2.83(2.53)$ \\
\hline Conduct Disorder & & $0.50(1.13)$ \\
\hline
\end{tabular}


Teacher Disruptive Behavior Disorders Rating (\# of Symptoms)

ADHD-Inattention

$6.11(2.88)$

ADHD-Hyperactive/Impulsive

$5.37(3.11)$

Oppositional Defiant Disorder

$1.89(2.06)$

Conduct Disorder

$0.48(1.03)$ 
Table 4. Frequency Counts of Number of Excerpts Per Code and of Number of

Teachers Who Cited That Code (Out of 23 Interviews with Teachers)

\begin{tabular}{cc} 
Interviews & Total \\
Cited & Number of \\
$(N=23)$ & Excerpts \\
\hline
\end{tabular}

\section{Overarching theme 1: Teacher's ATTITUDES toward the DRC}

$\begin{array}{lll}\text { Theme 1.1: Positive attitudes toward the DRC } & 23 & 105\end{array}$

-Everything is "perfect" with the DRC $\quad 1928$

$\begin{array}{lll}\text {-Positive Reinforcement works } & 23 & 27\end{array}$

$\begin{array}{lll}\text {-DRC works because everyone has to follow the rules } & 19 & 19\end{array}$

$\begin{array}{lll}\text {-"Respeto" Respect is important, possible to target with DRC } & 11\end{array}$

-"That's life" - DRC teaches you have to work to get what you want 12

$\begin{array}{lll}\text { Theme 1.2: Negative attitudes toward the DRC } & 13 & 69\end{array}$

$\begin{array}{lll}\text {-DRC doesn't work without engaged students/parents } & 10 & 35\end{array}$

$\begin{array}{lll}\text {-Students should behave on their own without teachers rewarding } & 14 & 20\end{array}$

every little thing
-Sometimes student is engaged, but the DRC just doesn't work anyway

$13 \quad 14$

Theme 1.3: Mixed success with the DRC $\quad 23 \quad 125$

-PROBLEM: It depends on the student, sometimes DRC doesn't work $\quad 23 \quad 69$

-SOLUTION: DRC is adaptable/individualizable $\quad 22 \quad 42$

-SOLUTION: DRC is compatible with uniqueness in the classroom $\quad 19 \quad 14$

\section{Overarching theme 2: Perceived behavioral control}

$\begin{array}{lll}\text { Theme 2.1: High self-efficacy } & 23 & 157\end{array}$

$\begin{array}{lll}\text {-Self-efficacy } & 23 & 81\end{array}$

$\begin{array}{lll}\text {-Familiar with/have helpful ideas about Design Quality/Packaging } & 19 & 41\end{array}$

$\begin{array}{lll}\text {-Knowledgeable about culture } & 13 & 18\end{array}$

-Relative Advantage: DRC is the cherry on top of my good behavior $\quad 4 \quad 9$

management skills

-Low complexity $\quad 4 \quad 8$

Theme 2.2: Low controllability $\quad 22 \quad 123$

-SOLUTION: Pick our battles $\quad 22 \quad 55$

-PROBLEM: Few Available Resources in a Title I school $\quad 22 \quad 38$

$\begin{array}{lll}\text {-SOLUTION: Consultants who are "always here" onsite } & 20 & 30\end{array}$

Note: $\mathrm{DRC}=$ Daily Report Card 
Table 5. Joint Display Table: Individual-level Teacher Data Describing Intervention Participation and Satisfaction, as well as Most Frequently Cited Thematic Code During Semi-Structured Interview

\begin{tabular}{|c|c|c|c|c|c|c|c|c|}
\hline $\begin{array}{l}\text { Teacher } \\
\text { ID } \\
\text { Number }\end{array}$ & $\begin{array}{c}\text { \# of DRC } \\
\text { meetings }\end{array}$ & $\begin{array}{c}\text { Total } \\
\text { Resched/NS }\end{array}$ & $\begin{array}{c}\text { Min per } \\
\text { meeting } \\
M(S D)\end{array}$ & $\begin{array}{c}\text { Total \# } \\
\text { DRC } \\
\text { Students }\end{array}$ & $\begin{array}{l}\text { DRC Perc. } \\
\text { Completed }\end{array}$ & $\begin{array}{c}\text { DRC } \\
\text { Tool } \\
\text { Satisfact }\end{array}$ & $\begin{array}{c}\text { DRC } \\
\text { Meet } \\
\text { Satisfact }\end{array}$ & Most Frequently Cited Thematic Code \\
\hline$\# 1$ & 6 & 1 & $30.8(9.7)$ & 2 & $85 \%$ & 4.60 & 3.70 & It depends on the student \\
\hline \#2 & 7 & 0 & $32.9(9.5)$ & 2 & $93 \%$ & 4.90 & 5.20 & It depends on the student \\
\hline \#3 & 2 & 0 & $40.0(7.1)$ & 1 & Ticket* & 5.00 & 5.00 & Self-efficacy \\
\hline \#4 & 5 & 0 & $24.4(7.4)$ & 4 & $78 \%$ & 4.10 & 5.00 & Everything is "perfect" with the DRC \\
\hline \#5 & 7 & 1 & $15.0(5.0)$ & 5 & $72 \%$ & 4.40 & 4.70 & It depends on the student \\
\hline \#6 & 3 & 3 & $30.0(0.0)$ & 2 & $97 \%$ & - & - & Consultants "always here" onsite \\
\hline$\# 7$ & 9 & 1 & $22.0(6.9)$ & 2 & $80 \%$ & 5.00 & 5.00 & Pick our battles \\
\hline \#8 & 8 & 0 & $14.4(5.0)$ & 5 & $72 \%$ & 5.00 & 5.00 & Consultants "always here" onsite \\
\hline$\# 9$ & 5 & 2 & $17.4(8.9)$ & 1 & $51 \%$ & 5.00 & 5.00 & Self-efficacy \\
\hline \#10 & 3 & 0 & $18.3(7.6)$ & 1 & $91 \%$ & 4.80 & 4.50 & Few available resources \\
\hline \#11 & 3 & 0 & $18.3(2.9)$ & 1 & $69 \%$ & 5.00 & 4.00 & Adaptability \\
\hline$\# 12$ & 9 & 1 & $19.3(7.1)$ & 6 & $98 \%$ & 3.80 & 4.80 & Design quality/packaging \\
\hline \#13 & 2 & 0 & $17.5(10.6)$ & 1 & $91 \%$ & 4.80 & 5.00 & It depends on the student \\
\hline \#14 & 3 & 0 & $23.3(18.9)$ & 1 & $80 \%$ & 5.90 & 6.00 & Self-efficacy \\
\hline \#15 & 3 & 0 & $20.0(7.1)$ & 3 & $69 \%$ & 4.80 & 4.90 & It depends on the student \\
\hline \#16 & 5 & 1 & $31.0(5.5)$ & 2 & $89 \%$ & 5.20 & 5.00 & Pick our battles \\
\hline \#17 & 1 & 0 & $25.0(0.0)$ & 2 & $78 \%$ & 5.60 & 6.00 & It depends on the student \\
\hline \#18 & 4 & 0 & $21.3(8.5)$ & 2 & $96 \%$ & 4.70 & 5.60 & Self-efficacy \\
\hline \#19 & 4 & 0 & $25.0(14.1)$ & 1 & $59 \%$ & 3.50 & 3.20 & It depends on the student \\
\hline$\# 20$ & 6 & 0 & $13.2(7.8)$ & 3 & $88 \%$ & 4.90 & 5.00 & Few available resources \\
\hline \#21 & 4 & 1 & $20.3(2.4)$ & 2 & $77 \%$ & 5.10 & 4.60 & Few available resources \\
\hline$\# 22$ & 4 & 0 & $32.0(9.6)$ & 3 & $88 \%$ & 6.00 & 6.00 & Self-efficacy \\
\hline$\# 23$ & 3 & 0 & $36.0(6.6)$ & 3 & $88 \%$ & 4.80 & 5.00 & Design quality/packaging \\
\hline
\end{tabular}

Note: Ticket=Used ticket reward system instead of DRC (unable to calculate perc.); \# of DRC meetings= Number of Daily Report

Card (DRC)/behavioral consultation meetings attended; Total Resched/NS=Total number of DRC meetings rescheduled/no shows;

Min per meeting= Total number of minutes per DRC meeting; Total \# DRC Students; Total number of students per teacher with a

DRC; DRC Perc. Completed= Percentage of DRCs completed daily for one student per teacher selected at random; DRC Tool

Satisfact $=$ Out of 6, the Mean Satisfaction with the DRC tool itself on the Intervention Rating Profile-10 (IRP-10); DRC Meet

Satisfact= Out of 6, the Mean Satisfaction with the DRC Meetings on IRP-10 
Time of Day

Before school $33 \%$

Planning period $21 \%$

Lunch Break $16 \%$

Afterschool 29\%

Location

Classroom

$83 \%$

Library

$9 \%$

Hallway

$5 \%$

Other

$3 \%$

Note: Staff noted that many brief meetings took place in the hallway that were less than 5 minutes in duration; only those greater than 5 minutes were recorded herein 
Table 7. Teachers' Consumer Preferences: Reported interest in getting information about new strategies or recommendations to inform their work with students with behavior and/or attention problems

Full Sample

$(n=23)$

Interest in Formats*

Attending formal trainings/workshops [M(SD)]

$3.23(1.02)$

Reading materials (i.e., books, newsletters) $[M(\mathrm{SD})]$

$3.05(0.84)$

Meetings with a consultant $[M(\mathrm{SD})]$

$3.00(0.98)$

Through website(s) online/an application (i.e., an app) [M(SD)]

$3.18(0.96)$

From other teachers $[M(\mathrm{SD})]$

$3.36(1.00)$

Through trial and error $[M(\mathrm{SD})]$

$2.77(0.75)$

Through email $[M(\mathrm{SD})]$

$3.73(0.83)$

Note: Rated on Likert scale ranging from 1, Not at all Interested, to 5 Extremely Interested 
Table 8. Bivariate Correlations Among Study Variables.

\begin{tabular}{|c|c|c|c|c|c|c|c|c|c|c|c|}
\hline & 1 & 2 & 3 & 4 & 5 & 6 & 7 & 8 & 9 & 10 & 11 \\
\hline 1. \# yrs teach experience & 1 & - & - & - & - & - & - & - & - & - & - \\
\hline 2. IRP-10 DRC Rating & -.062 & 1 & - & - & - & - & - & - & - & - & - \\
\hline 3. Teacher Beliefs & -.317 & -.218 & 1 & - & - & - & - & - & - & - & - \\
\hline 4. Work-life Satis. & $.526^{*}$ & .111 & -.337 & 1 & - & - & - & - & - & - & - \\
\hline 5. Work-life Stress & $.429 *$ & .323 & -.120 & $.773 *$ & 1 & - & - & - & - & - & - \\
\hline 6. Latinx Orientat. & .147 & .241 & -.045 & .078 & .249 & 1 & - & - & - & - & - \\
\hline 7. Anglo Orientat. & .502 & -.208 & -.107 & .410 & .276 & -.367 & 1 & - & - & - & - \\
\hline 8. Latina/o Values & -.015 & .401 & -.209 & .206 & .244 & .282 & -.078 & - & - & - & - \\
\hline 9. DRC \% Completed & .401 & .106 & .019 & $.507 *$ & $.453 *$ & .199 & -.079 & .038 & 1 & - & - \\
\hline 10. Total \# of Meetings & $.452 *$ & -.342 & -.071 & .066 & .141 & .144 & .032 & -.106 & .047 & 1 & - \\
\hline 11. \# Students w/ DRCs & -.147 & -.315 & -.068 & -.110 & -.103 & .098 & -.119 & -.104 & .162 & $.617 *$ & 1 \\
\hline
\end{tabular}

Note: yrs = years; IRP-10 = Intervention Rating Profile-10; satis. = satisfaction; orientat. = orientation; DRC $=$ Daily Report Card $* p<.05$ 
Figure 1. The Cycle of Translational Research, adapted from Glasgow \& Rabin (2014); Khoury et al. (2007); Khoury et al. (2011); Westfall et al. (2007); and Westfall \& Mensah, (2018)

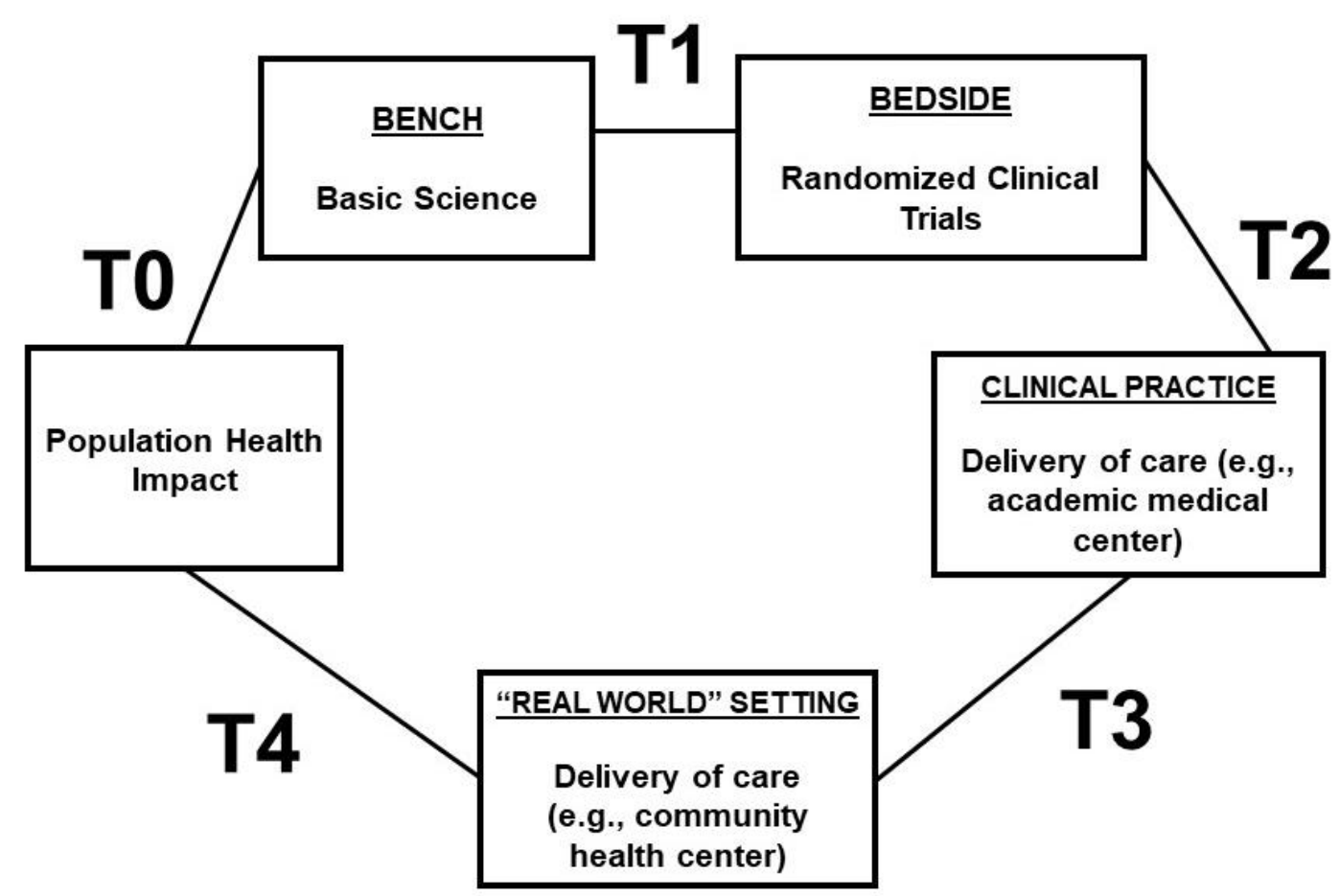


Figure 2. Example Daily Report Card

\begin{tabular}{|c|c|c|c|}
\hline Child's I & $\begin{array}{l}\text { Classroom Daily Re } \\
\text { e: Jeffrey }\end{array}$ & ort Card & \\
\hline & & $\begin{array}{c}\text { Percent } \\
\text { Correct or } \\
\text { \# of tallies? }\end{array}$ & Met goal? \\
\hline & Stay on Task & & \\
\hline & $\begin{array}{l}\text { Stays on Task w/ } 3 \\
\text { or fewer reminders }\end{array}$ & & YES \\
\hline & AM Accuracy & & \\
\hline & $\begin{array}{l}\text { Morning classwork } \\
\text { complete w/ } 75 \% \text { acc }\end{array}$ & & \\
\hline & PM Accuracy & & \\
\hline & $\begin{array}{l}\text { Afternoon classwork } \\
\text { complete w/ } 75 \% \text { acc }\end{array}$ & & \\
\hline $100 \%$ & written in agenda & NO & \\
\hline Parent & ature: & & \\
\hline
\end{tabular}


Figure 3. Thematic Map

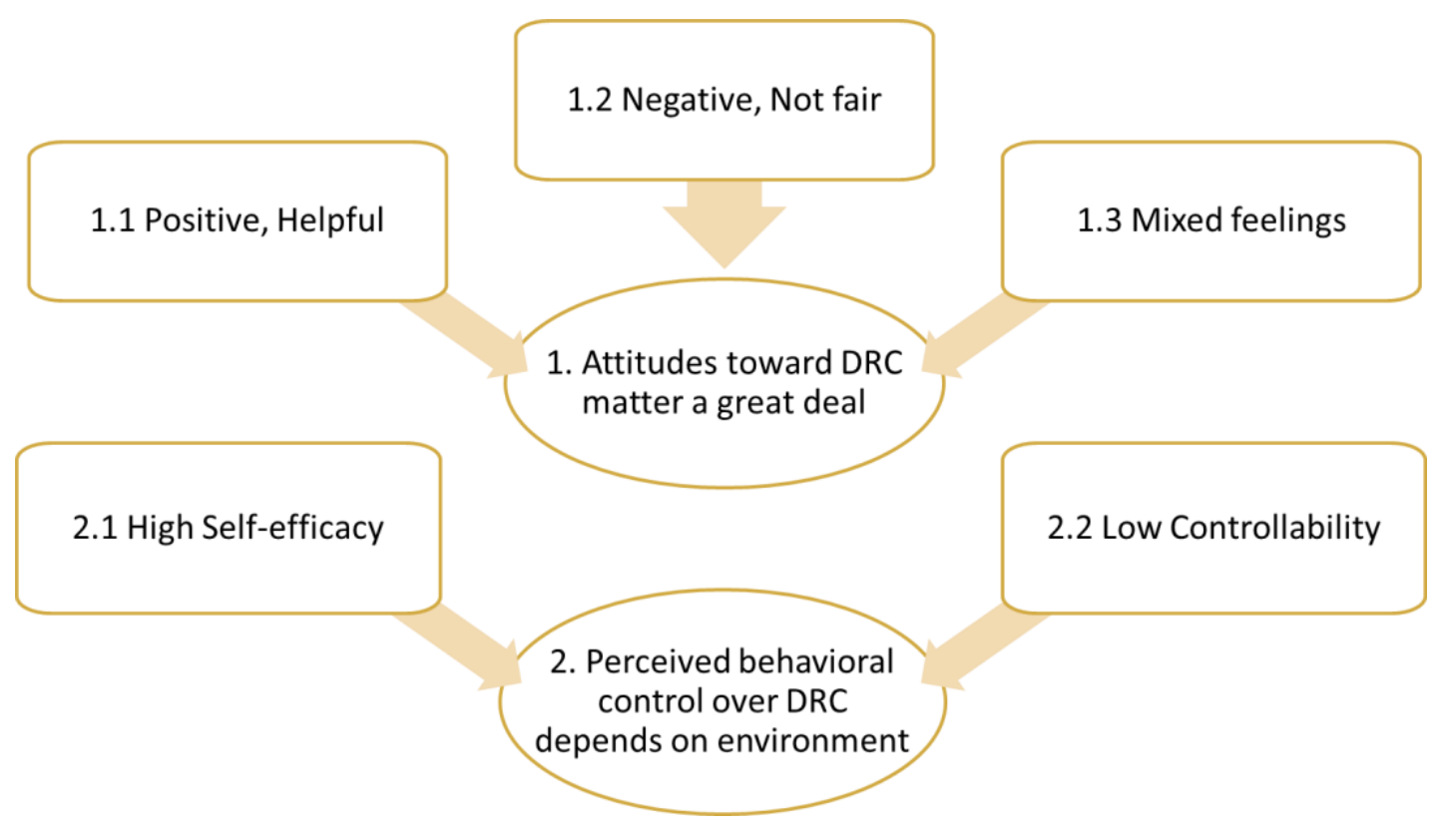


Figure 4. Daily Report Card Rubber Stamp Prototype; View 1

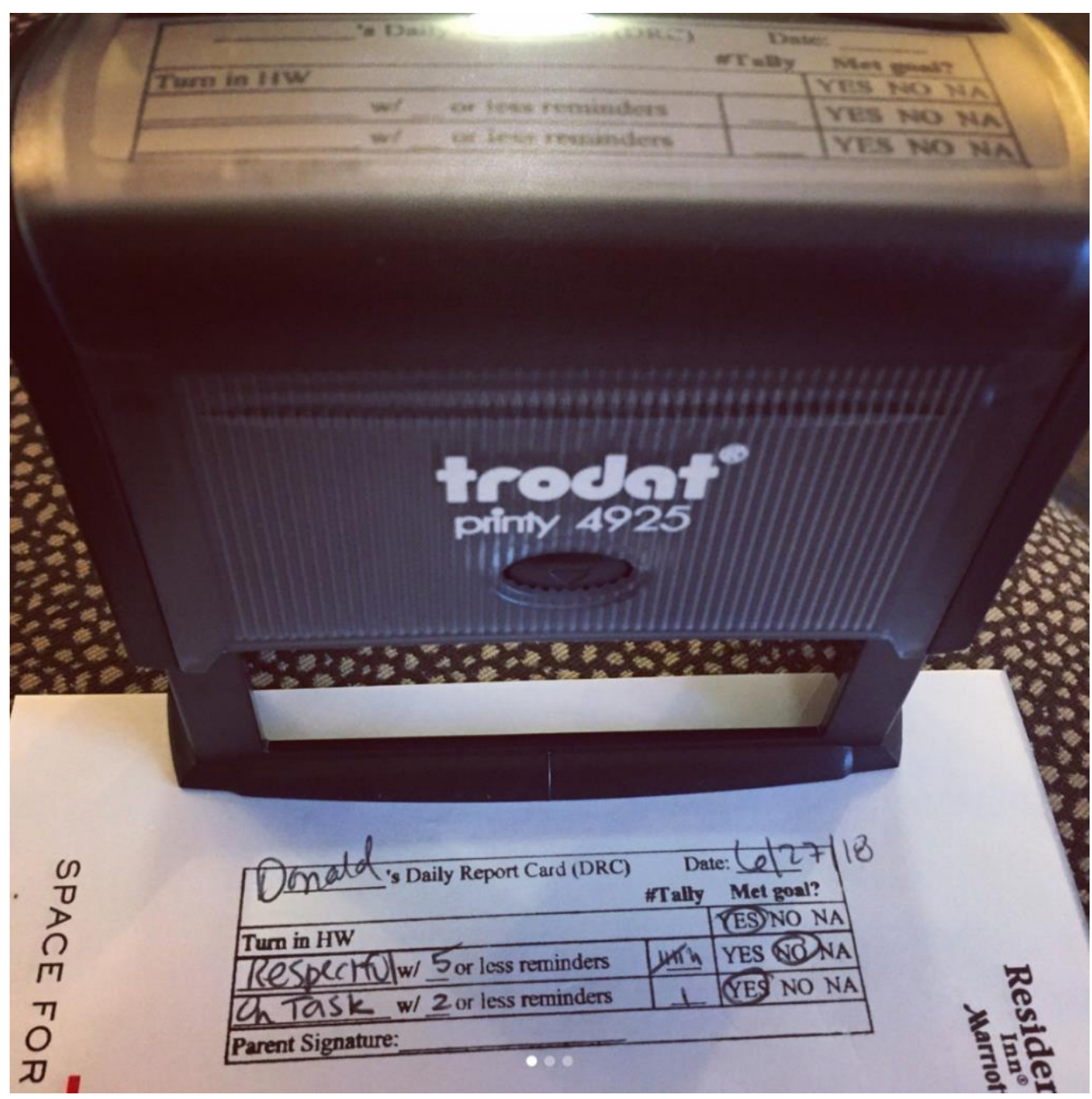


Figure 5. Daily Report Card Rubber Stamp Prototype, View 2

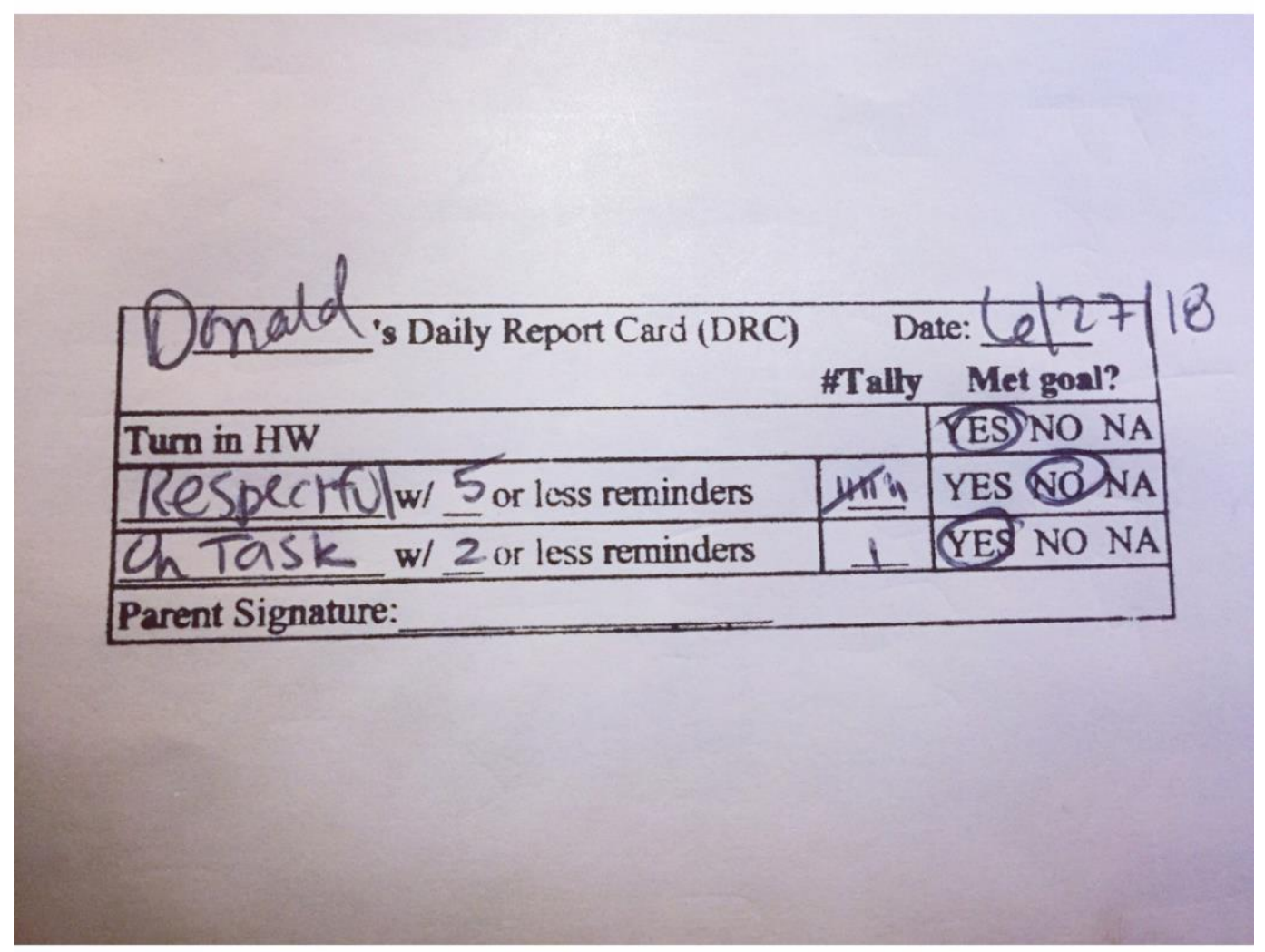


Figure 6. Daily Report Card Rubber Stamp Prototype, View 3

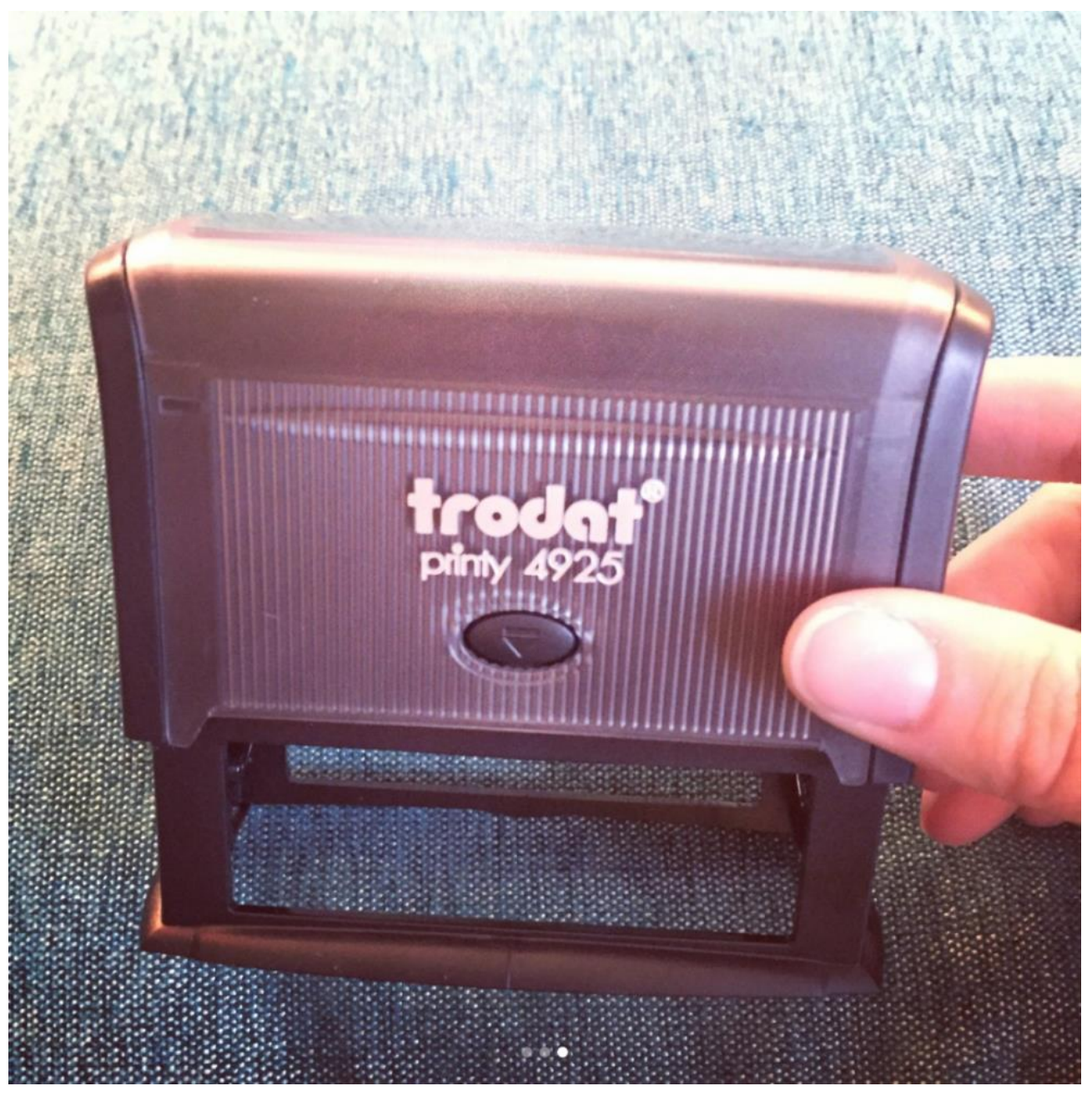




\section{Daily Report Card FACT SHEET}

2018-2019 SCHOOL YEAR

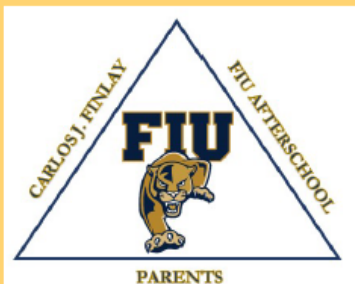

Established: 2015

Children Enrolled: 45

Florida International University

Afterschool Treatment Program

The FIU program is a treatment program located at Dr. Carlos J. Finlay Elementary. Students receive services afterschool to improve behavior/attention. Teachers collaborate with us during the day.

Sample Daily Report Card

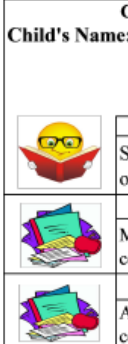
Classroom Daily Report Card Cleffrey

$100 \%$ of HW written in agenda

Parent Signature:

\section{Purpose/Definition}

A Daily Report Card is an individualized behavior chart that works. We set goals for students, and we teach them that you have to work hard to have fun. That's life.

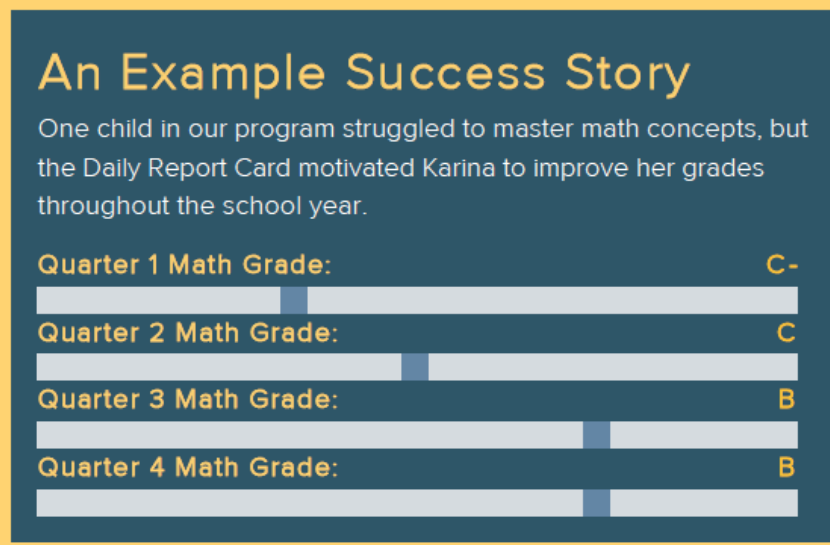

"I've seen wonderful, wonderful things happen with students this year and the years past. The DRC keeps them on track." -Teacher who worked $10+$ years in MDCPS schools

\section{Your collaboration}

We are asking you, the substitute teacher, to fill out the little paper attached, so that we will know whether or not the student(s) had a good day in class. Students may earn (or fail to earn) daily and weekly privileges based on how they perform in class with you today.

- Substitute teachers verify the number of tallies/the percentage (the number of reminders)

- We ask that you circle YES or NO and sign your initials 
Figure 8. One-page Daily Report Card Fact Sheet for Substitute Teachers, Back-view

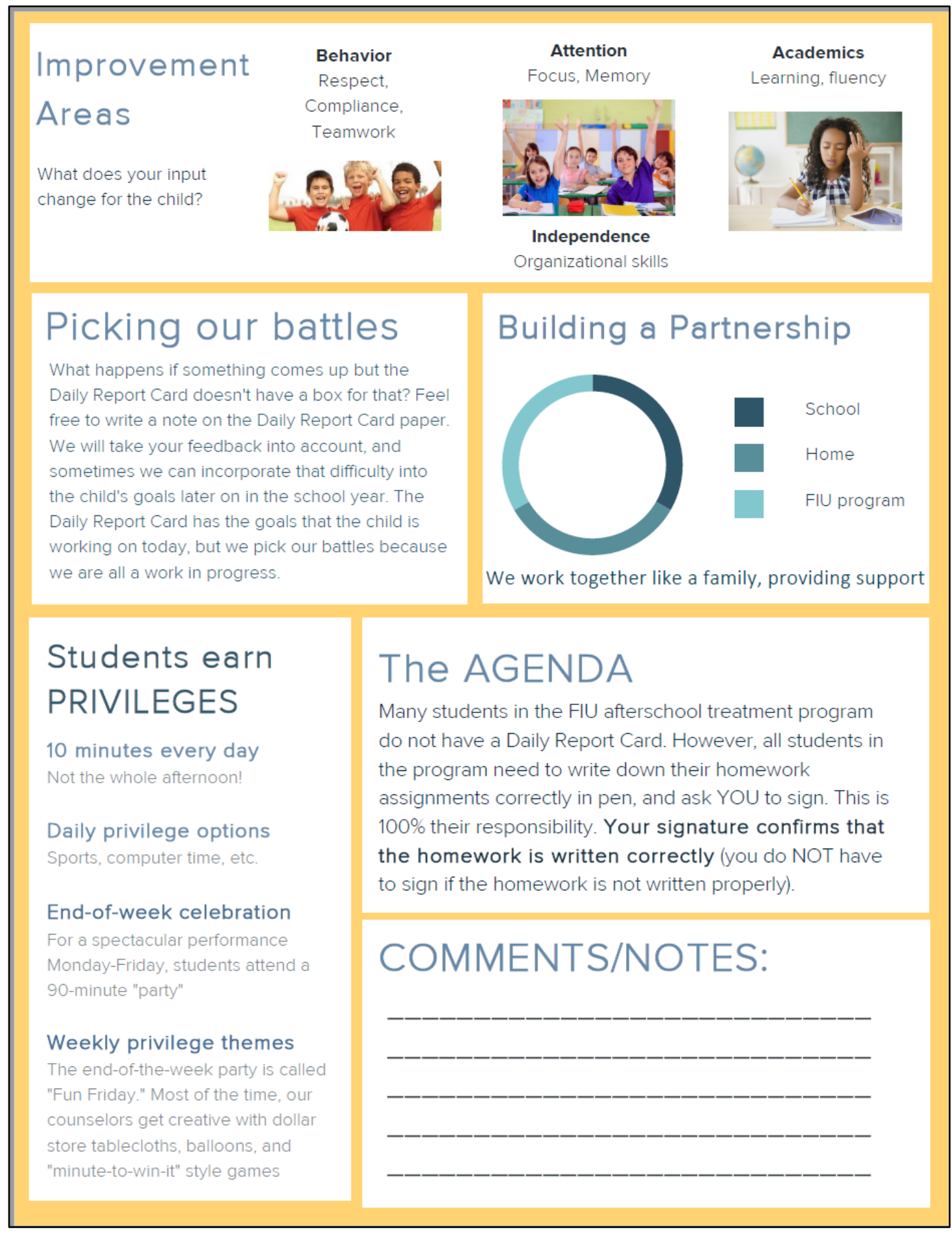




\section{CONCLUSION AND FUTURE DIRECTIONS}

\section{Conclusion}

After studying the prospective relationship between externalizing behavior, school engagement, and functional outcomes (Chapters 1 and 2), I was interested in intervening in the lives of at-risk children to mitigate risk for negative outcomes (Chapter 3). Though many elements of mental health treatment remain constant across varying settings, I have noticed that individuals from traditionally underserved communities often struggle with very different obstacles than patients with whom evidence-based mental health treatments were developed and evaluated. In order to address the research-to-practice gap, I elected to leverage our team's community research partnership at Dr. Carlos J. Finlay Elementary (a Title I, bilingual school) to conduct my mixed-method dissertation project on the barriers and facilitators to the implementation of a behavioral consultation intervention among predominantly Latinx teachers and students (Chapter 3).

\section{Future Directions}

The findings from my dissertation research could inform future investigations in which adaptations to improve teacher engagement in behavioral interventions (e.g., altered treatment delivery/format) are systematically implemented and evaluated, as needed. For example, during qualitative interviews presented in Chapter 3, teachers suggested helpful, flexible strategies for future dissemination and implementation efforts, such as the use of a rubber stamp version of the Daily Report Card to facilitate implementation with multiple students per class/reduce paperwork burden), as well as the use of a one-page fact sheet to educate substitute teachers/increase their participation. As a part of my program of doctoral research, I followed through on the teachers' ideas to develop a rubber stamp "DRC" prototype (see figures 4-6), as well as an example of a one-page fact sheet to educate substitute teachers (see figures 7-8). Yet these ideas have not yet been tested; more research is indicated to assess the potential benefit of these modifications. 
In addition to implementation science on face-to-face behavioral interventions, I am interested in leveraging technology to improve the quality of and access to youth mental health services. Given the overwhelming nature of the unmet need for mental health services, little makes me more hopeful to positively impact the issue in my lifetime than technology. I look forward to rigorously examining the effects of tools within the emerging subfield. For example, I have recently co-created a behavioral intervention technology prototype; a gratitude/positivity mHealth application that counts and graphs the number of positively-worded sentences audiorecorded daily. The mHealth application tracks positive/grateful sentences analogous to pedometer counting steps. Perhaps an mHealth app of this kind could be relevant to school-based behavioral interventions to track and visualize teachers' social reinforcement (a core component of treatment; optimally implemented frequently to modify students' behavior).

Throughout my training, I have had the opportunity to participate in translational research across many settings, beginning my post-baccalaureate fellowship in a neuroimaging laboratory, moving to tightly-controlled studies through university-based clinics, and currently, focusing on implementation research (i.e., my dissertation and endeavors on my pre-doctoral clinical psychology internship). I have intentionally selected to move across the spectrum of translational research toward areas with the potential to lead to relatively proximal positive impact in the community. In future research, I will continue to focus on T3 and T4 implementation science (Westfall \& Mensah, 2018), including innovative, mixed method approaches that emphasize listening the important voices of community stakeholders. I plan to grow my program of research through actively seeking the guidance of the children, families, and teachers who I hope to serve. Lastly, to the extent that technology fits within these goals, I will begin to leverage technological innovations to improve predictive analytics, as well as to scale core components of behavioral interventions (i.e., to improve reach) via mHealth applications. 
APPENDIX 1. Measures 


\title{
SEMI-STRUCTURED INTERVIEW INTRODUCTORY SCRIPT
}

\author{
PARTICIPANT \\ ID: \\ INTERVIEWER \\ ID: \\ LOCATION: \\ DATE OF INTERVIEW: \\ TIME \\ STARTED: \\ TIME ENDED:
}

\section{Welcome}

"Good afternoon and welcome. Thank you for taking the time to complete this interview. My name is [Name of Moderator] and I am [State Role on Project] for the program."

\section{Overview of the Topic}

"We would like to hear from you regarding your experience with the FIU program. Your honest input will inform our ongoing efforts to improve the content and format of the meetings about the DRC so they are relevant, meaningful, and impactful toward supporting your classroom and students. You were invited because of your participation and collaboration with us so far. Thank you again for all of your hard work!

\section{Ground Rules}

"There are no right or wrong answers. We expect that teachers will have many different points of view and opinions. Please feel free to share your point of view so that we can learn about ways to improve our program.

We expect this semi-structured interview to last for approximately 30 minutes. We want to be respectful of your time, while also getting as much comprehensive information as possible toward improving our support for your classrooms and students. We are recording the interview so that we don't miss any of your comments. Later, this recording will be transcribed and maintained on a secure computer and destroyed upon completion of the study. All of your information will be associated with a numeric ID, and none of your identifying information will be linked to your responses. That is, no names or identifying information will be included in any recording(s) or transcriptions.

Please don't feel like there is any answer that we are looking for in particular. If you want to bring up topics that you think are important, or you want to recommend adaptations to the program, or give an example, feel free to do that throughout our interview. I'm here to ask questions, listen, and make sure all of the teachers have a chance to share. 
What questions do you have before we get started?

$\underline{\text { Interview goals/process }}$

1. Confidentiality

2. Learn about your experiences working with us to support children with attention/behavior problems 


\section{SEMI-STRUCTURED INTERVIEW GUIDE}

\section{SPECIFIC AIM 2: Acceptability \\ *Introduction question (knowledge about intervention) and satisfaction}

\section{C-FIR CONSTRUCT; IV. Characteristics of individuals; A. Knowledge and beliefs about}

intervention; I. Intervention Characteristics; C. relative advantage

1. Please tell me about your use of DRC with students in your classroom. [probe] \# of students that have DRCs, what kinds of targeted goals they have [probe] To what extent were you satisfied with the DRC? [probe] To what extent did you find the DRC helpful (or not) in managing students' off-task or disruptive behavior/inattention?

[probe] To what extent did you find the DRC resulted in student improvement?

[probe] To what extent did you find it easy (or difficult) to use?

2. Please tell me about the meetings about the DRC that you participated in. [probe] How many meetings scheduled? attended? rescheduled/cancelled (and what interfered)? [probe] What was discussed? [probe] To what extent were you satisfied with the meetings about the DRC? [probe] To what extent did you find the meetings about the DRC helpful (or not) for managing students' off-task or disruptive behavior/inattention? [probe] What makes the meetings about the DRC most useful/valuable?

3. How does the DRC fit into your toolkit for minimizing disruptive behaviors/improving attention? before?

[probe] To what extent is it similar to or different from strategies you've used

[probe] Tell me about some of your other strategies.

[probe] What advantages does it have over other strategies you've used before? Disadvantages?

\section{SPECIFIC AIM 1: Feasibility}

C-FIR CONSTRUCT; III. Inner setting; E. Readiness for implementation; 2. Available resources; I. Intervention Characteristics; C. Complexity, Adaptability, Cost

4. What do you think is needed for a teacher to utilize a DRC effectively? [probe] What would a teacher need to know to use a DRC effectively? [probe] What skills would they need to have? [probe] How much time would they need to allot?

5. To what extent was the DRC feasible, given the current demands and resources of teaching?

[probe] To what extent were you able to give yes/no feedback for behavioral targets? To what extent were you able to give feedback about percentage (completion/accuracy) or tallies for behavioral targets? 
[probe] How many targets per child is reasonable to manage simultaneously? How many DRCs per classroom is reasonable to manage simultaneously? What are the possible risks of having too many targets or too many DRCs?

6. To what extent were the consultation meetings feasible, given the current demands and resources of teaching? [probe] What makes it difficult to arrange or attend them? feasibility? [probe] To what extent does the frequency of the meetings impact efficiently?

[probe] To what extent did you feel that the meeting time was used

\section{SPECIFIC AIM 3: Potential associated factors}

C-FIR CONSTRUCT; IV. Characteristics of individuals; A. Knowledge and beliefs about intervention; B. Self-efficacy; E. Other personal attributes; I. Intervention Characteristics;

7. To what extent does the spirit of the DRC (based on principles of behavioral reinforcement) align with your values?

[probe] positive reinforcement (e.g., praise, material rewards)?

[probe] ignoring minor misbehavior?

[probe] rewarding behavior that is a little bit better, but still does not meet your standards [for behavior] yet??

[probe] targeted goals?

[probe] punishment?

[probe] communicating with family?

8. To what extent do you believe there are different cultural norms (shared expectations/rules of a group) for how to manage students' off-task or disruptive behavior/inattention?

[probe] To what extent do you adhere to a particular set of cultural norms for managing student behaviors in your classroom?

[probe] To what extent does the DRC align with those norms or values?

9. To what extent do you feel confident and competent in utilizing a DRC?

[probe] Prior experience/exposure to this

[probe] DRC independently/on your own (e.g., If you moved to a new school without the teacher meetings)

\section{SPECIFIC AIM 2: Acceptability \\ *Interest in modifications to format/content}

\section{C-FIR CONSTRUCT; I. Intervention Characteristics; D. Adaptability; F. Complexity (e.g., duration, scope); G. Design quality and packaging}

10. What would you change about the Daily Report Card (DRC) and why?

[probe] What makes it difficult to use? What gets in the way of using it?

[probe] What changes would you recommend to make it more user-friendly?

More effective? 
[probe] What shouldn't change?

[probe] To what extent is the DRC flexible?

11. What would you change about the teacher consultation meetings and why? [probe] What would they need to look like for you to prioritize them among everything else you're doing? [probe] What shouldn't change? is realistic?) [probe] How often should we meet? (How often is valuable versus how often

12. What format is best to receive information from our program (e.g., biweekly meetings, email, text, an app like Classdojo, etc.)? [best = convenience, utility]

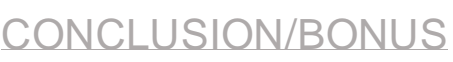

\section{*just for fun, really}

C-FIR CONSTRUCT; I. Intervention Characteristics; G. Design quality and packaging

13. We are looking for a new name for the "Daily Report Card" (DRC)—what ideas do you have for us for a better one? 
Table \#. Objectives of Daily Report Card Meetings (Volpe \& Fabiano, 2013)

\section{Brief Session Outlines}

Session 1

- Problem Identification

Session 2

- DRC Development

Session 3

- Initial DRC Evaluation

Session 4-8

- Repeated DRC Evaluation meetings as needed

Note: DRC = Daily Report Card 
What is your gender?

\section{Demographics}

-Male

-Female

Date of Birth:

Please specify your race:

-Native American or Alaska Native

-Asian

-Black or African-American

-Native Hawaiian or Other Pacific Islander

-White

Please specify your ethnicity:

-Hispanic or Latina/o

-Not Hispanic or Latina/o

In which country were you born?

If you were born outside of the U.S.A., at what age did you immigrate to the U.S.A.?

In which country was your mother born?

In which country was your father born?

What is the highest degree that you have completed? Please select one.

-BA/BS

$-\mathrm{MA} / \mathrm{MS}$

-Ed.S./Ed.M./Ed.D.

-PsyD/ Ph.D.

Disciplines: Please indicate the discipline that you studied when working towards the highest degree that you have

earned.
-Education
-School Psychology
-Special Education
-Clinical Psychology
-Counseling
-Educational Psychology
-Other

For how many years have you been teaching?

For how many years have you been teaching at [your current] Elementary School? 
Teacher Beliefs About Behavioral Strategies

For each statement, please indicate which answer best represents your beliefs.

1 = "Disagree a lot"; 2 = "Disagree moderately"; 3 = "Disagree a little"; 4 = "Agree a little"; 5 = "Agree moderately"; 6 = "Agree a lot"; 7 = "Unsure"

1) It is important to reward children for good behavior.

2) It's unfair to praise the good behavior of a child with ADHD more than the good behavior of a typical child.

3) It's unfair to give a reward/privilege to a child with ADHD if I'm not giving one to other children.

4) Improving children's behavior can improve their academic performance.

5) Children often misbehave just to cause me stress.

6) If children can be taught how to read or do math, they can be taught how to behave appropriately.

7) Children with ADHD would behave if they received supportive counseling rather than a classroom.

8) The behavior of children with ADHD will not improve until medication starts.

9) Rewarding children reduces their own internal motivation to behave appropriately.

10) Behavioral classroom interventions are likely to improve children's behavior.

11) If a classroom intervention is going to improve behavior, I should see positive results in the first week.

12) Learning about new behavioral interventions is not worth my time.

13) Once a child's behavior improves, there is no need to keep using the intervention. 
14) Individualized interventions should only be used for individuals with severe behavior problems, not mild or moderate behavior problems.

15) Using a classroom intervention for one student would be embarrassing for that student.

16) Interventions that are individualized to a specific child take too much time.

17) Individualized interventions should be handled by special education teachers rather than general education teachers.

18) I benefit when others observe my teaching and provide feedback about my strengths and areas for growth.

19) If I consult with a school mental health professional about classroom interventions, it will look like I can't manage my classroom.

20) Implementing a classroom intervention can be helpful even if the parents are not engaged in the intervention.

21) I would benefit from consultation or coaching on behavioral classroom interventions.

22) Using good classroom management allows me more time for instruction.

23) My behavior has little impact on students' rule following behavior.

24) I should give multiple reminders before giving a consequence for most classroom rule violations. 


\section{Latina/o Values Scale (LVS)}

Use the scale below to indicate the extent to which you agree with the value expressed in each statement.
1
2
3
4
Strongly Disagree
(2)
Strongly Agree

1. One does not need to be loyal to one's cultural origin.

2. One does not need to follow one's cultural customs.

3. One's bond with one's cultural group must be very strong.

4. One does not need to maintain one's cultural traditions.

5. One must preserve one's cultural heritage.

6. One does not need to preserve the customs of one's cultural background.

7. One does not need to practice one's cultural celebrations.

8. One should work to preserve the language of one's ethnic group.

9. One should never lose one's language of origin.

10. One must be proud of one's cultural group.

11. One does not need to always avoid conflict with others.

12. One does not need to always be cordial with others.

13. One must not offend others.

14. A woman does not need to successfully endure all adversity.

15. A woman should sacrifice everything for her family.

16. One should never offend one's elders.

17. One should never bring shame upon one's family.

18. A woman must be a source of strength for her family.

19. A mother must keep the family unified.

20. A woman is considered the backbone of the family. 
21. A man must provide for his family financially.

22. One does not need to trust a higher being.

23. One does not need to have faith in premonitions.

24. A woman should be the spiritual leader in the family.

25. One should be able to question one's elders.

26. A man's strength comes from being a good father and husband.

27. One does not need to be emotionally affectionate to familiar individuals.

28. One's successes should be attributed to one's family.

29. One does not need to always present oneself as likable to others.

30. One's family is the main source of one's identity.

31. One must defer to one's elders for advice.

32. One must maintain a sense of interdependence with one's group.

33. One does not need to always support one's group.

34. One must help one's group to achieve its goals.

35. One should be respectful to people who have a higher status. 
Please read each statement and select the answer that best applies.

\begin{tabular}{|c|c|c|c|c|}
\hline 1 - Not at all & $\begin{array}{l}2 \text { - Very little or } \\
\text { not so often }\end{array}$ & 3 - Moderately & $\begin{array}{l}4 \text { - Much or very } \\
\text { often }\end{array}$ & $\begin{array}{c}5 \text { - Extremely } \\
\text { often or almost } \\
\text { always }\end{array}$ \\
\hline
\end{tabular}

1. I speak Spanish.

2. I speak English.

3. I enjoy speaking Spanish.

4. I associate with Anglos.

5. I associate with Latinos.

6. I enjoy listening to Spanish language music.

7. I enjoy listening to English language music.

8. I enjoy Spanish language on TV.

9. I enjoy English language on TV.

10. I enjoy English language movies.

11. I enjoy Spanish language movies.

12. I enjoy reading (e.g., books in Spanish).

13. I enjoy reading (e.g., books in English).

14. I write letters in English.

15. I write letters in Spanish.

16. My thinking is done in the English language.

17. My thinking is done in the Spanish language.

18. My contact with Latin America has been:

19. My contact with the U.S.A. has been: 
20. My father identifies or identified as Latino.

21. My mother identifies or identified as Latino.

22. My friends, while I was growing up, were of Latino origin.

23. My friends, while I was growing up, were of Anglo origin.

24. My family cooks Latino foods.

25. My friends now are of Anglo origin.

26. My friends now are of Latino origin.

27. I like to identify myself as an Anglo American person.

28. I like to identify myself as a Latino person.

29. I like to identify myself as American. 
Intervention Rating Profile-10 (IRP-10) DRC Meetings

Please answer the questions in reference to the FIU teacher consultation program.

Strongly Disagree (1), Disagree, Slightly Disagree, Slightly Agree, Agree, Strongly Agree (6)

1. This would be an acceptable intervention for this child's school difficulties.

2. This intervention should prove effective in changing this child's school problems.

3. I would suggest the use of this intervention to other teachers.

4. This child's school problems are severe enough to warrant use of this intervention.

5. Most teachers would find this intervention suitable for a child with characteristics similar to this child.

6. This intervention would not result in negative side effects for this child.

7. This intervention is a fair way to handle this child's school difficulties.

8. This intervention is a reasonable for this child.

9. I liked the procedure used in this intervention.

10. Overall, this intervention would be beneficial for this child. 
Intervention Rating Profile-10 (IRP-10) DRC Tool

Considering the student in your class with the highest level of impairment, please answer the questions in reference to filling out the Daily Report Card.

Strongly Disagree (1), Disagree, Slightly Disagree, Slightly Agree, Agree, Strongly Agree (6)

1. This would be an acceptable intervention for this child's school difficulties.

2. This intervention should prove effective in changing this child's school problems.

3. I would suggest the use of this intervention to other teachers.

4. This child's school problems are severe enough to warrant use of this intervention.

5. Most teachers would find this intervention suitable for a child with characteristics similar to this child.

6. This intervention would not result in negative side effects for this child.

7. This intervention is a fair way to handle this child's school difficulties.

8. This intervention is a reasonable for this child.

9. I liked the procedure used in this intervention.

10. Overall, this intervention would be beneficial for this child. 


\section{Consumer Preference Questions (Project-developed)}

If you were interested in getting information about new strategies or recommendations to inform your work with students with behavior and/or attention problems, how would you prefer to receive that information?

Not at all Interested $=1$; Not very Interested $=2$; Somewhat Interested $=3$; Very interested $=4$; Extremely Interested $=5$

\section{Attending formal trainings or workshops}

2. Reading materials (i.e., books, newsletters, distributed information)

3. Meetings with a consultant

4. Through website(s) online/an application (i.e., an "app")

5. From other teachers

6. Through trial and error

7. Through email 


\section{Organizational Health Inventory-Elementary (OHI-E)}

Directions: The following are statements about your school, Please indicate the extent to which each statement characterizes your school from rarely occurs to very frequently occurs.

$1=$ Rarely Occurs

$2=$ Sometimes Occurs

$3=$ Often Occurs

$4=$ Very Frequently Occurs

1. The principal explores all sides of topics and admits that other opinions exist.

2. The principal gets what he or she asks for from superiors.

3. The principal discusses classroom issues with teachers.

4. The principal accepts questions without appearing to snub or quash the teacher.

5. Extra materials are available if requested.

6. Students neglect to complete homework.

7. Students are cooperative during classroom instruction.

8. The school is vulnerable to outside pressures.

9. The principal is able to influence the actions of his or her superiors.

10. The principal treats all faculty members as his or her equal.

11. The principal goes out of his or her way to show appreciation to teachers.

12. Teachers are provided with adequate materials for their classrooms.

13. Teachers in this school like each other.

14. Community demands are accepted even when they are not consistent with the educational program.

15. The principal lets faculty know what is expected of them.

16. Teachers receive necessary classroom supplies

17. The principal conducts meaningful evaluations. 
18. Students respect others who get good grades.

19. Teachers feel pressure from the community.

20. The principal's recommendations are given serious consideration by his or her superiors.

21. The principal maintains definite standards of performance.

22. Supplementary materials are available for classroom use.

23. Teachers exhibit friendliness to each other.

24. Students seek extra work so they can get good grades.

25. Select citizen groups are influential with the board.

26. The principal looks out for the personal welfare of faculty members.

27. Teachers express pride in their school.

28. Teachers identify with the school.

29. The school is open to the whims of the public.

30. A few vocal parents can change school policy.

31. Students try hard to improve on previous work.

32. Teachers accomplish their jobs with enthusiasm.

33. The learning environment is orderly and serious.

34. The principal is friendly and approachable.

35. There is a feeling of trust and confidence among the staff.

36. Teachers show commitment to their students.

37. Teachers are indifferent to each other. 


\section{Quality of Teacher Work-life Survey (QTWL)}

For this part of the survey, please write the appropriate number representing your present degree of satisfaction and the degree of stress you experience in each of the following job related areas.

For example, you may be moderately dissatisfied with the, "daily time for preparation" and would place the number 2 in the space provided indicating "Moderately Dissatisfied". On the other hand, "daily time for preparation" may cause you to experience little or no stress so you would place a 5 in the space provided indicating, "No Stress".

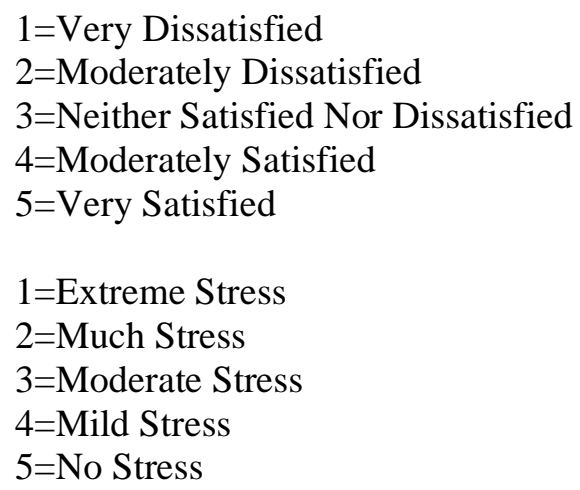

1. Salaries

2. Fringe Benefits

3. Class Sizes

4. Daily time to recuperate between work responsibilities

5. Daily time for preparation

6. Competence of administration

7. Competence of Teachers

8. Competence of staff

9. Time spent in extracurricular activities

10. Time spent in clerical and administrative work

11. Student discipline 
12. Number of breaks in the teaching process (i.e., telephone calls, announcements, etc.)

13. Number of breaks in the teaching process due to support personnel

14. Students missing class due to extracurricular classes

15. Job Security

16. Availability of jobs within the educational profession

17. Your ability to evaluate student performance

18. Time spent individualizing programs for special needs children

19. Work environment

20. School equipment

21. Education curriculum

22. Faculty relations

23. Present teaching assignment (e.g., subject area or grade level)

24. Support from administration

25. Support from parents

26. Support from local community

27. Opportunity for promotion and advancement.

28. Amount of student motivation

29. Amount of student interest student performance

30. Teacher relationship with administrators

31. Teacher relationship with parents

32. Time required to adapt instruction to individual differences in ability,interest and needs.

33. Formal evaluation of teaching performance

34. Feedback or reinforcement other than pay

35. Public perception of education

36. Participation in decision-making affecting school policy 
37. New Federal and State Requirements generated by law (No Child Left Behind Act 2001, IDEA, MONTCAS, etc.) 


\section{VITA}

\section{ANNE S. MORROW}

2006-2010

2010-2012

2012-2016

2012-2019

2018-2019
B.A. Psychology and French

Amherst College

Amherst, Massachusetts

Post-Baccalaureate Intramural Research Training Award National Institute of Mental Health

Bethesda, Maryland

M.S., Clinical Science in Child Psychology

Florida International University

Miami, Florida

Doctoral Candidate

Florida International University

Miami, Florida

Predoctoral Intern

University of Mississippi Medical Center

Jackson, Mississippi

\section{PUBLICATIONS AND PRESENTATIONS}

Morrow, A.S., Villodas, M.T. \& Cunius, K. (2019). Identifying Prospective Risk Factors for Juvenile Justice Involvement in a Sample of Youth At-Risk for Maltreatment: An Actuarial Approach. Child Maltreatment.

Merrill, B.M., Molina B.S.G., Coxe, S., Gnagy, E.M., Altszuler, A.R., Macphee, F.L., Morrow, A.S., Trucco, E.M. and Pelham, W.E. (2019). Functional Outcomes of Young Adults with Childhood ADHD: A Latent Profile Analysis. Journal of Clinical Child and Adolescent Psychology.

Villodas, M.T., Villodas, F.M, Lozano, C.M., Morrow, A.M., Cromer, K.D. García, B.H., and Raiker, J.S., (2018, May The Effects of a Daily Intensive After-School Intervention on Sluggish Cognitive Tempo Symptoms Among Latina/o Children with ADHD and Disruptive Behavior Problems Symposia presentation at the Association for Psychological Science, San Francisco, CA.

Picchioni, D., Schmidt, K., McWhirter, K., Loutaev, I, Pavletic, A., Speer, A., Zametkin, A., Miao, N., Bishu, S., Turetsky, K., Morrow, A.S., Nadel, J., Evans, B., Vesselinovitch, D., Sheeler, C., Balkin, T., Smith, C. (2018). Rates of Cerebral Protein Synthesis in Primary Visual Cortex during Sleep-Dependent Memory Consolidation, a Study in Human Subjects. Sleep. doi: 10.1093/sleep/zsy088 
Morrow, A. S., \& Villodas, M.T. (2017). Direct and Indirect Pathways from Adverse Childhood Experiences to High School Dropout Among High-Risk Adolescents. Journal of Research on Adolescence. doi: 10.1111/jora.12332

Altszuler, A.R., Macphee, F.L., Merrill, B.M., Morrow, A. S., Schatz, N.K., Pelham, W.E. (2017). Attention-Deficit Hyperactivity Disorder. In Piacentini, J. \& Flessner, C.A. (Eds.), Clinical Handbook of Psychological Disorders in Children and Adolescents: A Step-by-Step Treatment Manual. New York, NY: The Guildford Press.

Altszuler, A. R., Morrow, A. S., Merrill, B. M., Bressler, S., Macphee, F. L., Gnagy, E. M., Greiner, A. R., Coxe, S., Raiker, J. S., Coles, E. K., Pelham, W. E. (2017). The Effect of Stimulant Medication and Training on the Sports Competence of Children with ADHD. Journal of Clinical Child and Adolescent Psychology.

Merrill, B. M., Morrow, A. S., Altszuler, A. R., Macphee, F. L., Gnagy, E. M., Greiner, A. R., Coles, E. K., Raiker, J. S., Coxe, S., \& Pelham, W. E. (2016). Improving homework performance among children with ADHD: A randomized clinical trial. Journal of Consulting and Clinical Psychology. doi:10.1037/ccp0000144

Sibley, M. H., Campez, M., Perez, A., Morrow, A. S., Merrill, B. M., Altszuler, A. R., \& Yeguez, C. E. (2016). Parent Management of Organization, Time Management, and Planning Deficits among Adolescents with ADHD. Journal of Psychopathology and Behavioral Assessment, 1-13. doi:10.1007/s10862-015-9515-9

Morrow, A.S. (2016, October). Adapting teacher consultation for diverse populations: what are the barriers to intervention implementation? Oral presentation given at the annual ADHD preconvention of the Association for Cognitive and Behavioral Therapies, New York, NY

Morrow, A. S., Baldivieso, M., \& Coles, E. (2015, November). Modifying the Daily Report Card to Treat a Child with Disruptive Behavior and Callous-Unemotional Traits: A case report. Oral presentation given at the annual ADHD pre-convention of the Association for Cognitive and Behavioral Therapies, Chicago, IL.

McWhirter, K. K., Morrow, A. S., Lee, B. A., Bishu, S., Zametkin, A. J., Balkin, T. J., \& Picchioni, D. (2015). A Pilot Study on the Encoding of a Perceptual Learning Task Following Sleep Deprivation. Perceptual and Motor Skills, 121(1), 80-93. doi:10.2466/23.PMS.121c11x9

Sibley, M. H., Altszuler, A. R., Morrow, A. S., \& Merrill, B. M. (2014). Mapping the academic problem behaviors of adolescents with ADHD. School Psychology Quarterly, 29(4), 422-437. doi:10.1037/spq000007 